\title{
Abundances in the Galactic bulge: results from planetary nebulae and giant stars ${ }^{\star}, \star \star$
}

\author{
C. Chiappini ${ }^{1,2}$, S. K. Górny ${ }^{3}$, G. Stasińska ${ }^{4}$, and B. Barbuy ${ }^{5}$
}

\author{
1 Observatoire de Genève, Université de Genève, 51 chemin des Maillettes, 1290 Sauverny, Switzerland \\ e-mail: Cristina.Chiappini@unige.ch \\ 2 Osservatorio Astronomico di Trieste - OAT/INAF, via G. B. Tiepolo 11, 34131 Trieste, TS, Italy \\ e-mail: chiappini@oats.inaf.it \\ 3 Copernicus Astronomical center, Rabiańska 8, 87-100 Toruń, Poland \\ e-mail: skg@ncac. torun.pl \\ 4 LUTH, Observatoire de Paris, CNRS, Université Paris Diderot, Place Jules Janssen, 92190 Meudon, France \\ e-mail: grazyna.stasinska@obspm.fr \\ 5 Universidade de São Paulo, IAG, Rua do Matão 1226, Cidade Universitária, São Paulo 05508-900, Brazil \\ e-mail: barbuy@astro.iag.usp.br
}

Received 22 August 2008 / Accepted 27 October 2008

\begin{abstract}
Context. Our understanding of the chemical evolution (CE) of the Galactic bulge requires the determination of abundances in large samples of giant stars and planetary nebulae $(\mathrm{PNe})$. Studies based on high resolution spectroscopy of giant stars in several fields of the Galactic bulge obtained with very large telescopes have allowed important progress.

Aims. We discuss PNe abundances in the Galactic bulge and compare these results with those presented in the literature for giant stars.

Methods. We present the largest, high-quality data-set available for PNe in the direction of the Galactic bulge (inner-disk/bulge). For comparison purposes, we also consider a sample of PNe in the Large Magellanic Cloud (LMC). We derive the element abundances in a consistent way for all the PNe studied. By comparing the abundances for the bulge, inner-disk, and LMC, we identify elements that have not been modified during the evolution of the PN progenitor and can be used to trace the bulge chemical enrichment history. We then compare the PN abundances with abundances of bulge field giant.

Results. At the metallicity of the bulge, we find that the abundances of $\mathrm{O}$ and $\mathrm{Ne}$ are close to the values for the interstellar medium at the time of the PN progenitor formation, and hence these elements can be used as tracers of the bulge CE, in the same way as $\mathrm{S}$ and $\mathrm{Ar}$, which are not expected to be affected by nucleosynthetic processes during the evolution of the PN progenitors. The PN oxygen abundance distribution is shifted to lower values by 0.3 dex with respect to the distribution given by giants. A similar shift appears to occur for $\mathrm{Ne}$ and $\mathrm{S}$. We discuss possible reasons for this PNe-giant discrepancy and conclude that this is probably due to systematic errors in the abundance derivations in either giants or PNe (or both). We issue an important warning concerning the use of absolute abundances in CE studies.
\end{abstract}

Key words. stars: abundances - ISM: planetary nebulae: general - Galaxy: bulge - Galaxy: abundances

\section{Introduction}

The Galactic bulge is old, distant, and highly obscured and studies of its chemical composition include two types of stars that represent evolved stages of intermediate mass stars: planetary nebulae (PNe) (e.g. Górny et al. 2004), for which abundances are derived using the intensities of conspicuous emission lines, and giant stars (e.g. Lecureur et al. 2007; Zoccali et al. 2008), whose luminosities enable spectra of sufficient quality suitable for abundance determination to be obtained, using very large telescopes.

However, the use of evolved stars as test particles for probing the chemical evolution of the Galactic bulge requires some caution, since it is known that some elements have their abundances modified during stellar evolution. For example,

\footnotetext{
* Based on observations made at the Cerro Tololo Interamerican Observatory and the European Southern Observatory.

$\star \star$ Full Table 1 is only available in electronic form at http://www. aanda.org
}

intermediate-mass stars compete with massive stars in the enrichment of the interstellar medium (ISM) in $\mathrm{N}$ and $\mathrm{C}$ (e.g. Chiappini et al. 2003; Henry 2004), and contribute to the enrichment of He. However, other elements (such as S and Ar) are unaffected by nucleosynthetic processes during the evolution of intermediate-mass stars and probe the chemical composition of the ISM at the time when the stars were born. The status of $\mathrm{O}$ and $\mathrm{Ne}$ is less clear, since their abundances can be affected by nucleosynthesis and mixing during stellar evolution, in amounts that depend on metallicity and other properties (Charbonnel 2005; Leisy \& Dennefeld 2006; Peña et al. 2007).

In this paper, we use data sets both for PNe and giant stars to discuss the chemical evolution of the Galactic bulge. For PNe, we use a high quality sample obtained by merging the data from Górny et al. (2009) with those from Górny et al. (2004) and Wang \& Liu (2007). All PN abundances were recomputed in a consistent way. A detailed comparison of our sample with other bulge PN samples in the literature was presented by Górny et al. (2009). Our bulge PN sample constitutes the largest high-quality 
data-set of abundance measurements for bulge PNe available in the literature.

We complete a detailed analysis of the chemical abundances of these PNe with two main goals. First, we compare the properties of the PN population in an old, metal-rich ${ }^{1}$ environment (the Galactic bulge) with those in both metal-poor (LMC) and metalrich (inner-disk) environments with ongoing star formation. We are then able to gain insights into processes occurring during the evolution of low- and intermediate-mass stars that can affect the abundances observed in the PN stage (such as hot-bottom burning and dredge-up), and infer their dependence on stellar mass and metallicity. Second, we attempt to improve our understanding of the formation and evolution of the Galactic bulge by studying elements that have not been modified during the evolution of the PN progenitor and, hence, can be compared with chemical evolution model predictions. After these elements have been safely identified, we compare the bulge PNe abundances with those of bulge giant stars quoted in the literature.

This paper is organized as follows. In Sects. 2 and 3, we describe the PN and giant star samples on which we based our study, and discuss the main uncertainties in their abundance determinations. In Sect. 4, we review current ideas about the main mixing processes occurring in low- and intermediate mass stars. In Sect. 5 we compare the properties of PNe in different environments. We present compelling evidence that both $\mathrm{O}$ and $\mathrm{Ne}$ are reliable chemical-evolution tracers for metal-rich, old populations, in contrast to their unreliability for metal-poor systems. In Sect. 6, bulge PN abundances are compared with field-giant bulge abundances. We start this section by recalling the recent results on the bulge formation obtained from the study of stars. We approach the question of whether PNe and giant stars provide similar answers concerning the bulge chemical evolution and discuss the biases involved. Section 7 contains a summary of our main results.

\section{Planetary nebulae: samples and abundances}

\subsection{The adopted samples}

\subsubsection{Bulge and inner-disk}

Our PN sample is obtained by merging the following data sets: $90 \mathrm{PNe}$ observed with 4m-class telescopes from Górny et al. (2009, their sample C), 164 PNe from Górny et al. (2004), and 29 PNe from Wang \& Liu (2007), the latter two data sets have been acquired with $2 \mathrm{~m}$-class telescopes. The data set for 164 PNe from Górny et al. (2004) come from the merging of data for $44 \mathrm{PNe}$ observed by Górny in 2000 with those for PNe observed by Cuisinier et al. (2000), Escudero \& Costa (2001), and Escudero et al. (2004). In this way, we obtain the largest sample of PNe with high-quality data observed in the direction of the Galactic bulge (for a detailed description, see Górny et al. 2009), with 245 objects (for the 39 objects belonging to more than one sample, the best data were chosen). This sample contains both bulge and inner-disk objects.

The bulge sample was assembled following the standard criteria (e.g. Stasińska \& Tylenda 1994): they have locations within $10^{\circ}$ of the Galactic centre, diameters smaller than 20 arcsec, and radio fluxes at $5 \mathrm{GHz}$ of less than $100 \mathrm{mJy}$. The contamination of a bulge PN sample defined in this way by

1 The bulge appears to be metal-rich with respect to the halo and thick disk (the other two old components of the Milky Way). Within the central region, the bulge contains cold gas from which stars form until today.
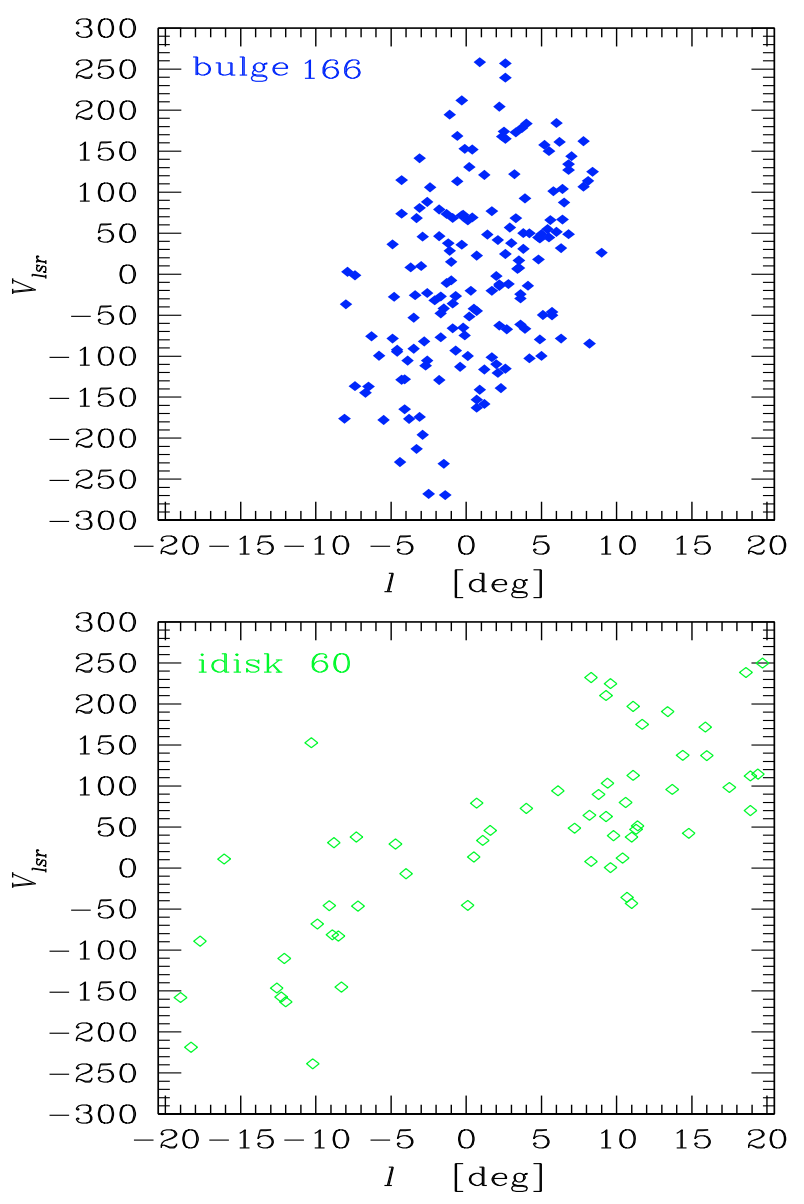

Fig. 1. Distributions of bulge (upper panel) and inner-disk (lower panel) $\mathrm{PNe}$ in a radial velocity (corrected for the solar motion) versus Galactic longitude diagram. All the objects of the initial sample with known velocities are represented (this excludes 11 bulge and 5 inner-disk PNe for which the velocities were unavailable).

disk PNe is estimated to be less than $10 \%$ and most probably around 5\% (Stasińska et al. 1991). Objects observed in the direction of the Galactic centre, but rejected according to the standard criteria described before, most probably belong to the inner-disk ${ }^{2}$. We note that the two samples have different distributions in a radial-velocity versus Galactic-longitude diagram (see Fig. 1), which are consistent with the bulge/inner-disk classification. PNe have indeed the advantage over stars that one can use their angular diameter as an additional constraint to decide the Galactic component to which they belong. Practically all of the 90 PNe of Gorny et al. (2009, sample C) can be regarded as belonging to the bulge, given that most of the objects were selected according to the above criteria. Only 4 PNe were classified as inner-disk objects because they are located just beyond 10 degrees from the Galactic centre.

We note that the inner-disk sample is less well defined than the bulge one, and possibly includes both thick and thin disk objects. However, we expect most of them to be located at small Galactocentric distances due to the increasing density of stars towards the inner regions of the Galaxy.

Figure 2 shows the distribution of the bulge and inner-disk PN samples in a Galactic latitude versus Galactic longitude

\footnotetext{
2 PNe seen in the direction of the bulge but known to belong to the Sgr B2 galaxy were removed from the sample.
} 


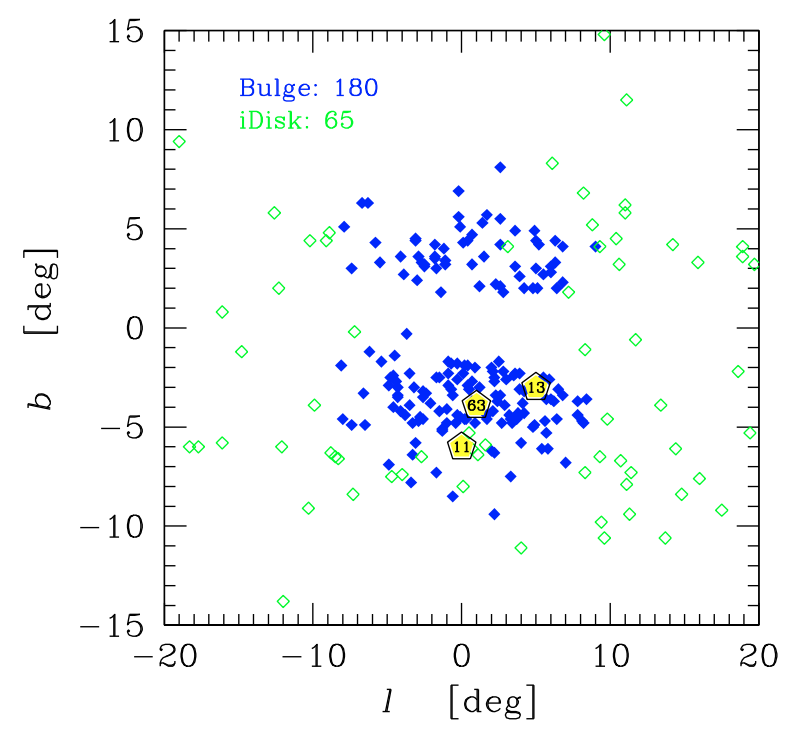

Fig. 2. Distribution of our bulge and inner-disk samples in a Galactic latitude versus Galactic longitude diagram. The larger symbols mark the location of the observed fields in the case of bulge stars (the number of stars in each field is also indicated).

diagram. We also indicate the fields in which the bulge stars discussed in Sect. 3 are found.

From the above PN samples, we rejected objects for which abundances could not be computed from the available data or were too uncertain (see Sect. 2.3). The rejection criteria adopted in this work were far more restrictive than in Górny et al. (2004). This explains why, despite adding data for many additional PN $(\sim 80)$, we have increased the final bulge PN sample with respect to Górny et al. (2004) by only $\sim 40$ objects. We considered it to be of greater importance to analyse reliable abundances than increase the number of objects.

\subsubsection{The Large Magellanic Cloud sample}

A data set of PNe with low metallicities is critical to a comparison with the two samples described before. Both the Small Magellanic Cloud (SMC) and the LMC are suitable candidates for this type of study because both galaxies are close to the Milky Way and sufficiently massive to contain a large number of PNe. We chose to use data for PNe in the LMC in our comparison because of the larger number of objects with good quality spectra available.

The LMC PN sample originates in a compilation by Leisy \& Dennefeld (2006) and contains 138 objects. We derived abundances in the same way as for the other two PN samples, and applied the same restriction criteria as above concerning the abundance quality. Our final sample contains $\sim 100$ objects.

\subsection{Abundance determinations in the $P N$ samples}

In all of our samples, the abundances were determined in exactly the same way with an identical set of atomic data, using a classical temperature-based empirical method described in detail by Górny et al. (2009). Briefly, interstellar reddening was obtained from the observed hydrogen Balmer decrement by comparison with the case B theoretical decrement at a given temperature (first assumed to be equal to $10^{4} \mathrm{~K}$ ). All the line intensities were then corrected for interstellar extinction. The electron temperature was then derived from the [O III] $\lambda 4363 / 5007$ and/or
[N II] $\lambda 5755 / 6584$ ratios, and the electron density from the [S II] $\lambda 6717 / 6731$ ratio $^{3}$. An iteration was performed over these first steps. From the intensities of observed recombination lines of $\mathrm{H}$ and $\mathrm{He}$ and forbidden lines of $\mathrm{N}, \mathrm{O}, \mathrm{Ne}, \mathrm{S}$, and $\mathrm{Ar}$ ions, ionic abundances were then derived with respect to $H$. The elemental abundances were finally obtained by using the ionization correction factors (ICFs) proposed by Kingsburgh \& Barlow (1994) (except for Cl, in which case we used the ICF of Liu et al. 2000).

In some cases, the observational data did not allow us to estimate the electron temperature. We rejected the corresponding PNe from further consideration because trustworthy abundances are unattainable in such cases, even when using tailored photoionization modelling instead of empirical methods (Stasińska 2002). This involved discarding 12 objects out of 180 from our bulge sample, 4 objects out of 65 from our inner-disk sample, and 27 out of 138 from the LMC sample.

The [N II] $\lambda 5755$ and [O II] $\lambda \lambda 7320,7330$ lines can be affected by recombination from $\mathrm{N}^{++}$and $\mathrm{O}^{++}$ions. We estimate the effects of the latter process by using the expressions given in Liu et al. (2000), the [N II] $\lambda 5755 / 6584$ temperature, and by assuming that $\mathrm{N}^{++} / \mathrm{H}=\mathrm{O}^{++} / \mathrm{H} \times \mathrm{N}^{+} / \mathrm{O}^{+}$. We find that the final effect on the computed abundances is negligible for our objects ${ }^{4}$.

As explained in Górny et al. (2009), the uncertainties in abundance ratios were estimated by propagating uncertainties in the observed emission line intensities using Monte Carlo simulations. In the case of the LMC sample, the uncertainties in the observed line intensities were estimated using information provided in the tables of Leisy \& Dennefeld (2006), considering that the uncertainty is a factor of 0.4 the intensity of lines marked as upper limits or a factor of 0.3 the intensity of the weakest line measured. The accuracies in the final abundances in the bulge, inner-disk, and LMC samples were found to be similar.

To avoid dealing with values that are too uncertain, we remove from further consideration any abundance ratio for which the two-sigma error from the Monte Carlo simulation is larger than 0.3 dex. The median uncertainty in the abundance ratios for the data remaining in the sample is about \pm 0.1 dex for $\log \epsilon(\mathrm{O}), \log \epsilon(\mathrm{N}), \log \epsilon(\mathrm{Ne}), \log \epsilon(\mathrm{Ar}), \log \epsilon(\mathrm{S})$, and $\log (\mathrm{N} / \mathrm{O})$, where $\log \epsilon(\mathrm{X})=\log (\mathrm{X} / \mathrm{H})+12$.

We note that our Monte Carlo procedure does not take account of possible variations in the reddening law, the effect of unknown temperature and density structure of the nebulae, and the uncertainty in the ionization correction factors (see below).

\subsection{Biases and uncertainties in $P N$ abundances}

We now discuss in more detail the additional sources of errors mentioned above.

\section{Atomic data}

The atomic data used in abundance determinations from optical lines are generally believed to be quite accurate (to within $5-10 \%)$. Atomic data is presently not a major issue for abundance determinations in PNe from optical data.

\footnotetext{
3 If the density could not be obtained from the [S II] $\lambda 6717 / 6731$ ratio, we adopted a value of $2000 \mathrm{~cm}^{-3}$ (the average of the values of the measured densities).

4 This effect could be larger if, as suggested by Liu (2006 and references therein), the recombination lines originate from a much cooler zone. However, even in the most extreme cases shown in Wang \& Liu (2007), where the observational data allow a more accurate correction for the effect of recombination, the resulting abundances are modified by a few percent at most.
} 


\section{Extinction}

It is known that the Galactic extinction curve is not identical in all directions, and can be, to a first approximation, characterized by the ratio of the total to selective extinction, $R_{V}$ (Cardelli et al. 1989; Fitzpatrick 1999). In the analysis of their sample of Galactic bulge PNe, Wang \& Liu (2007) were able to derive the extinction curve corresponding to each object by combining $\mathrm{UV}$ and optical H I and He II lines, and found values of $R_{V}$ ranging from 1.8 to 4.2. An inapropriated extinction law has its most significant effect on the N/O ratio, when the extinction is high. We tested various extinction laws and found that, in our samples, the $\mathrm{N} / \mathrm{O}$ ratios obtained using $R_{V}=2.1$ and 4.2, differed on average by less than 0.1 dex. Therefore, we assumed the same extinction law (Seaton 1979) for all the samples, which corresponds to the standard case, $R_{V}=3.1$.

\section{Temperature gradients and fluctuations}

As known, the temperature in PNe is not uniform. Radial gradients are expected, due to variations in heating and cooling processes across the nebula. This is partly taken into account by our procedure if temperatures from both [O III] $\lambda 4363 / 5007$ and [N $\mathrm{NI}] \lambda 5755 / 6584$ are measured with good accuracy. However, some authors (Peimbert \& Peimbert 2006) argue that significant temperature fluctuations occur within PNe, and that abundances derived from collisionally excited lines may be significantly underestimated if those temperature fluctuations are not properly taken into account. In particular, they argue that the correct abundances of the heavy elements are those obtained by using recombination lines. A more widespread view, however, is that abundances from collisionally excited lines reflect the average abundances in the nebulae, while the recombination lines are mostly affected by cold, hydrogen-poor inclusions, which represent only a small fraction of the total mass (see Wang \& Liu 2007, and references therein). The origin of such inclusions is not yet fully understood. In this paper, we adopt the view that the abundances derived from collisionally excited lines are not biased in any significant way.

\section{Ionization correction factors}

The ionization correction factors (ICFs) are another source of uncertainty. One could overcome this problem by constructing tailored photoionization models for each object. However, this would require: 1) taking into account the geometrical structure of the nebula (rarely known in detail at the distance of the bulge); 2) knowing the exact spectral energy distribution of the ionizing radiation field (but the model atmospheres of hot stars computed by various state-of-the art codes for model atmospheres do not agree on the energy distribution in the H Lyman continuum).

Another option could be to complement ionic abundances measured from optical spectra with those from UV and IR spectra, so that most of - if not all - relevant ions are observed. This procedure was employed by Pottasch \& Bernard-Salas and their coworkers (see Pottasch \& Bernard-Salas 2006; see also Gutenkunst et al. 2008). However, these results can be affected by aperture and calibration problems. In fact, without a detailed photoionization modelling, it is impossible to take into account the effect of ionization stratification in the different observing apertures. In addition, when abundances of ions such as $\mathrm{Ne}^{++}$, $\mathrm{S}^{++}$or $\mathrm{Ar}^{++}$are derived simultaneously from optical and infrared data, the latter are generally higher by factors of $2-3$. The reason for this is presently not understood. So, while the method is in principle appealing, its results are not necessarily more trustworthy than those from optical data alone. We are thus left with the simple ICF method which, in addition, has the advantage of being easily applicable to a large number of objects.

Unfortunately, the uncertainty in abundance ratios arising from the ICFs is difficult to evaluate. It probably dominates the other sources of uncertainty in our final samples. From our experiments with large grids of photoionization models, we estimate a typical uncertainty of \pm 0.1 dex for $\log \epsilon(\mathrm{O})$ (except for $\mathrm{PNe}$ of rather low excitation, for which most of the oxygen is in the optically visible forms $\mathrm{O}^{+}$and $\mathrm{O}^{++}$and the ICF uncertainty is almost zero). For $\log (\mathrm{N} / \mathrm{O})$, uncertainties could exceed these values at the high excitation end, whereas for $\log (\mathrm{Ne} / \mathrm{O})$ this would happen at the low excitation end. The $\log (\mathrm{Ar} / \mathrm{O}) \mathrm{ra}-$ tio should be accurate to within \pm 0.1 dex, except at the very low and very high excitation ends. The $\log (\mathrm{S} / \mathrm{O})$ ratio, on the other hand, is probably uncertain by more than \pm 0.2 dex in the entire excitation range ${ }^{5}$.

A practical way of testing whether the ICF method may generate biases is to check whether the derived abundance ratios show any trend with respect to the ionization level of the nebula. We checked the values of $\mathrm{He} / \mathrm{H}, \mathrm{O} / \mathrm{H}, \mathrm{N} / \mathrm{O}, \mathrm{Ne} / \mathrm{O}, \mathrm{S} / \mathrm{O}$, and Ar/O as a function of $\mathrm{O}^{+} /\left(\mathrm{O}^{+}+\mathrm{O}^{++}\right)$for the merged sample of all PNe considered in this paper (as done in Górny et al. 2009, Appendix). We found that the ICFs of Kingsburgh \& Barlow (1994) do not lead to any artificial trend, provided that one removes PNe with $\mathrm{O}^{+} /\left(\mathrm{O}^{+}+\mathrm{O}^{++}\right)<0.4$ in the determination of $\mathrm{He} / \mathrm{H}, \mathrm{Ar} / \mathrm{O}$, and $\mathrm{S} / \mathrm{O}$. Hence, when considering the latter abundance ratios, we removed from our samples the objects with $\mathrm{O}^{+} /\left(\mathrm{O}^{+}+\mathrm{O}^{++}\right)<0.4$ (i.e. 23 out of 168 for the bulge sample, 5 out of 61 from the inner-disk sample, and 7 out of 111 for the LMC sample).

The plasma parameters and chemical abundances on which the present work is based are listed in Table 1, where we show separately bulge, inner-disk, and LMC PNe. There are three rows of data for each object, and a fourth row used to separate them. The first row indicates the values of parameters computed from the nominal values of the observational data. The second row gives the one sigma upward deviation obtained from our Monte Carlo simulations, while the third row gives the one sigma downward deviation.

In Table 1 we also report the quality of the derived parameters, marked by one of the following symbols: "+" marks data of the highest quality for which the derived individual error is smaller than the computed median error of that parameter for the entire PNe sample ${ }^{6}$; ":" indicates data of larger uncertainties but still not of errors exceeding the 0.3 dex limit; ";" labels data rejected from further consideration due to either an error superior to 0.3 dex or due to large uncertainties arising from the ICFs; an "-" marks objects for which the considered parameter could not be derived.

\footnotetext{
5 The comparison of our abundance determinations for LMC PNe with those of Leisy \& Dennefeld (2006) indicates differences. The most important one is for the $\mathrm{S} / \mathrm{H}$ values. The latter authors obtained a S/H larger than solar for more than half of their sample. In contrast, we obtain a median $\log (\mathrm{S} / \mathrm{H})+12$ value of 6.45 , below the solar value of 7.14. This difference is due to the different sulphur ICFs used in both studies. By comparing HII regions and PNe, Henry et al. (2006) noted that the latter tended to have much lower $\mathrm{S} / \mathrm{H}$ ratios for a given $\mathrm{O} / \mathrm{H}$ ratio, a fact which they called the "sulfur anomaly" and attributed to an inadequate correction for $\mathrm{S}^{+++}$in $\mathrm{PNe}$.

6 The PNe marked with a "+" are represented by filled symbols in the 2D diagrams (Figs. 3, 13, and 14) and by filled bar histograms (Figs. 4-7).
} 
Table 1. Plasma parameters and chemical abundances obtained in the present work* The quantities reported in each column are: Col. (1) - the PNG number; Col. (2) - the usual name of the PN; Col. (3) - the electron density deduced from the [S II] $\lambda 6717 / 6731$ ratio; Col. (4) - the electron temperature deduced from the [O III] $\lambda 4363 / 5007$ ratio; Col. (5) - the electron temperature deduced from the [N II] $\lambda 5755 / 6584$ ratio (the value of $T_{\mathrm{e}}\left(\mathrm{N}\right.$ II) is in parenthesis if $T_{\mathrm{e}}(\mathrm{O}$ III) was chosen for all ions); Cols. (6) to (12) - the $\mathrm{He} / \mathrm{H}, \mathrm{N} / \mathrm{H}, \mathrm{O} / \mathrm{H}, \mathrm{Ne} / \mathrm{H}, \mathrm{S} / \mathrm{H}, \mathrm{Ar} / \mathrm{H}, \mathrm{Cl} / \mathrm{H}$ abundance ratios, respectively.

\begin{tabular}{|c|c|c|c|c|c|c|c|c|c|c|c|}
\hline 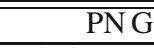 & Name & 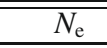 & $\overline{\overline{T_{\mathrm{e}}(\mathrm{OIII})}}$ & $\overline{\bar{T}} \overline{T_{\mathrm{e}}(\mathrm{NII})}$ & $\mathrm{He} / \mathrm{H}$ & $\overline{\mathrm{N} / \mathrm{H}}$ & $\overline{\mathrm{O} / \mathrm{H}}$ & $\mathrm{Ne} / \mathrm{H}$ & $\overline{\mathrm{S} / \mathrm{H}}$ & $\mathrm{Ar} / \mathrm{H}$ & $\overline{\mathrm{Cl} / \mathrm{H}}$ \\
\hline \multicolumn{12}{|l|}{ bulge: } \\
\hline \multirow[t]{3}{*}{$000.1-02.3$} & B13-10 & 446 ; & 12750: & -- & 0.220 : & -- & 4.41E-04: & 6.38E-05 & -- & 1.84E-06 : & -- \\
\hline & & 846 & 13440 & & 0.272 & & $5.16 \mathrm{E}-04$ & $9.41 \mathrm{E}-05$ & & $1.95 \mathrm{E}-06$ & \\
\hline & & 136 & 12410 & & 0.149 & & $3.60 \mathrm{E}-04$ & $6.01 \mathrm{E}-05$ & & $1.51 \mathrm{E}-06$ & \\
\hline \multirow[t]{3}{*}{$000.1+04.3$} & H 1-16 & 5890 ; & 10430: & $(17000)$ & 0.113 : & 5.83E-05 & 6.76E-04; & -- & 6.08E-06 ; & 2.94E-06; & -- \\
\hline & & 15100 & 11000 & (20570) & 0.211 & $8.48 \mathrm{E}-05$ & $1.12 \mathrm{E}-03$ & & $1.15 \mathrm{E}-05$ & $4.58 \mathrm{E}-06$ & \\
\hline & & 3820 & 9200 & (10260) & 0.105 & $4.86 \mathrm{E}-05$ & $5.63 \mathrm{E}-04$ & & $4.55 \mathrm{E}-06$ & $2.37 \mathrm{E}-06$ & \\
\hline
\end{tabular}

* The full table is available in electronic form at http://www . aanda. org

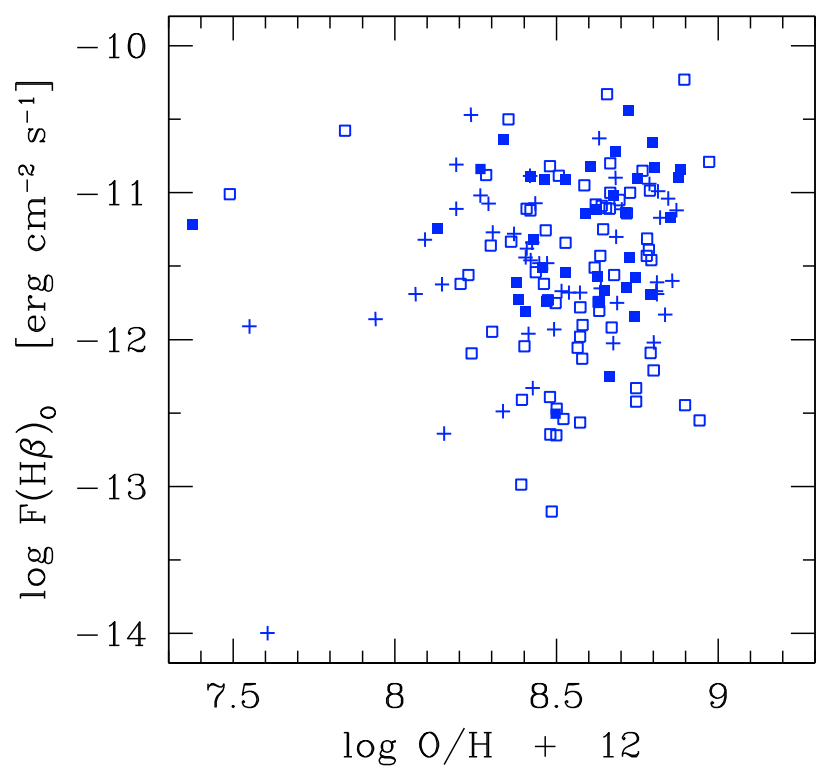

Fig. 3. The oxygen abundance as a function of the total nebular $\mathrm{H} \beta$ flux, corrected for extinction, for our final sample of bulge PNe. The filled symbols represent oxygen abundances of higher quality (see Sects. 2.3 and 2.4). The crosses represents objects with errors in $\log \epsilon(\mathrm{O})$ larger than 0.3 dex that were excluded from our analysis.

\section{The relation between $\mathrm{O} / \mathrm{H}$ and the $\mathrm{PN}$ luminosities}

Since PN progenitors span a wide range of ages, one expects that the $\mathrm{O} / \mathrm{H}$ abundances observed in PNe would be correlated with their progenitor ages, reflecting the chemical evolution of their environment. Stasińska et al. (1998) found that, in both the Large and Small Magellanic Clouds, more luminous PNe tend to be more oxygen-rich but that for the Galactic bulge, the picture was not clear. In Fig. 3, we display the value of the oxygen abundance as a function of $F(\mathrm{H} \beta)$, which is the extinction-corrected value of the total nebular flux in the $\mathrm{H} \beta$ line for our bulge PN sample. No trend is visible. We note that, by rejecting objects with oxygen-abundance uncertainties larger than $0.3 \mathrm{dex}$, we do not generate any significant bias in the abundance distribution since these objects span the entire metallicity range shown in Fig. 3.

\subsection{Abundance distributions}

Table 2 reports the median values of $\log \epsilon(\mathrm{He}), \log \epsilon(\mathrm{O})$, $\log \epsilon(\mathrm{Ar}), \log \epsilon(\mathrm{Ne}), \log \epsilon(\mathrm{S}), \log \epsilon(\mathrm{N}), \log \epsilon(\mathrm{Cl}), \log (\mathrm{S} / \mathrm{O})$, $\log (\mathrm{Ne} / \mathrm{O}), \log (\mathrm{Ar} / \mathrm{O}), \log (\mathrm{S} / \mathrm{Ar}), \log (\mathrm{N} / \mathrm{O})$, and $\log (\mathrm{N} / \mathrm{Ar})$ in bulge, LMC, and inner-disk PNe. We show in brackets the 25 and 75 percentiles, and in parenthesis the number of objects with relevant data in each sample. Also shown, for comparison, are the values found for the bulge giants (see Sect. 3), the solar abundances of Asplund et al. (2005), as well as values of $\log (\mathrm{S} / \mathrm{O})$, $\log (\mathrm{Ar} / \mathrm{O})$, and $\log (\mathrm{Ne} / \mathrm{O})$ at $\log \epsilon(\mathrm{O})=7$ and 8.66 for a sample of 109 blue compact dwarf galaxies with high quality spectra studied by Izotov et al. (2006). We note that, in HII regions, errors in abundance ratios due to ICFs are expected to be far smaller than in PNe. The ICFs used by Izotov et al. (2006) are based on a grid of photoionization models relevant to giant HII regions, and are different from those used for our PN samples. Izotov et al. (2006) noticed a slight increase in the $\mathrm{Ne} / \mathrm{O}$ ratio with increasing $\mathrm{O} / \mathrm{H}$ of $\sim 0.1$ dex over the entire metallicity range considered. This was interpreted as an indication that $\sim 20 \%$ of oxygen is locked in dust grains in the highest-metallicity HII regions of their sample.

Also shown are the $\mathrm{PNe}$ abundance distributions for: $\log \epsilon(\mathrm{N}), \log \epsilon(\mathrm{O})$, and $\log (\mathrm{N} / \mathrm{O})$ (in Fig. 4); $\log \epsilon(\mathrm{Ne}), \log \epsilon(\mathrm{S})$, and $\log \epsilon$ (Ar) (in Fig. 5); $\log (\mathrm{Ne} / \mathrm{O}), \log (\mathrm{S} / \mathrm{O})$, and $\log (\mathrm{Ar} / \mathrm{O})$ (in Fig. 6), and $\log (\mathrm{Ar} / \mathrm{S})$ (Fig. 7). To alleviate the problem of small number statistics and, at the same time, take into account the errors in the abundance ratios, we constructed histograms not only for the nominal values of the abundance ratios, but also the entire set of our Monte Carlo realizations for each object ${ }^{7}$.

The filled bar histograms show the location of our highest quality $\mathrm{PNe}$ data, namely those with errors in the abundance ratio smaller than the median error for the entire PN sample (these objects are represented by filled symbols in Fig. 3 and in the abundance ratio diagrams discussed in Sect. 5). This shows that, in general, accuracy does not depend on the value of the abundance ratio. In Table 3, we show the results of the KolmogorovSmirnov and Wilcoxson tests for pairs of samples, for the different histograms shown in Figs. 4-7. With both methods, one can test the null hypothesis that the investigated samples originate in identical parent distributions. If, as a result of the test, the probability of the latter hypothesis being correct is found to be very low (usually a border value of $1 \%$ is adopted, or at most $5 \%$ ), then it can be assumed that the two distributions or populations under study are truly different. Tests of this kind are crucial for allowing one to discard situations of apparent differences, which can result from random effects caused by sample selection and/or uncertainties.

These results are discussed in Sect. 5.

\footnotetext{
7 The last rows of Figs. 4-6 show the abundance distributions obtained for bulge field giants, which are discussed in Sects. 3 and 6.
} 

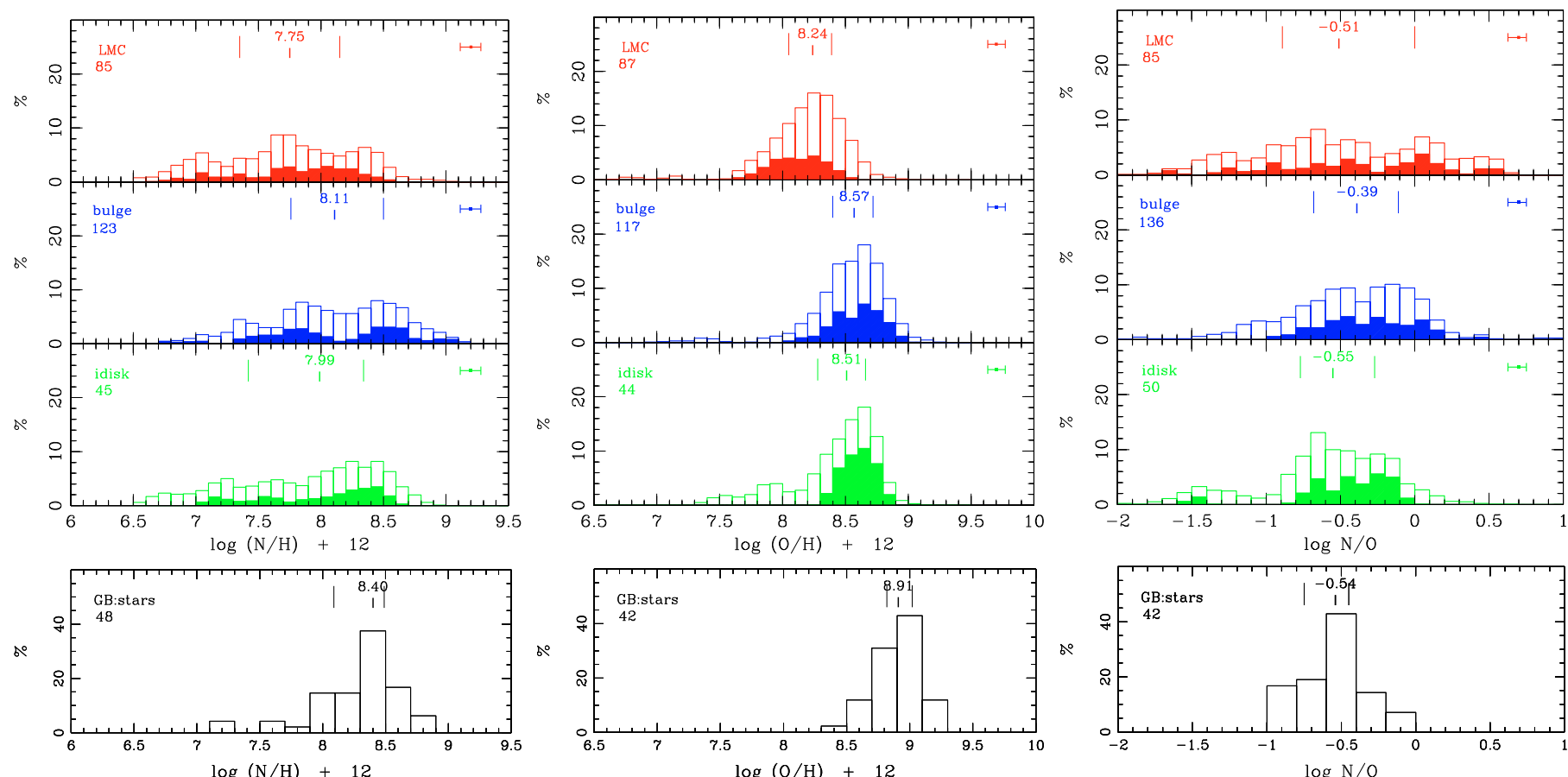

Fig. 4. In the first three rows, we present the PN abundance distributions in the LMC, bulge, and inner-disk for $\mathrm{N}$ (1st column), O (2nd column), and N/O (3rd column). The median values of the distributions, the 25 and 75 percentiles, the number of objects used in each panel, and the typical error bar are also shown. In the three first rows, the filled-bar histograms show the location of our highest quality data namely that have errors in the abundance ratio smaller than the median error for the entire PN sample (see text). In the last row, we show the abundance distributions of $\mathrm{N}$, $\mathrm{O}$, and N/O obtained for field-bulge giants.
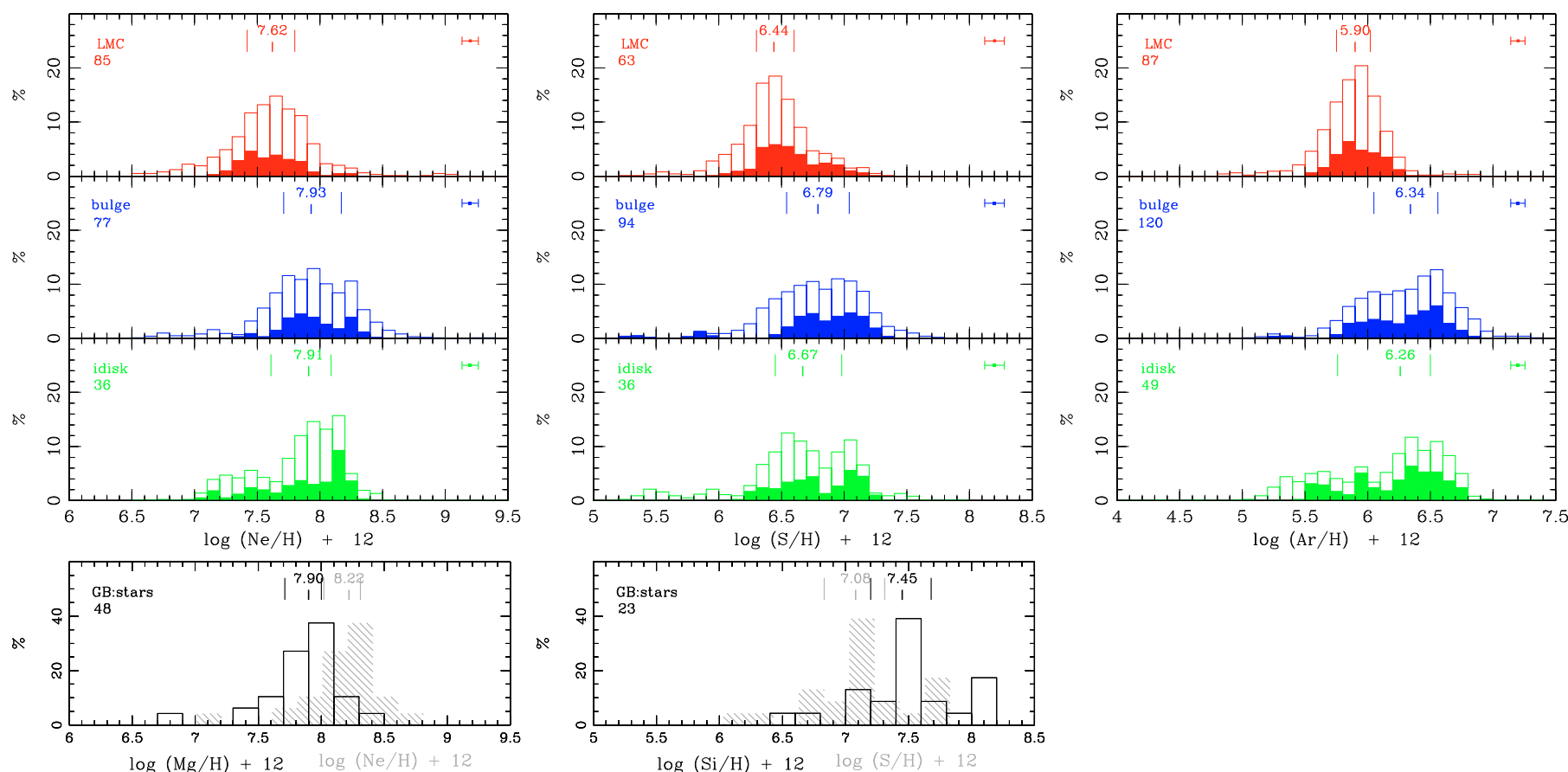

Fig. 5. In the first three rows, we present the PN abundance distributions of Ar, Ne, and S (labelled as in Fig. 4). In the last row, we show the abundance distributions of $\mathrm{Si}$ and $\mathrm{Mg}$ obtained for field-bulge giants. The shaded histograms in this row represent the distributions of $\mathrm{Ne} / \mathrm{H}$ and $\mathrm{S} / \mathrm{H}$ obtained from the distributions of $\mathrm{Mg} / \mathrm{H}$ and $\mathrm{Si} / \mathrm{H}$ by assuming solar $\mathrm{X} / \mathrm{O}$ ratios, where $\mathrm{X}=\mathrm{Si}, \mathrm{Mg}, \mathrm{Ne}$, and $\mathrm{S}$ (see $\mathrm{Sect}$. 6.2.2). 
Table 2. Median abundance values (number of objects).

\begin{tabular}{|c|c|c|c|c|c|c|c|c|c|c|}
\hline & Bulge PNe & & Inner-disk $\mathrm{PNe}$ & & LMC PNe & & Bulge giants & & $\operatorname{Sun}^{a}$ & HII regions ${ }^{b}$ \\
\hline $\log \epsilon(\mathrm{He})$ & $11.11[11.05,11.19]$ & (144) & $11.08[11.02,11.14]$ & (56) & $11.00[10.92,11.07]$ & (99) & - & & $10.93 \pm 0.01$ & - \\
\hline $\log \epsilon(\mathrm{O})$ & $8.57 \quad[8.40,8.72]$ & (117) & $8.51[8.28,8.66]$ & (44) & $8.24[8.05,8.39]$ & (87) & $8.91[8.82,9.02]$ & (42) & $8.66 \pm 0.05$ & - \\
\hline $\log \epsilon(\mathrm{Ar})$ & $6.34[6.05,6.56]$ & (120) & $6.26[5.76,6.50]$ & (49) & $5.90[5.75,6.02]$ & (87) & - & & $6.18 \pm 0.08$ & - \\
\hline $\log \epsilon(\mathrm{Ne})$ & $7.93 \quad[7.71,8.17]$ & (77) & $7.91[7.61,8.09]$ & (36) & $7.62[7.42,7.80]$ & (85) & $8.22[8.02,8.31]$ & (48) & $7.84 \pm 0.06$ & - \\
\hline $\log \epsilon(\mathrm{S})$ & $6.79 \quad[6.54,7.04]$ & (94) & $6.67 \quad[6.45,6.98]$ & (36) & $6.44[6.30,6.60]$ & (63) & $7.08[6.83,7.31]$ & (23) & $7.14 \pm 0.05$ & - \\
\hline $\log \epsilon(\mathrm{N})$ & $8.11[7.76,8.50]$ & (123) & $7.99 \quad[7.42,8.34]$ & (45) & $7.75[7.35,8.15]$ & (85) & $8.40[8.09,8.49]$ & (48) & $7.78 \pm 0.06$ & - \\
\hline $\log \epsilon(\mathrm{Cl})$ & $6.22[6.00,6.50]$ & (47) & $6.27 \quad[5.97,6.63]$ & (19) & $5.67[-,-]$ & (4) & - & & $5.50 \pm 0.30$ & - \\
\hline $\log (\mathrm{S} / \mathrm{O})$ & $-1.74[-1.91,-1.59]$ & (127) & $-1.79[-2.03,-1.63]$ & (42) & $-1.79[-1.99,-1.54]$ & (80) & $-1.64[-1.78,-1.58]$ & (22) & -1.52 & $-1.696,-1.739$ \\
\hline $\log (\mathrm{Ne} / \mathrm{O})$ & $-0.62[-0.74,-0.52]$ & (90) & $-0.59[-0.70,-0.48]$ & (46) & $-0.67[-0.78,-0.52]$ & (99) & $-0.78[-0.90,-0.64]$ & (64) & -0.82 & $-0.834,-0.688$ \\
\hline $\log (\mathrm{Ar} / \mathrm{O})$ & $-2.22[-2.38,-2.05]$ & (141) & $-2.22[-2.41,-2.08]$ & (51) & $-2.35[-2.48,-2.13]$ & (96) & - & & -2.48 & $-2.441,-2.376$ \\
\hline $\log (\mathrm{S} / \mathrm{Ar})$ & $0.46[0.31,0.61]$ & (111) & $0.39[0.23,0.59]$ & (37) & $0.52[0.39,0.66]$ & (69) & - & & 0.96 & $0.745,0.637$ \\
\hline $\log (\mathrm{N} / \mathrm{O})$ & $-0.39[-0.68,-0.11]$ & (136) & $-0.55[-0.77,-0.27]$ & $(50)$ & $-0.51[-0.89,0.00]$ & (85) & $-0.54[-0.75,-0.45]$ & (42) & -0.88 & - \\
\hline $\log (\mathrm{N} / \mathrm{Ar})$ & $1.86[1.60,2.05]$ & (138) & $1.81[1.51,1.95]$ & (45) & $1.86[1.55,2.22]$ & (84) & - & & 1.6 & - \\
\hline
\end{tabular}

${ }^{a}$ Asplund et al. (2005); ${ }^{b}$ Izotov et al. (2006).
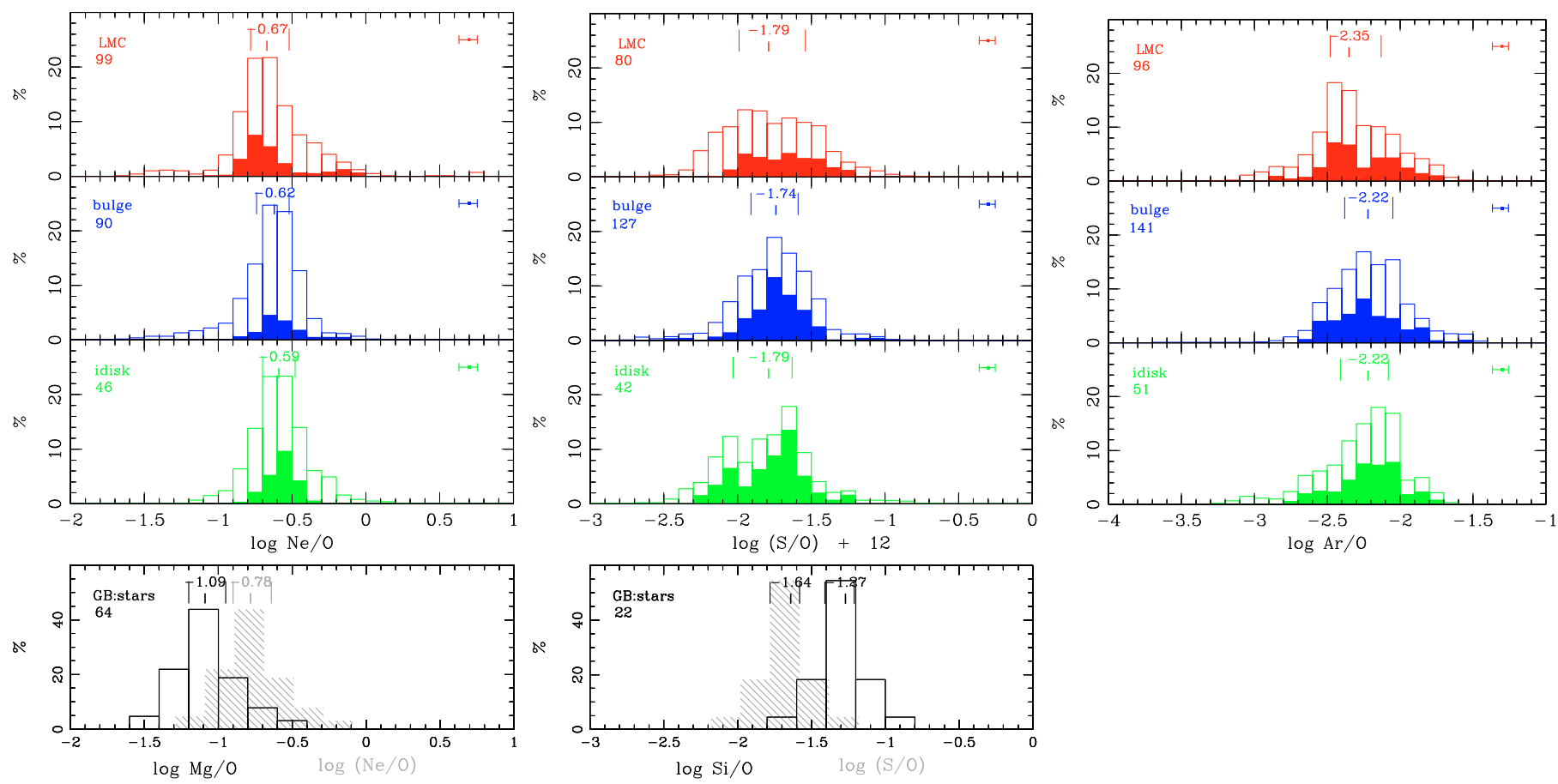

Fig. 6. In the first three rows, we present the $\mathrm{PN}$ abundance distributions of $\mathrm{Ne} / \mathrm{O}, \mathrm{Ar} / \mathrm{O}$, and $\mathrm{S} / \mathrm{O}$ (labeled as in Fig. 4). In the last row, we show the abundance distributions of $\mathrm{Si} / \mathrm{O}$ and $\mathrm{Mg} / \mathrm{O}$ obtained for field bulge giants. The shaded histograms in this row represent the distributions of $\mathrm{Ne} / \mathrm{O}$ and $\mathrm{S} / \mathrm{O}$ obtained from the distributions of $\mathrm{Mg} / \mathrm{O}$ and $\mathrm{Si} / \mathrm{O}$ by assuming solar $\mathrm{X} / \mathrm{O}$ ratios, where $\mathrm{X}=\mathrm{Si}, \mathrm{Mg}, \mathrm{Ne}$, and $\mathrm{S}$ (see $\mathrm{Sect}$. 6.2.2).

\section{Stars: samples and abundances}

Comparing the abundances of bulge planetary nebulae with those of a sample of bulge stars is not a straightforward task. Abundance measurements for bulge stars require the use of large telescopes and are only feasible for giants ${ }^{8}$. As a consequence the bulge giant samples, for which several chemical elements are measured, are still small compared to our present bulge

\footnotetext{
8 There have been a few abundance measurements for extremely metal-rich bulge $\mathrm{G}$ dwarfs. This was possible due to the magnification from microlensing (see Cohen et al. 2008). Abundances for dwarf bulge stars obtained from microlensing are promising, however complete samples will not be feasible before the $30 \mathrm{~m}$ class telescopes are available.
}

PN sample ${ }^{9}$. Hence, for elements other than iron, the sample selection effects can play an important role in shaping the abundance distributions. In addition, whereas for PNe, the measurements can cover the entire bulge area, for stars the measurements are made in the low extinction lines of sight (such as the Baade's Window) and/or require infrared spectra (e.g. Rich \& Origlia 2005). Aware of these caveats (see discussion in Sect. 3.3), we present here the adopted samples of bulge giants to be compared with our sample of bulge PNe in Sect. 6. We also briefly

\footnotetext{
9 Although this situation is changing quickly - e.g. Zoccali et al. (2008) obtained $[\mathrm{Fe} / \mathrm{H}]$ for $\sim 800$ bulge field stars, and the analysis of some elements measurable at the resolution of $R \sim 22000$ of the Flames instrument are under way for this large sample - at the present moment, abundances are available only for a smaller number of objects.
} 


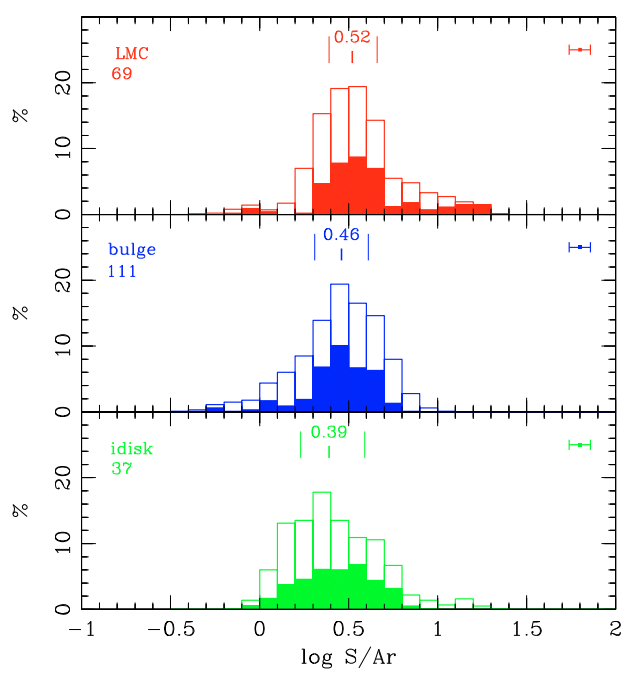

Fig. 7. The S/Ar distribution for PNe in the LMC, bulge, and inner-disk (labeled as in Fig. 4).

summarize the main steps and uncertainties involved in the abundance determinations of bulge giants.

\subsection{The adopted samples}

In the literature, there are few field ${ }^{10}$ giant stars for which high quality abundance measurements are available. Moreover, only oxygen (and in a few cases $\mathrm{C}$ and $\mathrm{N}$ ) are measured in both bulge $\mathrm{PNe}$ and bulge giants, making direct comparison difficult.

For the present work, we chose the Fulbright et al. (2007, hereinafter F07) and the Lecureur et al. (2007, hereinafter L07) samples as our two main reference samples for bulge giants. These two samples constitute presently the largest samples of bulge field giants with abundance measurements for several chemical elements. These data come from optical highresolution spectra taken with $8 \mathrm{~m}$-class telescopes.

$\mathrm{F} 07$ reported $\mathrm{O}, \mathrm{Na}, \mathrm{Mg}, \mathrm{Al}, \mathrm{Si}, \mathrm{Ca}$, and $\mathrm{Ti}$ abundances for 27 red giant branch stars observed towards the Baade's Window. These abundances were inferred from high resolution spectra obtained with the Keck I telescope. Of particular interest to our discussion are the $\mathrm{O}, \mathrm{Mg}$, and $\mathrm{Si}$ measurements.

L07 reported abundances (spectra obtained on the VLT) of $\mathrm{O}, \mathrm{Na}, \mathrm{Mg}$, and $\mathrm{Al}$ for 13 core He-burning giant stars and 40 red giant branch stars in four $25^{\prime}$ fields spanning the bulge from $-3^{\circ}$ to $-12^{\circ}$ along the bulge minor axis. Their stars were selected from bulge colour-magnitude diagrams, and the expected number of foreground contaminants in each field was around $15 \%$ in all fields, with the exception of one at $b=-12^{\circ}$ for which this contamination can reach $45 \%$. We chose not to use their $b=-12^{\circ}$ field (with 5 stars) to avoid significant contamination by disk stars. L07 also obtained $\mathrm{C}$ and $\mathrm{N}$ abundances.

We also include the abundance measurements from three other smaller samples, namely: Cunha \& Smith (2006), Rich \& Origlia (2005), and Meléndez et al. (2008). These abundances were obtained from infrared spectra. Cunha \& Smith (2006)

10 We do not include the abundance measurements in bulge stars inside globular clusters, since in this case the abundances of oxygen could have been affected by the so-called $\mathrm{Na}-\mathrm{O}$ anti-correlation typical of globular clusters (e.g. Gratton et al. 2004). In the sample of Fulbright et al. (2007) for field stars, two objects showing low $[\mathrm{O} / \mathrm{Fe}]$ ratios for low metallicities are also probably ex-members of globular clusters and were not included in the present discussion.
Table 3. Results of Kolmogorov-Smirnov and Wilcoxson statistical tests for abundance distributions. For each pair of samples, the probabilities of the hypothesis that two given distributions originate in identical parent distributions is given.

\begin{tabular}{llll}
\hline \hline Element & Bulge/Inner-Disk & Bulge/LMC & LMC/Inner Disk \\
\hline $\log \epsilon(\mathrm{He})$ & $0.09 / 0.04$ & $0.00 / 0.00$ & $0.00 / 0.00$ \\
$\log \epsilon(\mathrm{O})$ & $0.30 / 0.08$ & $0.00 / 0.00$ & $0.00 / 0.00$ \\
$\log \epsilon(\mathrm{Ar})$ & $0.08 / 0.06$ & $0.00 / 0.00$ & $0.00 / 0.00$ \\
$\log \epsilon(\mathrm{Ne})$ & $0.17 / 0.36$ & $0.00 / 0.00$ & $0.00 / 0.00$ \\
$\log \epsilon(\mathrm{S})$ & $0.30 / 0.12$ & $0.00 / 0.00$ & $0.00 / 0.00$ \\
$\log \epsilon(\mathrm{N})$ & $0.09 / 0.03$ & $0.00 / 0.00$ & $0.11 / 0.13$ \\
$\log \epsilon(\mathrm{Cl})$ & $0.95 / 0.60$ & $-/-$ & $-/-$ \\
\hline $\log (\mathrm{S} / \mathrm{O})$ & $0.21 / 0.17$ & $0.35 / 0.72$ & $0.59 / 0.38$ \\
$\log (\mathrm{Ne} / \mathrm{O})$ & $0.31 / 0.11$ & $0.27 / 0.46$ & $0.05 / 0.06$ \\
$\log (\mathrm{Ar} / \mathrm{O})$ & $0.67 / 0.41$ & $0.00 / 0.00$ & $0.01 / 0.12$ \\
$\log (\mathrm{S} / \mathrm{Ar})$ & $0.25 / 0.24$ & $0.17 / 0.04$ & $0.01 / 0.01$ \\
$\log (\mathrm{N} / \mathrm{O})$ & $0.05 / 0.01$ & $0.09 / 0.41$ & $0.10 / 0.28$ \\
$\log (\mathrm{N} / \mathrm{Ar})$ & $0.21 / 0.13$ & $0.02 / 0.42$ & $0.00 / 0.08$ \\
\hline
\end{tabular}

${ }^{*} \log \epsilon(\mathrm{X})=\log (\mathrm{X} / \mathrm{H})+12$.

measured the abundances in $7 \mathrm{~K}$ and $\mathrm{M}$ red giant members of the bulge (their target stars are a subset of the $\mathrm{K}$ giant sample of F07, plus two additional $\mathrm{M}$ giants, one in common with Rich \& Origlia 2005) from high-resolution infrared spectra obtained with the Phoenix spectrograph on Gemini South. The elements studied in this case were C, N, O, Na, Ti, and Fe. For objects in common, the oxygen abundances obtained by Cunha $\&$ Smith (2006) in the infrared agree with those obtained by F07 in the optical. Of interest to our discussion are their abundances for $\mathrm{O}$ and N. Rich \& Origlia (2005) reported abundances of $\mathrm{O}$, $\mathrm{Fe}, \mathrm{Si}, \mathrm{Mg}, \mathrm{Ca}, \mathrm{Ti}, \mathrm{C}$, and ${ }^{12} \mathrm{C} /{ }^{13} \mathrm{C}$ ratio, for 14 bulge $\mathrm{M}$ giant stars obtained by using the NIRSPEC spectrograph at the Keck Telescope. This sample spans a narrow metallicity range (from $-0.33 \leq[\mathrm{Fe} / \mathrm{H}] \leq-0.03$ ). We use their $\mathrm{O}$ and $\mathrm{Si}$ abundances in the abundance ratio plots, but not in the histograms (see Sect. 3.3). Meléndez et al. (2008) derived O, N, and Fe for 19 Baade's Window giants. The Meléndez et al. (2008) stars were taken from the F07 sample.

The final adopted stellar sample is described in Sect. 3.3. Figure 2 shows the location of the adopted samples in a $(l, b)$ diagram. We also report the number of stars studied in each field.

\subsection{Abundance determinations, uncertainties, and biases}

The formation of absorption lines is computed by sophisticated model atmospheres that take into account the radiative transfer from deeper to shallower layers (optical depths $2 \geq \log \tau \geq-5$ ). Available grids of model atmospheres assume conditions of Local Thermodynamic Equilibrium (LTE). The detailed abundance analysis of cool stars consists of using a set of FeI and FeII lines to derive four basic parameters: effective temperature $T_{\text {eff }}$, gravity $\log g$, metallicity $[\mathrm{Fe} / \mathrm{H}]$, and microturbulence velocity $v_{\mathrm{t}}$. Since these four stellar parameters are interdependent, the analysis has to consider simultaneously excitation equilibrium, ionization equilibrium, and an optimal $v_{\mathrm{t}}$ value that satisfies a range of equivalent widths. When the stellar parameters have been decided, the abundances of different elements are derived line-by-line, either using their equivalent widths or by fitting line profiles.

\section{Effective temperatures}

In the optical, the effective temperature is preferentially derived from the excitation equilibrium of FeI and FeII lines of different excitation potential. A change of $100 \mathrm{~K}$ in $T_{\text {eff }}$ causes a 
recognizable trend in the plane FeI abundance versus excitation potential and we can therefore consider that the uncertainty in $T_{\text {eff }}$ is of that order.

In the near-infrared $(H, K)$ bands region, the FeI lines have high excitation potentials (around 5.5-6.5 eV), with little variation, and thus have little sensitivity to excitation temperature equilibrium. Consequently, for bulge stars studied from $H$ and $K$-band spectra, temperatures must rely on photometric colours, and given the rather high and variable reddening in bulge regions, it is challenging to obtain intrinsic colours with the accuracy needed for effective temperature derivation (e.g. Cunha \& Smith 2006).

\section{Gravity}

The surface gravities $\log g$ are in general derived using the effective temperature $\left(T_{\text {eff }}\right)$ and in some cases also the parallax as input (in which case the bolometric magnitude $-M_{\text {bol }}^{*}-$ can be derived), with the classical relation (where $M_{*}$ is the stellar mass, in solar masses):

$\log \frac{g_{*}}{g_{\odot}}=4 \log \frac{T_{\mathrm{eff}}}{T_{\odot}}+0.4\left(M_{\mathrm{bol}}^{*}-M_{\mathrm{bol}}^{\odot}\right)+\log \frac{M_{*}}{M_{\odot}}$.

The spectroscopic gravity $\log g$ derived from ionization equilibrium of FeI and FeII lines shows typical uncertainties of 0.30 dex.

\section{Microturbulent velocities}

The microturbulent velocities $v_{\mathrm{t}}$ are usually determined using FeI lines. The uncertainty derived from the FeI abundance versus the equivalent width $W_{\lambda}$ is in general around $0.2 \mathrm{~km} \mathrm{~s}^{-1}$.

\section{Atmospheric parameters: impact on oxygen abundance} Assuming typical parameters for a bulge giant $\left[T_{\text {eff }}, \log g\right.$, $\left.[\mathrm{Fe} / \mathrm{H}], v_{\mathrm{t}},\right]$ of $4500 \mathrm{~K}, 2.0,0.0$, and $1.5 \mathrm{~km} \mathrm{~s}^{-1}$, we estimate the uncertainties in the derivation of oxygen abundances due to the choice of stellar parameters, by showing in Table 4 the sensitivity of the abundances to variations in the temperature, gravity, and microturbulent velocity of $\Delta T_{\text {eff }}=100 \mathrm{~K}, \Delta \log g=0.30$ dex, and $\Delta v_{\mathrm{t}}=0.20 \mathrm{~km} \mathrm{~s}^{-1}$. The total error is given in the last column as the quadratic sum of all uncertainties. We can see that the total uncertainties in $[\mathrm{O} / \mathrm{Fe}]$ are about 0.05 dex. The $[\mathrm{O} / \mathrm{H}]$ abundances are affected by additional unknown systematic effects, whereas for abundance ratios such as $[\mathrm{O} / \mathrm{Fe}]$, part of these uncertainties cancel out.

Finally, in general, ionized lines are combined with FeII, and neutral species with FeI. Some ratios are more reliable when compared with FeII, such as oxygen derived from [OI] $630 \mathrm{~nm}$, since these lines form in similar layers. In terms of the effects of non-LTE, the use of FeII is more reliable, since FeII lines are far less sensitive to NLTE than FeI lines.

\section{Other uncertainties}

The adopted oscillator strengths and oxygen abundances in the reference star may systematically alter the oxygen abundance. The important issue is the combination of oxygen abundance in the reference star, and the log gf value. For example, Bensby et al. (2004) use for the [OI]630 $\mathrm{nm}$ line a $\log g f$ value of -9.819 and a solar oxygen abundance of $\log \epsilon(\mathrm{O})=8.69$, and the same values were adopted by Zoccali et al. (2006) and L07, for comparison purpose. The more usual value of $\log g f=-9.717$ (e.g. Allende Prieto et al. 2001) leads to oxygen abundances that are higher by 0.1 dex.

Concerning the oxygen abundance used in the reference star, for the Sun, values of $\log \epsilon(\mathrm{O})=8.77$ recommended by
Table 4. Sensitivity of abundances to changes of $\Delta T_{\text {eff }}=100 \mathrm{~K}$, $\Delta \log g=+0.3$, and $\Delta v_{\mathrm{t}}=0.2 \mathrm{~km} \mathrm{~s}^{-1}$. In the last column, the corresponding total error is given.

\begin{tabular}{lcccc}
\hline \hline $\begin{array}{l}\text { Species } \\
(1)\end{array}$ & $\begin{array}{c}\Delta T \\
(2)\end{array}$ & $\begin{array}{c}\Delta \log g \\
(3)\end{array}$ & $\begin{array}{c}\Delta v_{\mathrm{t}} \\
(4)\end{array}$ & $\begin{array}{c}\left(\sum \mathrm{x}^{2}\right)^{1 / 2} \\
(5)\end{array}$ \\
\hline \multicolumn{2}{l}{ Original: $T_{\text {eff }}=4500 \mathrm{~K}, \log g$} & $2.0,[\mathrm{Fe} / \mathrm{H}]=0.0, v_{\mathrm{t}}=1.5 \mathrm{~km} \mathrm{~s}^{-1}$ \\
\hline$[\mathrm{Fe} / \mathrm{H}](\mathrm{I})$ & -0.02 & +0.04 & -0.09 & +0.10 \\
{$[\mathrm{Fe} / \mathrm{H}](\mathrm{II})$} & -0.19 & +0.13 & -0.05 & +0.23 \\
{$[\mathrm{O} / \mathrm{Fe}]$} & +0.01 & +0.05 & -0.01 & +0.05 \\
\hline
\end{tabular}

Allende Prieto et al. (2001) for 1D model atmosphere calculations down to $\log \epsilon(\mathrm{O})=8.66$ (Asplund et al. 2004) are presently being used. For Arcturus, when used as the reference star for fitting oscillator strengths, the stellar parameters and C, N, O abundances also can vary among different authors.

In the derivation of the bulge giant abundances, Arcturus has been adopted as the reference star in all cases, except for L07 who adopted $\mu$ Leo as reference star, but they give the parameters for Arcturus based on those deduced from fitting $\mu$ Leo lines. The log gf values of FeI and FeII lines (which are the lines used to derive effective temperature, gravity, metallicity, and microturbulence velocity) are fitted to Arcturus, and then used to derive stellar parameters of the sample bulge giants. For example, $[\mathrm{Fe} / \mathrm{H}]=-0.50$ or -0.60 for Arcturus can produce a 0.1 dex difference in $\log g f$ values of FeI and FeII, which can affect the final abundances by this much.

In Table 5, we show the basic parameters and resulting $\mathrm{C}, \mathrm{N}$, and $\mathrm{O}$ abundances obtained or adopted by different authors for Arcturus and the Sun. It is clear that, while for $\mathrm{C}$ and N, the abundances are similar to within $0.15 \mathrm{dex}$, for oxygen differences of up to 0.27 dex are seen. This is caused by differences in solar oxygen abundance, oscillator strengths, and oxygen lines used, as well as small differences in stellar parameters for Arcturus.

Another source of error is the use of 1-D model atmospheres, since the strengths of lines depend on the detailed structure of the atmospheres. Stellar granulation, including the effects of temperature gradients, atmospheric inhomogeneities, and velocity fields caused by convection, affect the ratio of line to continuous absorption (Asplund 2005). These effects were taken into account by the use of 3-D time-dependent, hydrodynamical, model atmospheres. Such calculations when applied to [OI]630 nm and FeII lines by Nissen et al. (2002), demonstrated that for metalpoor stars, a correction of 0.2 dex was required. On the other hand, essentially no difference was found for metal-rich stars. Another point is that 3-D effects compensate for NLTE effects, so that both improvements must be taken into account at the same time. However, in the case of [OI] $630 \mathrm{~nm}$, the NLTE effects are negligible and the predictions by Nissen et al. (2002) using 3D-models should apply. For infrared OH lines, NLTE and 3-D corrections could have some effect, but detailed calculations are unavailable.

\subsection{Abundance distributions}

Figure 8 shows the oxygen distributions for the L07, F07, and Meléndez et al. (2008) samples (for the other two samples, the number of objects was too small and we do not show their oxygen histograms). We note the generally good agreement between the F07 (optical) and Meléndez et al. (2008 - infrared) oxygen distributions.

The median oxygen abundance of each of the L07 and F07 samples differ by 0.11 dex, the Lecureur sample being narrower 
Table 5. Comparison of results from different recent studies for Arcturus (employed as a reference star in bulge studies) and the Sun. This table is organized as follows: stellar parameters employed for Arcturus (Cols. 1-4); solar abundances (Cols. 5-8); Arcturus abundances (Cols. 9-12); References $^{a}$ (Col. 13).

\begin{tabular}{|c|c|c|c|c|c|c|c|c|c|c|c|c|}
\hline $\begin{array}{l}T_{\text {eff }} \\
(\mathrm{K})\end{array}$ & $\log g$ & $\begin{array}{c}v_{\mathrm{t}} \\
\mathrm{km} \mathrm{s}^{-1}\end{array}$ & {$[\mathrm{Fe} / \mathrm{H}]$} & $\log \epsilon(\mathrm{O})_{\odot}$ & $\log \epsilon(\mathrm{C})_{\odot}$ & $\log \epsilon(\mathrm{N})_{\odot}$ & $\log \epsilon(\mathrm{Fe})_{\odot}$ & $\log \epsilon(\mathrm{O})$ & $\log \epsilon(\mathrm{C})$ & $\log \epsilon(\mathrm{N})$ & $\log \epsilon(\mathrm{Fe})$ & Reference \\
\hline 4275 & 1.55 & 1.65 & -0.54 & 8.87 & 8.55 & 7.97 & 7.50 & 8.76 & 7.93 & 7.73 & 6.96 & 1 \\
\hline 4300 & 1.7 & 1.6 & -0.60 & 8.77 & 8.59 & 8.00 & 7.50 & 8.49 & 7.92 & 7.60 & 6.78 & 2 \\
\hline 4250 & 1.5 & 1.5 & -0.60 & 8.83 & 8.52 & 7.92 & 7.50 & 8.58 & 7.72 & - & 6.90 & 3 \\
\hline 4290 & 1.55 & 1.67 & -0.50 & 8.69 & - & - & 7.45 & 8.67 & - & - & 6.95 & 4 \\
\hline 4300 & 1.5 & 1.5 & -0.52 & 8.77 & 8.46 & 7.94 & 7.50 & 8.70 & 7.96 & 7.74 & 6.98 & 5 \\
\hline
\end{tabular}

${ }^{a} 1$ - Meléndez et al. 2008; 2 - Cunha \& Smith (2006) (based on Smith et al. 2000); 3 - Rich \& Origlia (2005); 4 - Fulbright et al. (2006, 2007); 5 - Lecureur et al. (2007) (based on Smith et al. 2002). Note: $\log \epsilon(X)=\log (X / H)+12$.
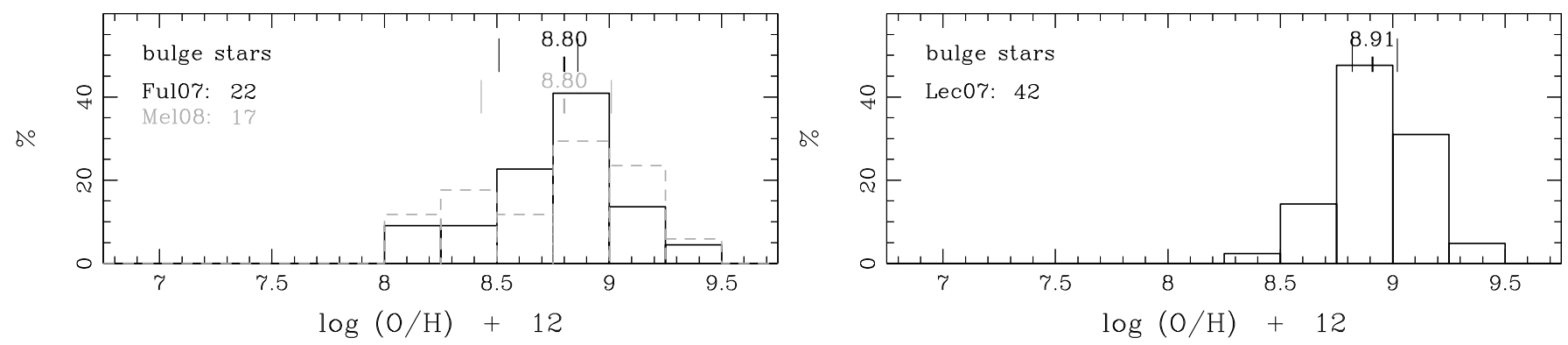

Fig. 8. The distribution of $\mathrm{O} / \mathrm{H}$ for the F07 (left panel, solid histogram), Meléndez et al. (2008) (left panel, dashed histogram), and L07 (right pannel) samples of bulge giant stars. The solar values from Asplund et al. (2005) is $\log \epsilon(\mathrm{O})=8.66 \pm 0.05$. The final adopted oxygen distribution (see text) can be seen in Fig. 4.

and shifted towards larger oxygen abundance values. This difference reflects, in part, the fact that these samples were selected according to different criteria. This means that the final abundance distributions may not reflect the true bulge distributions. This is certainly the case for the F07 sample (and of course will also be the case for the Meléndez et al. 2008 sample). The latter authors selected a number of stars covering a wide range of metallicities to study the $[\mathrm{O} / \mathrm{Fe}]$ versus $[\mathrm{Fe} / \mathrm{H}]$ diagram and not the metallicity distribution. In addition, the oxygen distributions of F07 and L07 can differ due to the combined effect of basic parameters such as oxygen abundance in the Sun and Arcturus and oscillator strength differences, as previously discussed (see Sect. 3.2).

The L07 sample is derived from the larger sample of Zoccali et al. (2008). To avoid strong biases in the resulting ironmetallicity distribution, Zoccali et al. (2008) included targets spanning the entire colour range in the red giant branch at a given magnitude. The raw distribution was corrected for a possible remaining metallicity bias, but the resulting distribution turned out to be indistinguishable from the original one, which implied that their selection criteria was robust (see Zoccali et al. 2008, for details). For a subset of data from Zoccali et al. (2008), UVES spectra were obtained, and these data constitute the L07 sample. A comparison between the iron metallicity distribution calculated with the L07 sample with the more complete one of Zoccali et al. (2008) confirms that the former still provides a good estimate of the bulge metallicity distribution.

For reasons already discussed, the final oxygen abundance distribution (shown in Fig. 4) was obtained using only the L07 sample, and will be compared with one obtained from bulge PNe in Sect. 5.

Figure 9 shows that the $\mathrm{Mg}$ distribution obtained with the L07 sample is narrower than that of F07 and is also shifted towards larger $\mathrm{Mg}$ values by almost $0.3 \mathrm{dex}$. This again reflects the different sample-selection criteria, as discussed before. However, in this case, the discrepancy is larger than for oxygen showing that other systematic effects can also play a role. In this case, we again use only $\mathrm{L07}$ data in our final $\mathrm{Mg} / \mathrm{H}$ distribution (see Fig. 5).

Figures 10 and 11 show the distributions of the $\mathrm{Mg} / \mathrm{O}$ and $\mathrm{Si} / \mathrm{O}$ ratios. The $\mathrm{Mg} / \mathrm{O}$ ratio measured by both $\mathrm{L} 07$ and $\mathrm{F} 07$, are close to the solar $\mathrm{Mg} / \mathrm{O}$ ratio of Asplund et al. (2005). Similarly, the $\mathrm{Si} / \mathrm{O}$ ratio measured by $\mathrm{F} 07$ was found to be close to the solar $\mathrm{Si} / \mathrm{O}$ ratio of Asplund et al. (2005). We note that the $\mathrm{Si} / \mathrm{O}$ ratio from the Rich \& Origlia (2005) sample, is not solar. In this case, the final $\mathrm{Si} / \mathrm{O}$ distribution includes only the data from Fulbright and collaborators. The final distributions of $\mathrm{Si} / \mathrm{H}, \mathrm{Mg} / \mathrm{H}, \mathrm{Si} / \mathrm{O}$, and $\mathrm{Mg} / \mathrm{O}$ for the bulge giant stars are shown in Figs. 5 and 6.

Finally in Fig. 12, the distribution of N/O for the samples of L07 and Cunha \& Smith (2006) are shown. Since Cunha \& Smith (2006) also included some stars from F07, we compare this histogram with that obtained by Meléndez et al. (2008), who measured N in 17 of the F07 stars. Despite the low number of objects in the Cunha \& Smith (2006) sample, the median N/O ratio values agree well with those of L07. The Meléndez et al. (2008) $\mathrm{N} / \mathrm{O}$ distribution is instead shifted to lower values by $\sim 0.25 \mathrm{dex}$. Given these differences, we adopted only that of L07 (see Fig. 4) as our final N/O bulge giant distribution.

\section{How do mixing processes affect the observed abundances?}

To be able to interpret the abundance results described in Sects. 2 and 3, we recall some of the main aspects of the evolution of lowand intermediate-mass stars (for details, see the review by Siess 2008).

Before ascending the asymptotic giant branch (AGB) phase, the original surface abundance of low- and intermediate-mass 

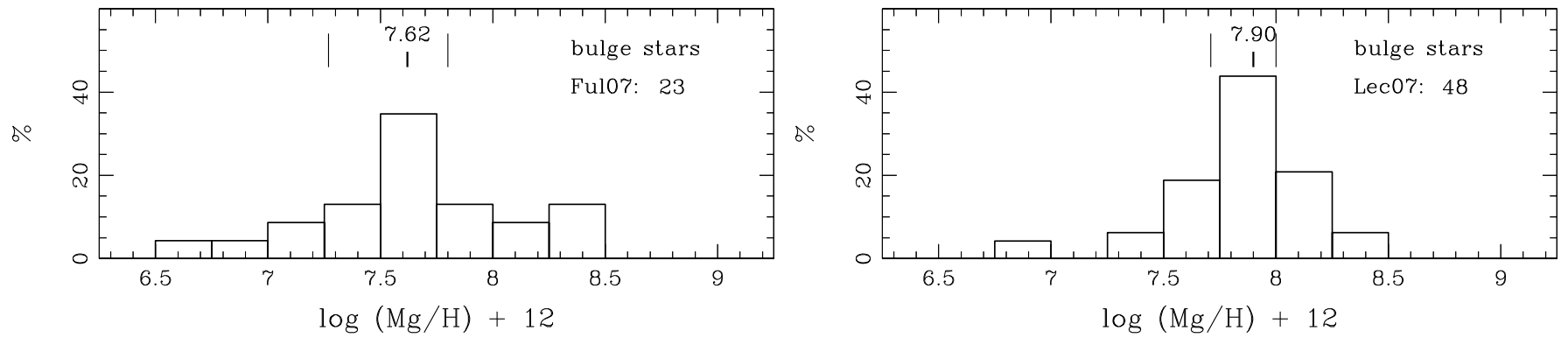

Fig. 9. The distribution of $\mathrm{Mg} / \mathrm{H}$ for the F07 (left panel) and L07 (right panel) samples of bulge giant stars. The solar values from Asplund et al. (2005) is $\log \epsilon(\mathrm{Mg})=7.53 \pm 0.05$. The adopted final magnesium distribution (see text) can be seen in Fig. 5.
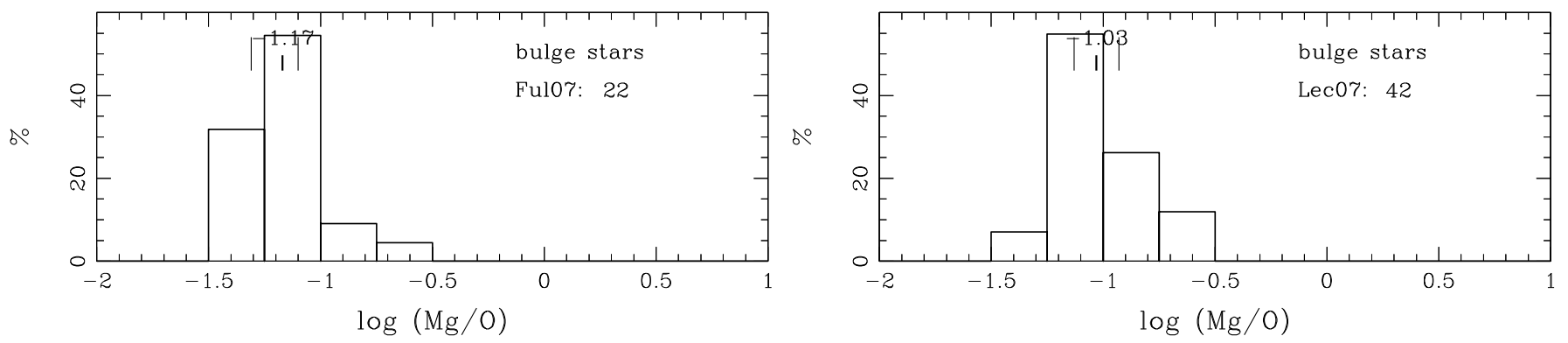

Fig. 10. The distribution of $\mathrm{Mg} / \mathrm{O}$ for the $\mathrm{F} 07$ (left panel) and L07 (right panel) bulge giant samples. The solar value from Asplund et al. (2005) is $\log (\mathrm{Mg} / \mathrm{O})=-1.13$. The final distributions for bulge giant stars (see text) can be seen in Fig. 6 .
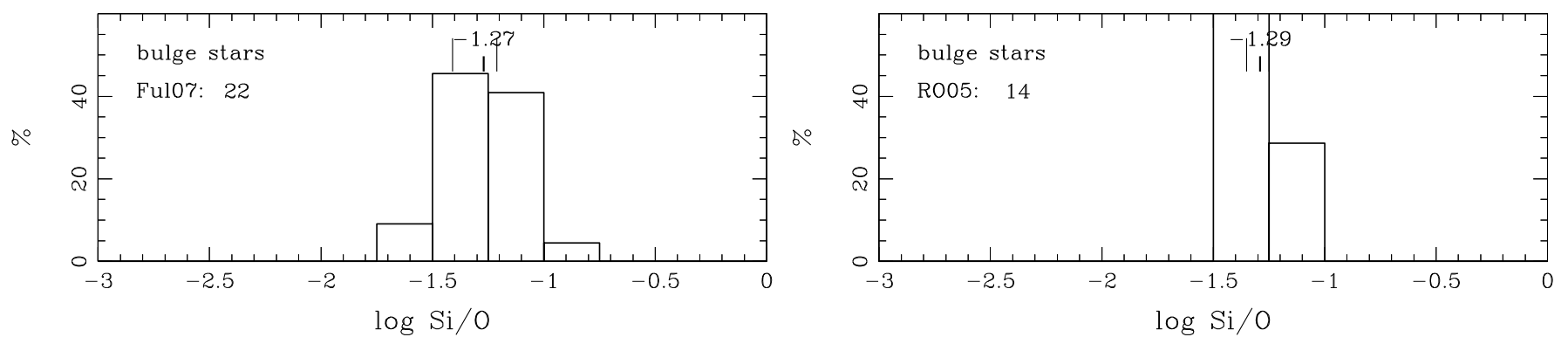

Fig. 11. The distribution of Si/O for the F07 (left panel) and Rich \& Origlia (2005) (right panel) samples. The solar value from Asplund et al. (2005) is $\log (\mathrm{Si} / \mathrm{O})=-1.15$. The final $\mathrm{S} / \mathrm{H}$ and $\mathrm{Si} / \mathrm{O}$ distributions for bulge giant stars can be seen in Figs. 5 and 6, respectively.

stars can be modified. Products of central and shell hydrogen burning are brought to the outer layers by the first and second dredge-up episodes (DUPs) taking place during the red giant branch (RGB) and early AGB phases, respectively. During the first DUP, the surface abundance of ${ }^{4} \mathrm{He}$ is increased, ${ }^{14} \mathrm{~N}$ and ${ }^{13} \mathrm{C}$ are enhanced at the expense of ${ }^{12} \mathrm{C}$, while ${ }^{16} \mathrm{O}$ remains essentially unchanged. The second DUP occurs in stars initially more massive than 3-5 $M_{\odot}$ during the early AGB phase, and modifies the stellar surface abundances by increasing ${ }^{4} \mathrm{He}$ and ${ }^{14} \mathrm{~N}$, and decreasing ${ }^{12} \mathrm{C},{ }^{13} \mathrm{C}$ and ${ }^{16} \mathrm{O}$ (an increase in ${ }^{16} \mathrm{O}$ is predicted for this phase if stars rotate and are metal-poor - see below).

Products of shell helium burning are also brought to the stellar surface during the AGB phase, after the third dredgeup episodes (3DUP) that occur in stars of masses higher than $1.5 M_{\odot}$ of solar composition, starting at lower masses for lower metallicities. The outcome is an increase in the ${ }^{12} \mathrm{C}$ surface abundance and, in stars more massive than $\simeq 3 M_{\odot}$, a small increase in the ${ }^{16} \mathrm{O}$, heavy s-elements, ${ }^{22} \mathrm{Ne},{ }^{25} \mathrm{Mg}$, and ${ }^{24} \mathrm{Mg}$ abundances. Part of the helium-burning products such as ${ }^{12} \mathrm{C}$ and ${ }^{16} \mathrm{O}$ can undergo further $H$ burning if the bottom of the convective envelope reaches sufficiently high temperatures. This leads to a decrease in ${ }^{12} \mathrm{C}$ and ${ }^{16} \mathrm{O}$ and the further production of ${ }^{14} \mathrm{~N}$ and ${ }^{13} \mathrm{C}$ (a process called hot bottom burning - $\mathrm{HBB}$ - and thought to occur only in stars of masses above $\simeq 4 M_{\odot}$ ). The 3DUP is believed to be more efficient at lower metallicities. Due to lower mass loss rates, the stellar lifetime is increased and more thermal pulses can occur, producing more $\mathrm{N}$ at the expense of $\mathrm{C}$ and, in some cases, O (e.g. van den Hoek \& Groenewegen 1997).

These processes not only depend on the stellar mass and metallicity, but also on mass loss, stellar rotation, opacity, and overshooting (see Charbonnel 2005, for a review). In particular, rotation can have an important impact on the contribution of lowand intermediate-mass stars to the production of ${ }^{16} \mathrm{O}$ and ${ }^{14} \mathrm{~N}$. During central He burning, primary ${ }^{16} \mathrm{O}$ diffuses from the core and is later carried to the surface in large quantities during the 2nd DUP. This process can be extremely efficient (especially at low metallicities and for the high mass end of intermediate-mass stars) to the point that such an enhancement cannot be erased by HBB later on during the AGB phase (in other words, these processes could affect the predictions for the $\mathrm{N}$ and $\mathrm{O}$ yields in intermediate mass stars). The quantitative estimates of this effect are still uncertain since it depends on many unconstrained 

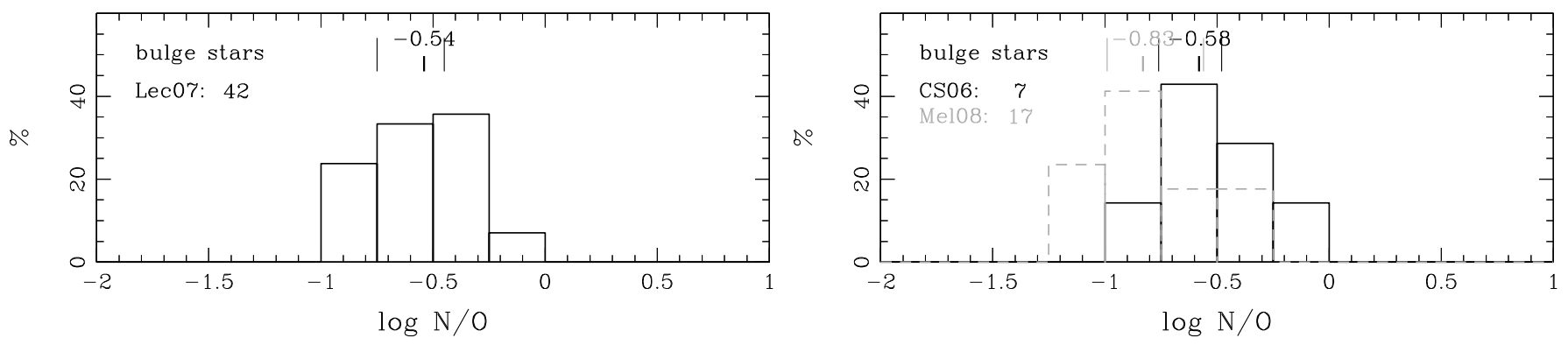

Fig. 12. The distribution of N/O ratios for the samples of L07 (left panel), Cunha \& Smith (2006) (right panel, solid histrogram) and Melendez et al. (2008) (right panel, dashed histogram). The final total N and N/O distributions for bulge giant stars can be seen in Fig. 4.

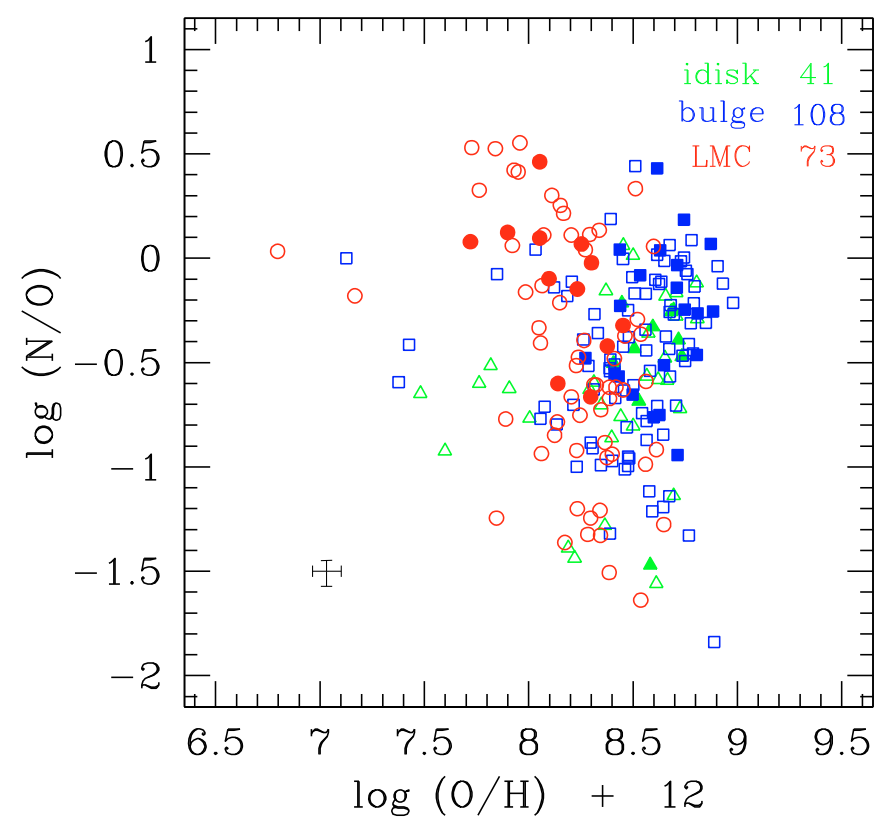

Fig. 13. Left panel: the nebular abundance ratios $\mathrm{N} / \mathrm{O}$ versus $\mathrm{O} / \mathrm{H}$ for our bulge (squares), LMC (circles) and inner-disk (triangles) PN samples. The filled symbols represent the more accurate abundances (see Sect. 2.4).

model parameters, the most important being overshooting, rotational velocity, and mass loss (which in turn affects the stellar lifetime).

Calculations by Decressin (2007) and Decressin et al. (in preparation) show that the masses of ejected oxygen and neon, for a $5 M_{\odot}$ star of initial metallicity of $Z=5 \times 10^{-4}$, increase by a factor of $\sim 2$ upon the inclusion of rotation (for a rotational velocity of $300 \mathrm{~km} \mathrm{~s}^{-1}$ ). It is interesting to note that in this case, despite the increase in $\mathrm{O}$ and $\mathrm{Ne}$ due to rotation, the PNe would have the same $\mathrm{Ne} / \mathrm{O}$ ratio as if their surface abundance had not been modified. However, for a $3 M_{\odot}$ star, the opposite result is obtained, that models with rotation predict a factor of $\sim 2$ decrease in $\mathrm{O}$ and almost no change in Ne. The differences seen between the $5 M_{\odot}$ and $3 M_{\odot}$ cases are due to the fact that the second DUP is more efficient in the former, and hence brings more helium-burning material to the surface.

The effects of both the first and second DUPs are expected to affect the surface abundances of $\mathrm{PNe}$ and giants in particular for elements produced by the $\mathrm{CN}$-cycle. Carbon deficiencies and nitrogen excesses are observed in the bulge giants (see discussion in L07). For PNe, the effects of the 3DUP should also be evident: during the AGB phase, recurrent occurrences of the 3DUP enrich the stellar surface with freshly synthesized nuclides, which are then ejected into the ISM by strong winds. For stars of masses higher than $4 M_{\odot}$, the 3DUP signatures may be modified by HBB. The 3DUP and HBB are expected to produce the most significant changes in $\mathrm{CNO}$ and He abundances. It has been common practice to assume that oxygen would reflect the composition of the ISM from which PNe formed, and that the quantities of oxygen brought to the stellar surface during the 3DUP or consumed during HBB were negligible in stars of masses lower than $4 M_{\odot}$ (e.g. Maciel \& Köppen 1994; Henry 1989). However, in the presence of stellar rotation, the surface abundance of oxygen could increase considerably and it would no longer represent the pristine value (hereinafter defined as the element abundance in the ISM when the PN progenitor formed). This effect should be stronger in low metallicity stars and could be negligible in old metal-rich populations.

In summary, the $\mathrm{C}$ and $\mathrm{N}$ abundances measured in PNe provide important information about the efficiency of the 3DUP compared to that of the HBB, as well as the impact of rotation. On the other hand, He abundance probes the cumulative effect of the 1st, 2nd, and 3rd DUPs, and the HBB. Oxygen also contains information about the efficiency of the HBB and the effects of rotation. In constrast, the abundance of $\mathrm{Ne}$ is related to the efficiency of the 3DUP and HBB (Charbonnel 2005; Marigo et al. 2003).

\section{Planetary Nebulae: disentangling mixing and chemical evolution}

We compare our results for our bulge PN sample with those for the LMC and inner-disk ones.

We expect that the LMC PN population should differ from that of the bulge for the following main reasons. The first is that, due to the almost continuous and ongoing star formation in the LMC (Cioni et al. 2006; Hill et al. 2000; Pagel \& Tautvaisiene 1998), the LMC PN progenitors should cover the full low- and intermediate-mass range (the same is expected for the innerdisk sample). This is not expected to be the case for the bulge, where star formation is believed to have stopped long ago (see Sect. 6.1) and PNe produced by the most massive AGBs will have already disappeared ${ }^{11}$.

The second reason is that, due to the lower metallicity of the LMC, its PN progenitors must have undergone more

\footnotetext{
11 However, if a fraction of low-mass stars coalesce, producing objects of higher mass, the difference between the LMC and bulge PN progenitor mass distributions could be reduced. This suggestion has been made to explain the observational fact that the bright end of the PN luminosity function (PNLF) is the same in star-forming and old systems (see Ciardullo et al. 2005, and references therein).
} 

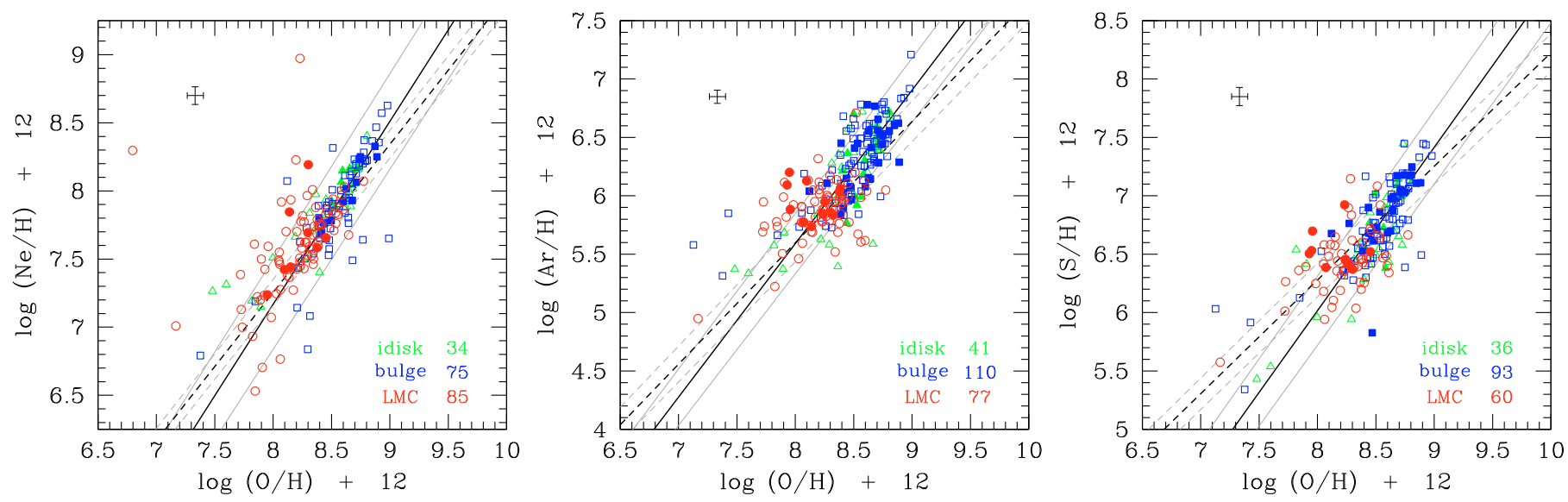

Fig. 14. The variation in Ne, Ar, and $\mathrm{S}$ with oxygen for our PN sample (bulge: blue squares; LMC: red circles; and inner-disk: green triangles). The filled symbols represent the more accurate abundance measurements. The solid line is the fit obtained by using only the bulge PNe. This is compared to the relations derived by Izotov et al. (2006 - dashed lines) for a sample of blue compact galaxies and star-forming galaxies from the SDSS survey. Grey lines show the one-sigma ranges obtained by maximizing the combined uncertainties in the fit parameters " $a$ " and " $b$ " (see Table 6).

important mixing processes than the bulge and inner-disk ones ${ }^{12}$ (see Sect. 4). In the case of the inner disk sample, we would expect the metallicity to be larger than in the solar vicinity, although by how much is still an open question (e.g. Perinotto \& Morbidelli 2006; Cescutti et al. 2007). In addition, there is a transition region between the disk and the bulge with a stellar ring, which can be described by a Gaussian centered around $3.5 \mathrm{kpc}$ from the Galactic centre with $\sigma=0.5 \mathrm{kpc}$ (Bertelli et al. 1995). If our inner-disk objects come from this region (which is probably the case), they cannot be considered as part of the thin disk and should be treated as separate entities (see Smartt et al. 2001, for a detailed discussion ${ }^{13}$ ).

In summary, the first two reasons for the LMC PN population to differ from the bulge and inner-disk ones are related to the PN progenitor's evolution and its dependency on mass and metallicity and can be expressed as follows: one expects a larger $\mathrm{N} / \mathrm{O}$ for PNe in star-forming metal-poor systems (LMC) than in old (non-star forming), metal-rich ones (bulge).

In addition to the above mentioned facts related to the PN progenitor's evolution, we also expect the pristine $\mathrm{N} / \mathrm{O}$ ratios (i.e. the N/O ratio in the ISM when the PN progenitor formed) of the different systems to differ. Indeed, the N/O ratio will increase slowly in metal poor systems (due to essentialy primary contribution from low- and intermediate-mass stars), and much faster

\footnotetext{
12 There is one caveat: our PN samples could be biased against the highest metallicity objects (especially the inner-disk and bulge samples). Indeed, at high metallicities, high mass-loss rates can prevent the star from reaching the upper AGB and the PN phases, leading to the formation of the so-called AGB manqué (e.g. O'Connel 1999, see discussion in Sect. 6.2.1).

13 The interpretation of inner-disk abundances is complicated by the fact that different chemical elements appear to provide different answers in this region. Smartt et al. (2001) found a solar oxygen abundance for $6 \mathrm{~B}$ stars located in the inner-disk, whereas $\mathrm{Mg}$ and Si were found to have abundances higher than solar and consistent with that expected according to abundance gradients measured by Rolleston et al. (2000) also from B stars. An alternative way of interpreting these results is that the stars in the inner-disk belong to the thin disk and not to the inner stellar ring, but that the yield of oxygen decreases at high metallicities (see Maeder 1992).
}

in high metallicity systems where the secondary production of $\mathrm{N}$ will be more important (e.g. Henry et al. 2000; Chiappini et al. 2003).

Finally, another reason for differences among the PNe in the different samples could exist in the case of oxygen, if the amount of this element trapped by dust is metallicity dependent. This amount is difficult to estimate and for now we will assume that it is not strongly metallicity dependent (but see discussion in Sect. 6.2 and Gutenkunst et al. 2008), and has no impact on the relative comparisons we pursue in the following paragraphs.

In what follows we attempt to estimate which are the dominant effects and check if the expectations decribed here are confirmed by the data. In this way, we propose to clarify which PN abundances can be used as chemical-evolution tracers in the Galactic bulge. We now discuss the abundance distributions and the abundance ratio plots of $\mathrm{PNe}$ in the different samples. We begin with $\mathrm{N}$ (which is clearly modified during the PN progenitor's evolution) and $\mathrm{O}$ (which can be modified in particular cases). We then discuss $\mathrm{Ne}, \mathrm{Ar}$, and $\mathrm{S}$, which are more likely to reflect the abundances in the pristine ISM.

\subsection{Nitrogen and oxygen}

In the first three rows of Fig. 4, the distributions of N/H (left), $\mathrm{O} / \mathrm{H}$ (middle), and N/O (right) are shown for our three PN samples. Focusing first on oxygen, we observe that the bulge PN $\mathrm{O} / \mathrm{H}$ distribution is shifted to higher values with respect to that of the LMC by $\sim 0.3$ dex (see Table 2).

Recent chemical evolution models suggest that the IMF in the Galactic bulge is flatter (i.e. with a larger fraction of massive stars) than in the solar vicinity (Ballero et al. 2007a). There is no evidence for a variation in the IMF along the Galactic thin disk (e.g. Chiappini et al. 2000) and hence a standard IMF (Romano et al. 2005) is expected for the inner-thin disk. Should we expect the oxygen histograms of bulge and inner-disk to differ due to a difference in their IMFs? As shown in Fig. 4, the innerdisk PN distribution is similar to that of the bulge, which is also confirmed by the statistical tests in Table 3. To understand this 
result, one should keep an important fact in mind ${ }^{14}$ : it is possible that the net result of the oppositely-acting effects of the IMF and chemical evolution history of the different systems are similar metallicity distributions. Indeed, the metallicity distribution of the bulge (Zoccali et al. 2008) and thin disk in the solar vicinity (e.g. Rocha-Pinto \& Maciel 1995) are similar despite known differences in their star formation histories, star formation efficiencies, and probably their IMFs, which can be inferred from an $[\mathrm{O} / \mathrm{Fe}]$ versus $[\mathrm{Fe} / \mathrm{H}]$ plot (see Sect. 6.1).

We now turn to our results for the N/O distributions in the different PN samples. Richer (2006) compared PNe from different galaxy types (dwarf spheroidal - old; LMC - young; dwarf irregular - young; M31 bulge - old; M31 disk - young) and emphasized that all show a similar range of nitrogen enrichment (i.e. N/O ratios). In the present work, we find the median abundance values to be similar among our three PN samples (within 0.1 dex, see Table 2), which extends Richer's result to the bulge and inner-disk PN samples. On the other hand, due to the large number of objects in each of our samples, we detect differences in the N/O distributions (see Fig. 4, right column), such as: a) the N/O distribution that we obtain for LMC PNe appear broader than in the two other cases; b) the highest values of the N/O ratio are observed in the LMC diagram, whereas the bulge and innerdisk PNe show very few objects with $\log (\mathrm{N} / \mathrm{O})>0$ (the same is found for bulge giants that will be discussed in Sect. 6.2); and c) there is marginal indication that the LMC sample distribution shows an excess of objects with low N/O ratios, with respect to the bulge sample. The inner-disk also appears to contain the same excess with respect to the bulge, but this result is even less clear due to the small number of objects.

Assuming that the above differences are real ${ }^{15}$, could we use them to disentangle the effects of stellar evolution and Galactic chemical evolution summarized at the beginning of this section?

\section{Different pristine $N / O$ ratios}

Both the LMC and inner-disk samples have experienced continuous star formation. The effects of the different primary/secondary $\mathrm{N}$ contributions should be evident because the inner-disk is more metal-rich than the LMC (as confirmed by the oxygen metallicity distribution). To estimate the pristine $\mathrm{N} / \mathrm{O}$ ratios, we can analyze the HII regions in both systems. The difference between the mean LMC value of N/O obtained from HII regions and the solar vicinity value is estimated by Russell \& Dopita (1992) to be around 0.08 dex. Assuming that there is no N/O variation across the Galactic disk from the solar vicinity to the inner regions (e.g. Chiappini 2005), this could partially explain the larger number of PNe with low N/O in the LMC with respect to those in the inner-disk or bulge (although the effect is marginal). For the bulge, we expect an important secondary nitrogen contribution from massive stars and a small contribution from low- and intermediate-mass stars (e.g. Ballero et al. 2007a), although this cannot be empirically estimated since there are no HII regions with which to compare).

\section{Different amounts of mixing in the PN progenitors}

The fact that in the LMC (and also SMC - see Leisy \& Dennefeld 2006) there is a larger fraction of $\mathrm{PNe}$ with $\log (\mathrm{N} / \mathrm{O})>0$ than in the bulge is consistent with the idea that the

\footnotetext{
${ }^{14}$ Note that our inner-disk sample probably contains PNe from both the thin and thick disk populations possibly also contributing to the similarity of both distributions (Meléndez et al. 2008).

15 Although, for the N/O distributions, the statistical tests shown in Table 3 are inconclusive.
}

stellar evolution processes that increase $\mathrm{N}$ and consume $\mathrm{O}$ are less efficient in bulge PNe. Moreover, since the pristine N/O ratios are lower in the LMC, the fact that for this system several $\mathrm{PNe}$ show $\log (\mathrm{N} / \mathrm{O})>0$ suggests a significant contribution from mixing processes during the PN progenitor's life.

This can be understood as a: a) mass effect - the bulge PNe originate in less massive progenitors (as expected if the bulge formed rapidly and is not currently forming stars) than the LMC ones; and/or b) metallicity effect - bulge PNe have a systematic higher metallicity than the LMC PNe (confirmed by their distinct oxygen distributions, discussed above). Does one of these effects dominate?

We can address this question by comparing the N/O metallicity distributions of bulge and inner-disk PNe. If the mass effect plays a dominant role, we would expect the inner-disk PNe to also show objects with $\log (\mathrm{N} / \mathrm{O})>0$, since in this case the PN progenitors should span the full mass range, due to the ongoing star formation in the inner-disk (as in the LMC). However, this is not observed. Objects with $\log (\mathrm{N} / \mathrm{O})>0$ are almost absent in the inner-disk sample. It therefore appears that metallicity plays a dominant role in the observed differences of the N/O metallicity distribution between bulge and $\mathrm{LMC} \mathrm{PNe}{ }^{16}$.

In Fig. 13, we plot $\mathrm{O} / \mathrm{H}$ versus N/O abundances for PN samples. This figure presents a consistent picture: for the LMC (red filled circles), $\log (\mathrm{N} / \mathrm{O})$ is anti-correlated with oxygen as expected if the cycle $\mathrm{O}-\mathrm{N}$ had occurred converting part of the oxygen into $\mathrm{N}$. This again indicates that in the LMC, more objects are prone to this effect, and thus in this galaxy, oxygen cannot be assumed to be a metallicity tracer that can be compared with chemical evolution predictions. On the other hand, the correlation is not present for the bulge, which suggests that, in this case, the oxygen abundance can be safely used as a chemical evolution tracer.

\subsection{Ne, S, and Ar}

While Ar and $\mathrm{S}$ are produced in massive stars during explosive burning, $\mathrm{Ne}$, like $\mathrm{O}$, is produced during quiescent burning (e.g. Limongi \& Chieffi 2008). It is thus expected that Ne should trace $\mathrm{O}$ more closely than Ar and S. On the other hand, the possibility is not excluded that $\mathrm{Ne}$, as $\mathrm{O}$, can be modified during the evolution of the more massive PN progenitors (see Sect. 4, Leisy \& Dennefeld 2006).

Figure 5 shows the distributions of $\mathrm{Ne} / \mathrm{H}, \mathrm{S} / \mathrm{H}$, and $\mathrm{Ar} / \mathrm{H}$. As in the case of oxygen, the distribution of these elements in bulge PNe are shifted to higher values that those in the LMC. This is expected since the bulge had a more rapid and effective chemical enrichment than the LMC (see Sect. 6.1). Thus, the shift in the abundance distributions of elements produced essentially by type II SNe can be understood on chemical evolution grounds.

A second point to notice in Fig. 5 is that the abundance distributions of $\mathrm{Ne} / \mathrm{H}, \mathrm{Ar} / \mathrm{H}$, and $\mathrm{S} / \mathrm{H}$ in the $\mathrm{LMC}$ are narrower than those of the bulge and inner disk samples (as confirmed by the statistical tests in Table 3). This is also expected from chemical evolution: in the bulge and inner-disk, the rapid chemical enrichment leads to a broader metallicity distribution (a proportionally

\footnotetext{
${ }_{16}$ Interestingly, this interpretation is consistent with the idea that part of the PN progenitor mass difference expected for bulge vs. LMC objects could be washed out if stellar mergers occur (especially if the fraction of binaries is higher in the bulge - Gutenkunst et al. 2008). Stellar mergers in the bulge have been invoked to explain the fact that the upper part of the PN luminosity function is the same in spiral and elliptical galaxies (Ciardullo 2005).
} 
larger number of metal-poor stars). In contrast, in the LMC, less efficient star formation and longer infall timescales produce a narrower distribution ${ }^{17}$.

Figure 6 shows the distributions of the abundances of $\mathrm{Ne}$, $\mathrm{S}$, and $\mathrm{Ar}$ with respect to the oxygen abundance. The $\mathrm{Ne} / \mathrm{O}$ distributions are narrower and more symmetric than those of $\mathrm{Ar} / \mathrm{O}$ and S/O because of: a) the smaller uncertainties involved in the $\mathrm{Ne} / \mathrm{O}$ ratios, and b) the similarity of the nucleosynthetic sites of $\mathrm{O}$ and $\mathrm{Ne}$ (see above). Within the uncertainties, we consider that for each element $\mathrm{X}=\mathrm{Ar}, \mathrm{Ne}$, and $\mathrm{S}$, the $\mathrm{X} / \mathrm{O}$ distributions of LMC, bulge, and inner-disk reach their maxima at similar values. The bulge, inner-disk, and LMC also exhibit similar median values of S/Ar (see Table 2). The mean PN values are close to the values of Izotov et al. (2006) for solar metallicities ${ }^{18}$. This indicates that the $\mathrm{PN} \mathrm{X} / \mathrm{O}$ ratios are affected by dust in a similar way as HII regions of the highest metallicities in the Izotov et al. (2006) sample and that, globally, the PN abundances of Ne, Ar, $\mathrm{S}$, and $\mathrm{O}$ are not modified significantly inside $\mathrm{PN}$ progenitors (but see below).

A constant value of each of the Ne/O, Ar/O, S/O, and S/Ar (see Fig. 7) ratios, is expected, independently of the specific chemical evolution of a galaxy or a particular IMF, if these elements: a) originated only in type II SNe; b) have stellar yields that are not strongly metallicity dependent ${ }^{19}$ and c) have not been modified during the PN progenitor evolution. As discussed above, these conditions appear to hold globally when the mean values are considered.

However, some differences are seen in the form of the distributions, indicating that some of the above conditions might not apply to all objects. In the case of the LMC, there is an excess of objects with larger $\mathrm{X} / \mathrm{O}$ ratios with respect to that observed for the bulge and inner-disk samples. We interpret this as an indication that in the more massive LMC PN progenitors, the ON cycle took place (as already indicated by our N/O results previously discussed), which increased their $\mathrm{X} / \mathrm{O}$ ratios. This effect is observed most clearly in the $\mathrm{Ne} / \mathrm{O}$ distribution since, as discussed before, $\mathrm{Ne}$ and $\mathrm{O}$ undergo similar nucleosynthetic processes.

Figure 14 shows the abundances of $\mathrm{Ne}, \mathrm{Ar}$, and $\mathrm{S}$ versus $\log (\mathrm{O} / \mathrm{H})+12$. In each panel, the dashed line shows the result obtained by Izotov et al. (2006) for a sample of blue compact galaxies, while the solid line shows the fit $^{20}$ to our bulge PN

\footnotetext{
17 Indeed, in the solar vicinity, one can solve the so-called G-dwarf problem - i.e. the fact that we observe fewer metal-poor objects than predicted by the Simple Model - by assuming that the disk formed by slow gas accretion, or infall (e.g. Chiappini et al. 1997).

18 The $\log (\mathrm{X} / \mathrm{O})(\mathrm{X}=\mathrm{Ne}, \mathrm{Ar}, \mathrm{S})$ ratios obtained by Izotov et al. (2006) at low metallicities are the most representative of the ISM value, because they are the least affected by dust depletion. Their values are close to the solar ratios of Asplund et al. (2005), with the exception of S/O. In this case, the Izotov et al. (2006) value at low metallicities is $\sim 0.18$ dex below the solar one. This implies that either the solar $\mathrm{S}$ value of Asplund and co-authors is overestimated, or that the sulphur abundances of Izotov et al. (2006) are underestimated. Most probably, the second alternative is true (the $\mathrm{S}$ photospheric abundance given in Asplund et al. (2005) is in excellent agreement with the meteoritic value).

19 In fact, although it has been suggested (Maeder 1992) that the yields of oxygen should decrease strongly with increasing metallicity, the more recent calculations found this effect to be reduced and (Meynet \& Maeder 2002) confined only to the most massive stars (but see Sect. 6.1).

${ }^{20}$ Here, we used the routine fitexy from Numerical Recipes, which performs a linear least-squares approximation in one-dimension considering errors both in $x$ and $y$. For the giant stars, we adopted an error of 0.1 dex for all data points.
}

sample (the grey lines indicate the one-sigma uncertainty levels in the fits. See also Table 6). For Ne and Ar, the PN relations agree well with those derived by Izotov et al. (2006) (to within $20 \%$ for the slope and with almost overlapping one-sigma ranges as shown in the left and middle panels of Fig. 14), especially if we consider that blue compact galaxies and bulge PNe span different metallicity intervals (while the median $\log (\mathrm{O} / \mathrm{H})+12$ is 8.6 for bulge $\mathrm{PNe}$, it is always below 8.5 for the blue compact galaxies studied by Izotov et al. 2006). These results again suggest that $\mathrm{O}$ and $\mathrm{Ar}$ in bulge $\mathrm{PNe}$ reflect the pristine ISM composition. A larger difference is seen in the case of sulphur (at least $30 \%$ in the slope and no overlapping fit ranges - see right panel of Fig. 14), similar to that reported by Henry et al. (2006). This "sulfur anomaly" is probably due to the use of inappropriate ICFs, especially in the case of PNe. For this reason, all of the following results that are based on sulphur should be taken only as indicative.

The fact that the LMC PNe follow the same O-Ne relation found for bulge $\mathrm{PNe}$, despite their pristine oxygen having been modified (as previously shown) suggests that the mixing processes occurring in the PN progenitors at low metallicities are such that $\mathrm{O}$ and $\mathrm{Ne}$ are modified by similar amounts, leaving the $\mathrm{Ne} / \mathrm{O}$ ratio essentially unchanged. However, stellar evolution models discussed in Sect. 4 suggest that this is not always the case because the mixing processes depend on several parameters (e.g. mass and metallicity). This explains why in Fig. 14 the LMC sample exhibits a larger scatter than that of the bulge. On the other hand, Ar is not expected to be modified, and hence an even larger scatter should be seen in the O-Ar diagram for LMC $\mathrm{PNe}^{21}$. This appears to be the case in Figs. 6 and 14 .

Finally, Fig. 7 shows the S/Ar distributions. It can be seen that: a) the median value of S/Ar in the LMC sample is slightly larger than that in the bulge and inner-disk samples, and b) in the case of the LMC distribution, there is a clear excess of objects with high $\mathrm{S} / \mathrm{Ar}$ ratios compared with the bulge $\mathrm{PNe}$. This can be explained as follows: in the LMC, the chemical enrichment has proceeded on a longer timescale than that of the Galactic bulge. Hence, the contribution of type Ia SNe to the S abundance in the LMC has been important, whereas this has not been the case in the bulge (as confirmed by the abundance ratios; Hill et al. 2000). We therefore expect to find objects with high S/Ar ratios in the LMC and not in the bulge (the inner-disk being an intermediate case) as in Fig. 7.

\subsection{Summary}

We summarize the main results of this section.

- The bulge and inner-disk PN distributions of $\mathrm{O}, \mathrm{Ne}, \mathrm{S}$, and Ar are systematically shifted to higher values compared with those of the LMC. This clearly indicates that both the bulge and inner-disk are more metal-rich than the LMC, a result consistent with those of other abundance tracers (e.g. stars, and HII regions).

- S and Ar can be used as chemical-evolution tracers because their abundances are not modified by the PN progenitor's evolution. An important contribution of SNIa to the ISM enrichment in the LMC is clearly seen by the excess of PNe

21 The same thing should be seen also in the O-S relation. However, here a further complication arises. Sulphur can be produced in nonnegligible amounts in type Ia SNe (Iwamoto et al. 1999). 
Table 6. Linear least-square fit between oxygen and other elements in bulge PNe, bulge giants and in the blue compact galaxies studied by Izotov et al. (2006): $y=a x+b$ (and one-sigma uncertainties).

\begin{tabular}{lllll}
\hline \hline & $a$ & $b$ & $\chi 2$ & $q$ \\
\hline Bulge PNe & & & & \\
\hline $\log (\mathrm{Ne} / \mathrm{H})$ vs. $\log (\mathrm{O} / \mathrm{H})$ & $1.34 \pm 0.02$ & $-3.58 \pm 0.17$ & 208 & $5.79 \times 10^{-15}$ \\
$\log (\mathrm{Ar} / \mathrm{H})$ vs. $\log (\mathrm{O} / \mathrm{H})$ & $1.31 \pm 0.02$ & $-4.93 \pm 0.13$ & 554 & $4.11 \times 10^{-61}$ \\
$\log (\mathrm{S} / \mathrm{H})$ vs. $\log (\mathrm{O} / \mathrm{H})$ & $1.40 \pm 0.02$ & $-5.18 \pm 0.15$ & 425 & $1.36 \times 10^{-44}$ \\
$\log (\mathrm{N} / \mathrm{H})$ vs. $\log (\mathrm{O} / \mathrm{H})$ & $2.27 \pm 0.09$ & $-11.23 \pm 0.27$ & 836 & $4.37 \times 10^{-115}$ \\
\hline Stars & & & & \\
\hline $\log (\mathrm{N} / \mathrm{H})$ vs. $\log (\mathrm{O} / \mathrm{H})$ & 1.32 & -3.49 & 34.4 & - \\
$\log (\mathrm{Si} / \mathrm{H})$ vs. $\log (\mathrm{O} / \mathrm{H})$ & 1.22 & -3.24 & 6.71 & - \\
$\log (\mathrm{Mg} / \mathrm{H})$ vs. $\log (\mathrm{O} / \mathrm{H})$ & 1.02 & -1.26 & 102. & - \\
\hline $\mathrm{H} \mathrm{II} \mathrm{Regions}(\mathrm{Izotov}$ et al. 2006) & & & & \\
\hline $\log (\mathrm{Ne} / \mathrm{H})$ vs. $\log (\mathrm{O} / \mathrm{H})$ & $1.09 \pm 0.01$ & $-1.45 \pm 0.05$ & - & - \\
$\log (\mathrm{Ar} / \mathrm{H})$ vs. $\log (\mathrm{O} / \mathrm{H})$ & $1.04 \pm 0.01$ & $-2.71 \pm 0.08$ & - & - \\
$\log (\mathrm{S} / \mathrm{H})$ vs. $\log (\mathrm{O} / \mathrm{H})$ & $0.97 \pm 0.01$ & $-1.51 \pm 0.07$ & - & - \\
\hline
\end{tabular}

with high S/Ar ratios in the LMC sample compared with that of the bulge. Although this conclusion has been reached before from stellar (giant) abundance studies (Hill et al. 2000), it is the first time that this has been shown for a sample of $\mathrm{PNe}$. The caveat here is that the $\mathrm{S}$ abundance in $\mathrm{PNe}$ are still affected by large uncertainties, as discussed before.

- The oxygen and neon abundances of bulge PNe are close to their ISM values at the time of PN progenitor formation, and hence can also be used as tracers of the bulge chemical evolution. This view is supported by: a) the narrow $\mathrm{Ne} / \mathrm{O}$ distribution of bulge PNe; b) the mean values of $\log (\mathrm{X} / \mathrm{O})$ for bulge PNe (where $X=\mathrm{Ne}, \mathrm{Ar}$, and $\mathrm{S}$ ), which are similar to that found in $\mathrm{HII}$ regions; $\mathrm{c}$ ) the $\mathrm{O}$ versus $\mathrm{Ne}$ and $\mathrm{O}$ versus Ar relations for bulge PNe, similar to those derived by Izotov et al. (2006) for HII regions; d) the lack of anti-correlation between $\log (\mathrm{N} / \mathrm{O})$ and $\log (\mathrm{O} / \mathrm{H})$ for bulge $\mathrm{PNe}$, indicating that no/negligible amounts of oxygen were converted into $\mathrm{N}$ via the ON cycle; e) the lack of objects with $\log (\mathrm{N} / \mathrm{O})>0$ among bulge PNe.

- In the LMC PNe, both oxygen and neon have been modified by the evolution of the PN progenitor (see also Leisy $\&$ Dennefeld 2006). This is shown by: a) the large number of objects with $\log (\mathrm{N} / \mathrm{O})>0$ in the case of LMC PNe; b) the clear anti-correlation between $\mathrm{N} / \mathrm{O}$ and $\mathrm{O} / \mathrm{H}$ measured for a large number of $\mathrm{LMC} \mathrm{PNe}$; c) the excess of objects with high $\log (\mathrm{X} / \mathrm{O})$ (where $\mathrm{X}=\mathrm{Ne}, \mathrm{Ar}$, and $\mathrm{S}$ ) in the LMC sample compared with that of the bulge. This last result is a clear signature of the oxygen decrease due to the ON cycle, and d) the larger scatter in the $\mathrm{O}$ versus $\mathrm{Ne}$ and $\mathrm{O}$ versus $\mathrm{Ar}$ relations.

- Mixing processes responsible for the increase in $\mathrm{N}$ inside $\mathrm{PNe}$ are confirmed to be far more effective in metal-poor $\mathrm{PNe}$ (LMC) than in more metal-rich objects (bulge and inner-disk $\mathrm{PNe}$ ). Differences in metallicity appear to be more important than differences in the mass range of $\mathrm{PNe}$ progenitors.

\section{Stars and Planetary Nebulae: do their abundances convey the same story?}

We compare the abundances of our bulge PN sample with the stellar abundances of bulge giants obtained using highresolution spectroscopy. We start by briefly summarizing the main ideas about the bulge chemical evolution arising from the consideration of stellar samples. We then compare our bulge PN abundances with those obtained from giants.

\subsection{Results from bulge stars}

A consensus exists about some of the main properties of our Galactic bulge from the analysis of the bulge colour-magnitude diagram and the abundances of both field and globular-cluster giant stars. It has been shown that the bulge formed on a short timescale and, hence, consists of an old population with a rather small age dispersion (Ortolani et al. 1995; Zoccali et al. 2003). The bulge stars exhibit a large metallicity dispersion (Minniti et al. 1995; McWilliam \& Rich 1994; Fulbright et al. 2007) with a peak around $[\mathrm{Fe} / \mathrm{H}] \sim-0.2$. Based on a larger amount of spectroscopic data, Zoccali et al. (2008) demonstrated that the bulge iron distribution peaks at solar metallicity and is slightly narrower than inferred by previous works.

From abundance-ratio studies of both bulge globular clusters and bulge field-giant stars (obtained from high-resolution spectroscopy), it became clear that massive stars were the main contributors to the bulge chemical enrichment. The ISM became enriched more rapidly in elements produced by short-lived stars (i.e. massive stars) and more slowly in those elements produced by type Ia $\mathrm{SNe}$ and low- and intermediate-mass stars. Given this fact, the ratio of two elements - such as oxygen and iron - that are returned to the ISM on different timescales can be used as a clock when comparing with a metallicity indicator such as $[\mathrm{Fe} / \mathrm{H}]$ or $[\mathrm{O} / \mathrm{H}]$. Indeed, $[\mathrm{O} / \mathrm{Fe}]$ is higher for bulgefield giants than for thin-disk stars (see for instance F07 and L07). This was clearly demonstrated by five studies: Cunha \& Smith (2006), Rich \& Origlia (2005), and Meléndez et al. (2008) used the infrared OH lines, and Zoccali et al. (2006) and F07 who used the forbidden [OI]630 nm line. In Fig. 15, these five data sets are plotted in an oxygen-to-iron diagram. The fact that all five groups are in agreement, even if two different sets of lines are used, indicates that this result is rather robust. The high $[\mathrm{O} / \mathrm{Fe}]$ ratios measured for bulge stars suggest that most formed before type Ia SNe had time to contribute to the ISM enrichment, evidence that the bulge was formed on a short timescale (Matteucci \& Brocato 1990; Ballero et al. 2007).

Meléndez et al. (2008) concluded that the overenhancements of oxygen with respect to iron abundance in the bulge and thick disk are the same, whereas L07 and F07 argue that it is 


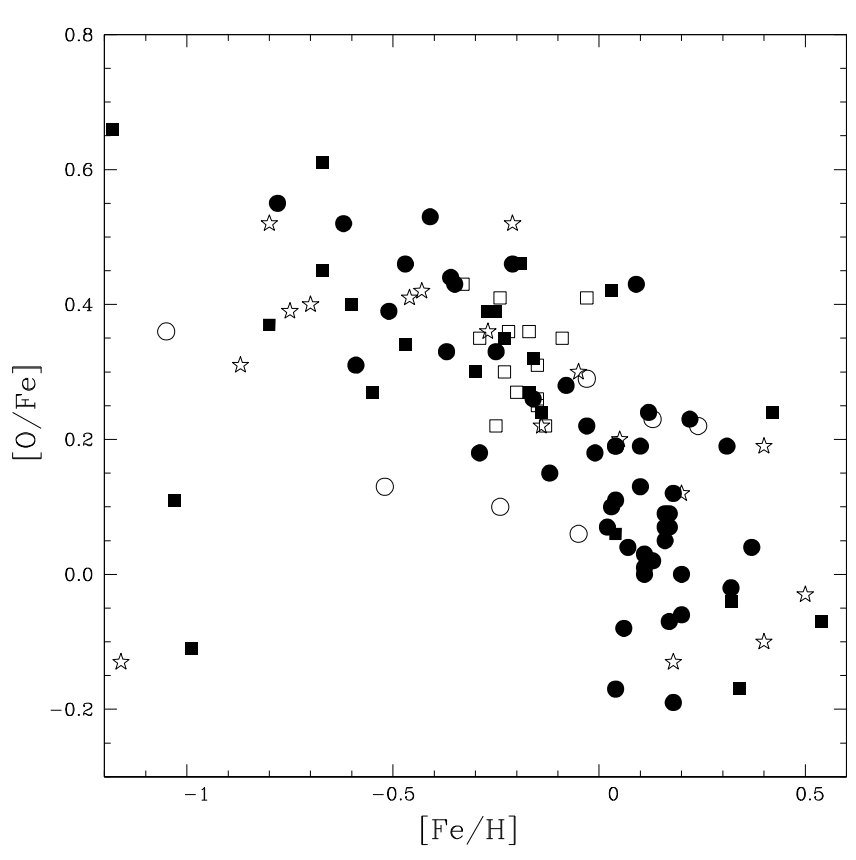

Fig. 15. $[\mathrm{O} / \mathrm{Fe}]$ vs. $[\mathrm{Fe} / \mathrm{H}]$ in red giants of the Galactic bulge from five groups, namely: Rich \& Origlia (2005 - open squares), Cunha \& Smith (2006 - open circles), Fulbright et al. (2007 - filled squares), Lecureur et al. (2007 - filled circles) and Meléndez et al. (2008 - stars).

overenhanced relative to the thick disk, as found by Bensby et al. (2004).

Abundance measurements of high accuracy are available for a range of different elements, other than oxygen and iron. The $[\alpha / \mathrm{Fe}]$ ratios versus $[\mathrm{Fe} / \mathrm{H}]$ detailed behavior depends on the particular $\alpha$ element chosen. One example is the difference between $[\mathrm{O} / \mathrm{Fe}]$ and $[\mathrm{Mg} / \mathrm{Fe}]$ ratios. $\mathrm{F} 07$ found that $[\mathrm{Mg} / \mathrm{Fe}]$ ratio declines more slowly with $[\mathrm{Fe} / \mathrm{H}]$ than $\mathrm{O}, \mathrm{Si}, \mathrm{Ca}$, and $\mathrm{Ti}$ over $\mathrm{Fe}$. This could be interpreted as being due to the oxygen yield dependency on metallicity (McWilliam et al. 2008). Some metallicity dependency of the stellar yield of oxygen cannot be excluded, especially in stars more massive than $\sim 40 M_{\odot}$ due to mass loss (see Hirschi 2007). However, as discussed before, current stellarevolution models predict this effect to be less strong than previously thought (Maeder 1992), and its impact on chemical evolution models is still unclear. L07 also measured an increase in the $\mathrm{Mg} / \mathrm{O}$ ratio with increasing metallicity, although less pronounced than reported by F07.

\subsection{Planetary Nebulae versus stars}

We compare the bulge-giant sample with our bulge PN sample. We start with a discussion of $\mathrm{O}$ and $\mathrm{N}$ for which a direct comparison between PNe and giants can be carried out, since these elements have been measured in both cases. However, whereas $\mathrm{O}$, both in PNe (Sect. 5) and giants, traces the chemical evolution of these systems, $\mathrm{N}$ is modified during the evolution of both the giant star and the PN progenitor by the processes described in Sect. 4. In the second part of this Section, we also present indirect comparisons, relating $\mathrm{S}(\mathrm{PNe})$ with $\mathrm{Si}$ (stars), and $\mathrm{Ne}(\mathrm{PNe})$ with $\mathrm{Mg}$ (stars).

\subsubsection{Direct comparison of $\mathrm{O}$ and $\mathrm{N}$}

In Fig. 4, the distributions of $\mathrm{O}, \mathrm{N}$, and $\mathrm{N} / \mathrm{O}$ for the sample of bulge giants are shown (last row) and can be compared with those found for bulge PNe (second row). There are striking differences that have to be understood.

The most important result is that for the oxygen distribution of bulge PNe and bulge giants. The bulge giant distribution is shifted to higher oxygen values by $\sim 0.3$ dex (see Table 2 ). Although both F07 and L07 agreed that some stars in the bulge have $\log (\mathrm{O} / \mathrm{H})+12>9$ (the same is also found by Meléndez et al. 2008), our measured PN oxygen abundances are all below this value. Systematic effects on the abundance determinations of both PNe and giants certainly account for part of this discrepancy.

For the present paper, we adopted PN abundances derived from collisionally excited lines. However, it is known that abundances from recombination lines are systematically higher. Could this result explain this oxygen discrepancy? This seems unlikely given that recombination line abundances do not appear to represent those of the bulk of the nebula, as described in Wang \& Liu (2007) and references therein. In some PNe, recombination lines lead to oxygen abundances that can be higher than those obtained from collisionally excited lines by a factor of 10 or more. It is difficult to imagine that such extreme values represent the true abundances in PNe.

On the other hand, stellar abundances are given relative to a reference element and the determinations are carried out differentially with respect to a reference star with well-known stellar parameters (e.g. Sun, Arcturus). However, the comparison with $\mathrm{PNe}$ requires the conversion to an absolute scale. This is not a trivial matter and involves an important uncertainty, as can be seen in Table 5 for both the Sun and Arcturus.

One must consider the possibility of two further biases in our PN sample. The first could be due to the fact that we removed some PNe from our original samples because we could not determine their abundances or considered the abundance estimates to be too uncertain. However, among the $53 \mathrm{PNe}$ with uncertain oxygen abundances (i.e. with an estimated error larger than 0.3 dex), only 6 objects have an estimated $\log \epsilon(\mathrm{O})>8.7$ (all of them have $\log \epsilon(\mathrm{O})<8.9$ ). There are 8 objects for which the temperature could not be derived. Even assuming that all of them have a $\log \epsilon(\mathrm{O})>8.9$, this is a small proportion $(6 \%)$ in comparison with the $50 \%$ of giant stars that have $\log \epsilon(\mathrm{O})>8.9$. Therefore, the bias that may be introduced in our sample of bulge $\mathrm{PNe}$ due to the fact that some objects were rejected does not explain the important discrepancy we find between the $\mathrm{O} / \mathrm{H}$ distribution of bulge $\mathrm{PNe}$ and giants.

A second possibility is that our bulge PN sample is biased against the highest metallicity objects. As pointed out in Sect. 5, at high metallicities, high mass-loss rates can prevent the stars from reaching the upper AGB and the PN phases, leading to the formation of the so-called AGB manqué (O'Connell 1999). However, in this case, one expects only the metal-rich part of the distribution to be affected. Instead, a shift in the entire PN distribution is observed towards lower metallicities. Hence, this effect does not appear to account fully for the observed discrepancy.

Apart from systematic effects and biases, are there additional reasons why oxygen abundance distributions in bulge stars and PNe differ?

One possibility is the presence of dust in PNe. If in PNe part of the oxygen is trapped by dust, the observed oxygen abundance distribution would be shifted to lower values. However, the maximum oxygen depletion into refractory material can be estimated 
using Eq. (24) of Dwek (1998) and amounts to $27 \%$ in oxygen corresponding to 0.1 dex. Therefore, dust alone cannot explain the discrepancy between the oxygen abundance distribution of PNe and giants in the bulge.

Another possibility is that the samples of PNe and giants do not trace the same population. One way to check this possibility is to monitor the behavior of nitrogen. In both cases, stellar evolution affects the nitrogen abundance ${ }^{22}$. In fact, the median $\mathrm{N} / \mathrm{O}$ values of our bulge PNe and giant samples peak at similar values, to within $0.1 \mathrm{dex}$, and are above solar (see Table 2). However, Fig. 4 shows that both the N/H and N/O bulge distributions are broader for PNe than for giants. Does this means that the two samples probe slightly different mass/metallicity ranges?

The bulge giants studied here are truly old objects (consistent with having initial masses of about $0.8 M_{\odot}$, see Zoccali et al. 2003). PNe also originate in old objects, but as they are already in the PN phase, they were either born earlier and/or had slightly more massive progenitors than the giants we observe today. If the PN progenitors had the same mass as the giants, but were born earlier, and thus more oxygen-poor, we would expect them to exhibit more $\mathrm{N}$ enrichment since the mixing processes are more efficient at lower metallicities (see Sect. 4). If instead the $\mathrm{PN}$ population originate in more massive progenitors than giants, again we would expect more $\mathrm{N}$ enrichment. Both situations could broaden the $\mathrm{N} / \mathrm{H}$ and $\mathrm{N} / \mathrm{O}$ metallicity distributions of PNe with respect to those of giant stars, and only in the first case would we expect the PNe distribution to be shifted to lower oxygen abundances than the giants. However, we expect the differences in both age and masses between PNe and bulge giants to be small (because the dominant bulge population seems to be old - see Sect. 6.1) and hence not to account for the observed 0.3 dex difference in oxygen. In addition, given the observational uncertainties and low number of giants with measured N/O abundances, the observed differences could also be due to systematics effects ${ }^{23}$ (see Sects. 2.3 and 3.2).

Therefore, there is the possibility that the two samples represent different populations, although this is unlikely to explain the oxygen discrepancy.

\subsubsection{Indirect comparisons}

We are unable to measure $\mathrm{Mg}$ and $\mathrm{Si}$ abundances using optical spectra of PNe (which would in all cases be trapped into dust grains), whereas no measurement of $\mathrm{S}$ and Ne are available

\footnotetext{
22 In the case of bulge giants, $\mathrm{L} 07$ searched for a C-N anticorrelation as a probe of internal mixing in their stars. It is well known that the $\mathrm{C}$ and $\mathrm{N}$ abundances evolve along the red giant branch. L07 concluded that within the uncertainties involved, no anti-correlation was found, but that some other mixing signatures were present for stars located above the RGB bump. The $\mathrm{C}_{2}$ and $\mathrm{CN}$ lines used in the optical are weak, whereas a more robust derivation of carbon and nitrogen abundances can be obtained from $\mathrm{OH}, \mathrm{CO}$, and $\mathrm{CN}$ lines in the near-infrared. Such data are currently under analysis for the L07 sample. Ryde et al. (2007) presented preliminary abundances of bulge giants computed from IR spectra obtained with Crires on the VLT, and found the giant stars studied to be depleted in $\mathrm{C}$ and enriched in $\mathrm{N}$, whereas the abundance of oxygen was unchanged (a typical sign of matter exposed to the $\mathrm{CN}$ cycle, which conserves the sum of $\mathrm{C}$ and $\mathrm{N}$ nuclei).

23 The $\mathrm{C}$ and $\mathrm{N}$ determinations of L07 have uncertainties of the order of 0.2 dex and their $\mathrm{N}$ abundance is strongly dependent on the derived carbon abundance, since it is determined from the strength of the $\mathrm{CN}$ molecular band. In the spectral region studied, the most prominent $\mathrm{C}_{2}$ bandhead at $563.5 \mathrm{~nm}$ is often weak, and only upper limits can be inferred for the carbon abundance. The result is that if $[\mathrm{C} / \mathrm{Fe}]$ is lower than the upper limit derived, the nitrogen abundance should be higher.
}

in bulge giant stars. However, we can still complete an indirect comparison by converting the bulge giant $\mathrm{Mg}$ and $\mathrm{Si}$ into $\mathrm{Ne}$ and $\mathrm{S}$ abundances, respectively, if we assume that $\mathrm{Mg} / \mathrm{O}$ and $\mathrm{Si} / \mathrm{O}$ ratios are solar and constant with metallicity (as assumed for $\mathrm{Ne} / \mathrm{O}$ and $\mathrm{S} / \mathrm{O}$ ratios). This assumption seems to be robust because the median values of $\mathrm{Mg} / \mathrm{O}$ and $\mathrm{Si} / \mathrm{O}$ for the bulge giant star sample are close to the solar ratios of Asplund et al. (2005) (see Figs. 6, 10 and 11$)$.

Figure 5 (bottom row) shows the distributions of $\mathrm{Ne} / \mathrm{H}$ and $\mathrm{S} / \mathrm{H}$ for bulge giants obtained after the transformation explained above (shaded histograms). The resulting distributions are shifted to higher values than those of the PNe by 0.29 dex both for $\mathrm{Ne} / \mathrm{H}$ and $\mathrm{S} / \mathrm{H}$, similar to that found for oxygen. Although for $\mathrm{S} / \mathrm{H}$ there is the possibility that this element is underestimated in PNe (according to the "sulfur anomaly" described by Henry et al. 2004), this is not expected to be the case for Ne (although see Gutenkunst et al. 2008). Confirmation that $\mathrm{S}$ in giants is systematically higher than in $\mathrm{PNe}$ will have to await measurements of $\mathrm{S}$ in stars. The $\mathrm{S}$ lines are faint and their measurement requires data of very high signal-to-noise. On the other hand, no Ne or Ar lines are present in the spectra of cool stars.

\section{Discussion and conclusions}

Zoccali et al. (2008) compared the metallicity distribution of about 400 clump and giant stars in Baade's window, with that of about 200 giants at $b=-6^{\circ}$ and $b=-12^{\circ}$. The metallicity distributions exhibited a gradient in stellar populations on the metal-rich side, such that in Baade's window there is a metalrich component at $[\mathrm{Fe} / \mathrm{H}] \sim+0.3$, which becomes less evident at $b=-6^{\circ}$. This result is based on iron abundances, and for oxygen the differences could be smaller (see below). In a preliminary kinematical study, Goméz et al. (in preparation) find a higher velocity dispersion for the metal-rich component by $\sim 20 \mathrm{~km} \mathrm{~s}^{-1}$, which could be interpreted as an indication of a different stellar population towards the inner regions.

Given that the Baade's window field seems to be more contaminated by the $[\mathrm{Fe} / \mathrm{H}] \approx+0.3$ component mentioned above than the field at $b=-6$, and given that our bulge PN sample are projected across a wider area (see Fig. 2), it is unclear in what proportion this new component is present in our PN sample. If we attempt to explain the 0.3 dex difference in oxygen (and probably in $\mathrm{Ne}$ and $\mathrm{S}$ as well) in terms of the properties of the stellar populations, we may conclude that our PN sample is essentially free of this metal-rich component. However, since $[\mathrm{O} / \mathrm{Fe}]$ decreases with $[\mathrm{Fe} / \mathrm{H}]$, the oxygen content in this metal-rich population will probably resemble that of the more metal-poor population.

To confirm that the metal-rich population in the Baade's window follows the same $[\mathrm{O} / \mathrm{Fe}]$ relation as shown in Fig. 15, it would be necessary to measure oxygen in the same stars. This would require very-high resolution $(R=40000)$ data, such as that acquired for the UVES sample of Zoccali et al. (2006) for all of the metal-rich population found by Zoccali et al. (2008) in the Baade's window.

Checking for any difference in the $V_{\text {lsr }}$ velocity dispersion of our bulge PNe with $b<4^{\circ}$ (88 objects) and $b>4^{\circ}$ (78 objects), we measured $121 \mathrm{~km} \mathrm{~s}^{-1}$ and $101 \mathrm{~km} \mathrm{~s}^{-1}$, respectively. Interestingly, the difference of $20 \mathrm{~km} \mathrm{~s}^{-1}$ is similar to that found for bulge giants in Baade's window with respect to other fields. However, for PNe this difference is not significant according to our statistical tests. 
Finally, we note that significant samples of bulge objects are now available for which the metallicity distribution can be studied (RGB stars, red clump giants - Zoccali et al. 2008 - and in $\mathrm{PNe}$ - this work). This opens the possibility of looking for additional constraints to stellar evolution models of low- and intermediate-mass stars, which would enhance our understanding of how metallicity and mass loss affect the metallicity distributions at different stellar evolution stages. It is also important to understand another discrepancy measured in the bulge: the metallicities of lensed turnoff stars (i.e. turnoff stars observed due to the amplification of their brightness by gravitational microlensing) appear to be systematically higher than giants, according to Cohen et al. (2008).

Our main conclusions are summarized below:

We have compared the properties of PNe in different systems (bulge, inner-disk, and LMC) by using the largest homogeneous sample of PN abundances presently available. We find that:

- The Galactic bulge and inner-disk PN distributions of O, Ne, $\mathrm{S}$, and Ar are shifted to higher values than those of the LMC, indicating that the bulge and inner-disk are more metal rich than the LMC (a result already known from other stellar studies).

- Oxygen and neon in bulge PNe are close to their ISM values at the time of the PN progenitor formation, and hence can also be used as tracers of the bulge chemical evolution.

- In LMC PNe, both oxygen and neon have been modified during the evolution of the PN progenitor.

- Differences in metallicity appear to play a more dominant role in the mixing processes occurring in low- and intermediate-mass stars than the differences in the mass range of $\mathrm{PN}$ progenitors.

After identifying reliably the bulge PN abundances that can be used as tracers the bulge chemical evolution (O, Ne, Ar, S), we compared these abundances with those measured in giant stars. We found that:

- The oxygen abundance distribution of bulge giant stars is shifted to higher values by 0.3 dex with respect to that of PNe.

- A similar shift appears to exist for Ne and S (after converting the $\mathrm{Mg}$ and $\mathrm{Si}$ abundances of giant stars to those of $\mathrm{Ne}$ and $\mathrm{S}$ by adopting the solar values of Asplund et al. (2005), although this method is rather uncertain).

- We discussed many reasons for the discrepancy between the abundances of PNe and giant stars, and concluded that the oxygen abundances in PNe (distributed over the entire bulge) and in giants (most of them in the Baade's window) do not convey the same evolutionary story.

After a thorough analysis, we conclude that the observed discrepancy between PN and giant star abundance distributions is probably due to systematic errors in the abundance derivations of either PNe or giant stars, or both. Our results constitute at least an important warning against a careless use of absolute abundances.

Acknowledgements. C.C. thanks CTIO and ESO staff in Chile and acknowledges partial support from Pronex-Brazil and the Swiss National Science Foundation (SNF). C.C. also thanks R. Walterbos and F. Cuisinier for interesting discussions. We also thank the referee for a careful reading of this manuscript. S.K.G. and G.S. wish to thank support by the European Associated Laboratory "Astronomy Poland-France". B.B. acknowledges support from CNPq and Fapesp.

\section{References}

Asplund, M. 2005, ARA\&A, 43, 481

Asplund, M., Grevesse, N., Sauval, A. J., Allende Prieto, C., \& Kiselman, D. 2004, A\&A, 417, 751

Asplund, M., Grevesse, N., \& Sauval, A. J. 2005, in Cosmic Abundances as Records of Stellar Evolution and Nucleosynthesis, ed. T. G. Barnes III, \& F. N. Bash, ASP Conf. Ser., 336, 25

Ballero, S. K., Matteucci, F., Origlia, L., \& Rich, R. M. 2007, A\&A, 467, 123 Bensby, T., Feltzing, S., \& Lundström, I. 2004, A\&A, 415, 155

Bertelli, G., Bressan, A., Chiosi, C., Ng, Y. K., \& Ortolani, S. 1995, A\&A, 301, 381

Cardelli, J. A., Clayton, G. C., \& Mathis, J. S. 1989, ApJ, 345, 245

Cescutti, R., Matteucci, F., François, P., \& Chiappini, C. 2007, A\&A, 462, 943

Charbonnel, C. 2005, in Planetary Nebulae as Astonomical Tools, ed. R. Szczerba, G. Stasińska, \& G. Górny, AIP Conf. Proc., 804, 117

Chiappini, C. 2005, in Planetary Nebulae as Astonomical Tools, ed. R. Szczerba, G. Stasińska, \& G. Górny, AIP Conf. Proc., 804, 257

Chiappini, C., Matteucci, F., \& Gratton, R. 1997, ApJ, 477, 765

Chiappini, C., Matteucci, F., \& Padoan, P. 2000, ApJ, 528, 711

Chiappini, C., Romano, D., \& Matteucci, F. 2003, MNRAS, 339, 63

Ciardullo, R. 2005, in Planetary Nebulae as Astonomical Tools, ed. R. Szczerba, G. Stasińska, \& G. Górny, AIP Conf. Proc., 804, 277

Cuisinier, F., Maciel, W. J., Köppen, J., et al. 2000, A\&A, 353, 543

Cunha, K., \& Smith, V. V. 2006, ApJ, 651, 491

Cioni, M. -R. L., Girardi, L., Marigo, P., \& Habing, H. J. 2006, A\&A, 448, 77

Cohen, J. G., Huang, W., Udalski, A., Gould, A., \& Johnson, J. 2008, ApJ, 682, 1029

Decressin, T. 2007, Ph.D. Thesis Abundance anomalies in globular clusters in light of models of rotating stars, Université de Genève

Dwek, E. 1998, ApJ, 501, 643

Escudero, A. V., \& Costa, R. D. D. 2001, A\&A, 380, 300

Escudero, A. V., Costa, R. D. D., \& Maciel, W. J. 2004, A\&A, 414, 211

Fitzpatrick, E. L. 1999, PASP, 111, 63

Fulbright, J., McWilliam, A., \& Rich, R. M. 2006, ApJ, 636, 821

Fulbright, J., McWilliam, A., \& Rich, R. M. 2007, ApJ, 661, 1152

Gratton, R., Sneden, C., \& Carreta, E. 2004, ARA\&A, 42, 385

Gorny, S. K., Stasińska, G., Escudero, A. V., \& Costa, R. D. D. 2004, A\&A, 427, 231

Gorny, S. K., Chiappini, C., Stasińska, G., \& Cuisinier, F. 2009, A\&A, in press

Gutenkunst, S., Bernard-Salas, J., Pottasch, S. R., Sloan, G. C., \& Houck, J. R. 2008, ApJ, 680, 1206

Henry, R. B. C. 1989, MNRAS, 241, 453

Henry, R. B. C. 2004, in Origin and Evolution of the Elements, The Carnegie Observatories Centennial Symposia, ed. A. McWilliam, \& M. Rauch (Cambridge University Press), 43

Henry, R. B. C., Edmunds, M. G., \& Koppen, J. 2000, ApJ, 541, 660

Henry, R. B. C., Kwitter, K. B., \& Balick, B. 2004, AJ, 127, 2284

Henry, R. B. C., Skinner, J. N., Kwitter, K. G., \& Milingo, J. B. 2006, in Planetary Nebulae in our Galaxy and Beyond, ed. J. B. Michael, \& H. M. Roberto (Cambridge: Cambridge University Press), IAU Symp., 234, 417

Hill, V., François, P., Spite, M., Primas, F., \& Spite, F. 2000, A\&A, 364, L19

Hirschi, R. 2007, A\&A, 461, 571

Iwamoto, K., Brachwitz, F., Nomoto, K., et al. 1999, ApJS, 125, 439

Izotov, Y. I., Stasińska, G., Meynet, G., Guseva, N. G., \& Thuan, T. X. 2006, A\&A, 448, 995

Kingsburgh, R. L., \& Barlow, M. J. 1994, MNRAS, 275, 605

Lecureur, A., Hill, V., Zoccali, M., et al. 2007, A\&A, 465, 799

Leisy, P., \& Dennefeld, M. 2006, A\&A, 456, 451

Limongi, M., \& Chieffi, A. 2008, in Stellar Nucleosynthesis: 50 years after B2FH, ed. C. Charbonnel, \& J. P. Zahn, EAS Publ. Ser., 32, 233

Liu, X.-W. 2006 in Planetary Nebulae in our Galaxy and Beyond, ed. J. B. Michel, \& H. M. Roberto (Cambridge: Cambridge University Press), IAU Symp., 234, 219

Liu, X.-W., Storey, P. J., Barlow, M. J., et al. 2000, MNRAS, 312, 585

Maeder, A. 1992, A\&A, 264, 105

Maciel, W. J., \& Köppen, J. 1994, A\&A, 282, 436

Marigo, P., Bernard-Salas, J., Pottasch, S. R., Tielens, A. G. G. M., \& Wesselius, P. R. 2003, A\&A, 409, 619

Matteucci, F., \& Brocato, E. 1990, ApJ, 365, 539

Meléndez, J., Asplund, M., Alves-Brito, A., et al. 2008, A\&A, 484, L21

McWilliam, A., \& Rich, R. M. 1994, ApJS, 91, 749

McWilliam, A., Matteucci, F., Ballero, S., et al. 2008, AJ, 136, 367

Minniti, D., Olszewski, E. W., Liebert, J., et al. 1995, MNRAS, 277, 1293

Nissen, P. E., Primas, F., Asplund, M., \& Lambert, D. L. 2002, A\&A, 390, 235

O'Connell, R. W. 1999, ARA\&A, 37, 603

Ortolani, S., Renzini, A., Gilmozzi, R., et al. 1995, Nature, 377, 701 
Pagel, B. E., \& Tautvaisiene, G. 1998, MNRAS, 299, 535

Peimbert, M., \& Peimbert, A. 2006, in Planetary Nebulae in our Galaxy and Beyond, ed. J. B. Michel, \& H. M. Roberto (Cambridge: Cambridge University Press), IAU Symp., 234, 227

Peña, M., Stasińska, G., \& Richer, M. G. 2007, A\&A, 476, 745

Perinotto, M., \& Morbidelli, L. 2006, MNRAS, 372, 45

Pottasch, S. R., \& Bernard-Salas, J. 2006, A\&A, 457, 173

Rich, R. M., \& Origlia, L. 2005, ApJ, 634, 1293

Richer, G. M. 2006, in Planetary Nebulae in our Galaxy and Beyond, ed. J. B. Michel, \& H. M. Roberto (Cambridge: Cambridge University Press), IAU Symp., 234, 119

Rolleston, W. R. J., Smartt, S. J., Dufton, P. L., \& Ryans, R. S. I. 2000, A\&A, 363,537

Romano, D., Chiappini, C., Matteucci, F., \& Tosi, M. 2005, A\&A, 430, 491

Russell, S. C., \& Dopita, M. A. 1992, ApJ, 384, 508

Ryde, N., Edvardsson, B., Gustaffson, B., \& Käufl, H.-U. 2007, in Stellar populations as building blocks of galaxies, ed. A. Vazdekis, \& R. F. Peletier (Cambridge: Cambridge University Press), IAU Symp., 241, 260
Seaton, M. J. 1979, MNRAS, 187, 73

Siess, L. 2008, in Stellar Nucleosynthesis: 50 years after B2FH, ed. C.

Charbonnel, \& J. P. Zahn, EAS Publ. Ser., 32, 131

Smartt, S. J., Venn, K. A., Dufton, P. L., et al. 2001, A\&A, 367, 86

Smith, V. V., Suntzeff, N. B., Cunha, K., et al. 2000, AJ, 119, 1239

Smith, V. V., Hinkle, K. H., Cunha, K., et al. 2002, AJ, 124, 3241

Stasińska, G. 2007, in Stellar Nucleosynthesis: 50 years after B2FH, ed. C. Charbonnel, \& J. P. Zahn, EAS Publ. Ser., in press

Stasińska, G. 2002, RMxAC, 12, 62

Stasińska, G., \& Tylenda, R. 1994, A\&A, 289, 225

Stasińska, G., Tylenda, R., Acker, A., \& Stenholm, B. 1991, A\&A, 247, 173

Stasińska, G., Richer, M. G., \& McCall, M. L. 1998, A\&A, 336, 667

van den Hoek, L. B., \& Groenewegen, M. A. T. 1997, A\&AS, 123, 305

Wang, W., \& Liu X.-W. 2007, MNRAS, 381, 669

Zoccali, M., Renzini, A., Ortolani, S., et al. 2003, A\&A, 399, 931

Zoccali, M., Lecureur, A., Barbuy, B., et al. 2006, A\&A, 457, L1

Zoccali, M., Hill, V., Lecureur, A., et al. 2008, A\&A, 486, 177 
C. Chiappini et al.: Abundance patterns in the Galactic bulge, Online Material $p 1$

Table A.1. Plasma parameters and chemical abundances (Galactic bulge sample).

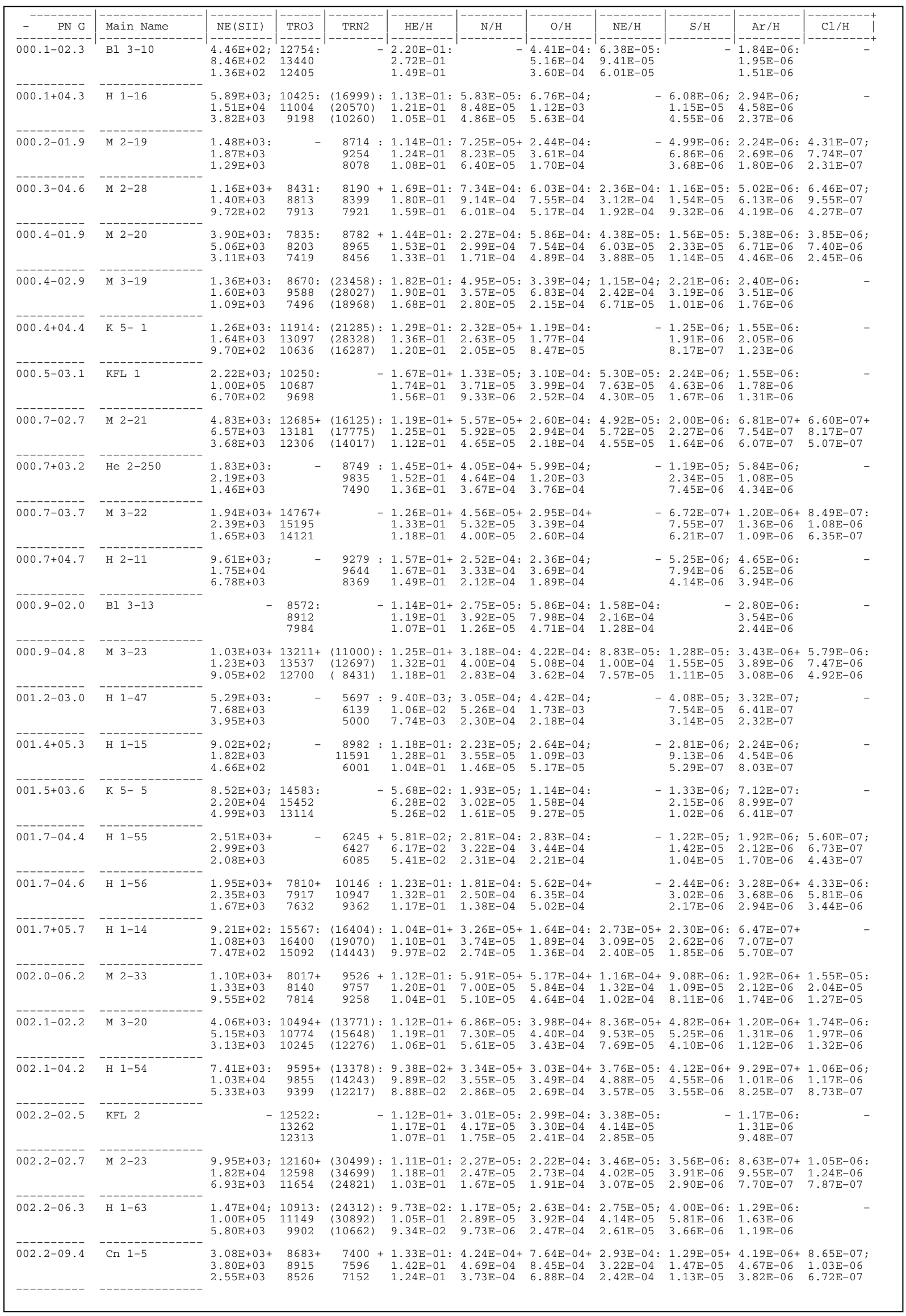


Table A.1. continued.

\begin{tabular}{|c|c|c|c|c|c|c|c|c|c|c|c|}
\hline PN G & Main Name & $\mathrm{NE}$ (SII) & TRO3 & TRN2 & $\mathrm{HE} / \mathrm{H}$ & $\mathrm{N} / \mathrm{H}$ & $0 / \mathrm{H}$ & $\mathrm{NE} / \mathrm{H}$ & $\mathrm{S} / \mathrm{H}$ & $\mathrm{Ar} / \mathrm{H}$ & $\mathrm{Cl} / \mathrm{H}$ \\
\hline $002.3+02.2$ & Te 5 & $\begin{array}{l}5.20 \mathrm{E}+02: \\
6.08 \mathrm{E}+02 \\
4.16 \mathrm{E}+02\end{array}$ & $\begin{array}{c}8703: \\
10493 \\
5924\end{array}$ & $\begin{array}{l}8628 \\
9557 \\
7057\end{array}$ & $\begin{array}{l}2.04 \mathrm{E}-01: \\
2.13 \mathrm{E}-01 \\
1.89 \mathrm{E}-01\end{array}$ & $\begin{array}{l}2.16 \mathrm{E}-04 \\
4.54 \mathrm{E}-04 \\
1.55 \mathrm{E}-04\end{array}$ & $\begin{array}{l}6.06 \mathrm{E}-04 \\
1.77 \mathrm{E}-03 \\
3.50 \mathrm{E}-04\end{array}$ & & $\begin{array}{l}7.10 \mathrm{E}-06 \\
1.95 \mathrm{E}-05 \\
4.16 \mathrm{E}-06\end{array}$ & $\begin{array}{l}4.19 \mathrm{E}-06 \\
6.60 \mathrm{E}-06 \\
2.54 \mathrm{E}-06\end{array}$ & - \\
\hline $002.3-03.4$ & H $2-37$ & $\begin{array}{l}3.00 \mathrm{E}+01+ \\
3.33 \mathrm{E}+01 \\
3.00 \mathrm{E}+01\end{array}$ & $\begin{array}{l}14086: \\
15892 \\
11344\end{array}$ & & $\begin{array}{l}1.91 \mathrm{E}-01: \\
2.06 \mathrm{E}-01 \\
1.76 \mathrm{E}-01\end{array}$ & $\begin{array}{l}1.15 \mathrm{E}-04 \\
2.07 \mathrm{E}-04 \\
8.08 \mathrm{E}-05\end{array}$ & $\begin{array}{l}1.14 \mathrm{E}-04 ; \\
2.51 \mathrm{E}-04 \\
6.73 \mathrm{E}-05\end{array}$ & $\begin{array}{l}7.14 \mathrm{E}-05: \\
8.61 \mathrm{E}-05 \\
4.16 \mathrm{E}-05\end{array}$ & $\begin{array}{l}2.44 \mathrm{E}-06 \\
4.96 \mathrm{E}-06 \\
1.71 \mathrm{E}-06\end{array}$ & $\begin{array}{l}9.16 \mathrm{E}-07 \\
1.40 \mathrm{E}-06 \\
7.74 \mathrm{E}-07\end{array}$ & - \\
\hline $002.4-03.7$ & M $1-38$ & $\begin{array}{l}5.49 \mathrm{E}+03: \\
7.60 \mathrm{E}+03 \\
4.15 \mathrm{E}+03\end{array}$ & - & $\begin{array}{l}7414 \\
7919 \\
6769\end{array}$ & $\begin{array}{l}1.32 \mathrm{E}-02 \\
1.41 \mathrm{E}-02 \\
1.22 \mathrm{E}-02\end{array}$ & $\begin{array}{l}8.91 \mathrm{E}-05: \\
1.22 \mathrm{E}-04 \\
6.68 \mathrm{E}-05\end{array}$ & $\begin{array}{l}2.58 \mathrm{E}-04 ; \\
5.00 \mathrm{E}-04 \\
1.36 \mathrm{E}-04\end{array}$ & & $\begin{array}{l}4.41 \mathrm{E}-06 \\
7.15 \mathrm{E}-06 \\
3.20 \mathrm{E}-06\end{array}$ & $\begin{array}{l}3.12 \mathrm{E}-07 \\
4.31 \mathrm{E}-07 \\
2.39 \mathrm{E}-07\end{array}$ & - \\
\hline $002.5-01.7$ & Pe $2-11$ & $\begin{array}{l}1.94 \mathrm{E}+02 \\
1.11 \mathrm{E}+03 \\
3.00 \mathrm{E}+01\end{array}$ & - & $\begin{array}{l}8889 \\
9240 \\
8230\end{array}$ & $\begin{array}{l}1.71 \mathrm{E}-01: \\
1.96 \mathrm{E}-01 \\
1.52 \mathrm{E}-01\end{array}$ & $\begin{array}{l}4.94 \mathrm{E}-04: \\
6.27 \mathrm{E}-04 \\
3.90 \mathrm{E}-04\end{array}$ & $\begin{array}{l}5.67 \mathrm{E}-04: \\
8.46 \mathrm{E}-04 \\
4.84 \mathrm{E}-04\end{array}$ & $\begin{array}{l}1.75 \mathrm{E}-04 ; \\
3.74 \mathrm{E}-04 \\
1.57 \mathrm{E}-04\end{array}$ & $\begin{array}{l}2.04 \mathrm{E}-05 \\
3.63 \mathrm{E}-05 \\
1.50 \mathrm{E}-05\end{array}$ & $\begin{array}{l}5.44 \mathrm{E}-06 \\
9.61 \mathrm{E}-06 \\
3.94 \mathrm{E}-06\end{array}$ & - \\
\hline $002.6+02.1$ & Te 1580 & $\begin{array}{l}1.06 \mathrm{E}+03: \\
1.40 \mathrm{E}+03 \\
8.92 \mathrm{E}+02\end{array}$ & - & $\begin{array}{r}9636 \\
12332 \\
6684\end{array}$ & $\begin{array}{l}1.46 \mathrm{E}-01: \\
1.76 \mathrm{E}-01 \\
1.06 \mathrm{E}-01\end{array}$ & $\begin{array}{l}\text { 5. } 51 \mathrm{E}-04 ; \\
1.29 \mathrm{E}-03 \\
1.40 \mathrm{E}-04\end{array}$ & $\begin{array}{l}4.28 \mathrm{E}-04 \\
1.18 \mathrm{E}-03 \\
1.53 \mathrm{E}-04\end{array}$ & $\begin{array}{l}9.86 \mathrm{E}-05 \\
3.60 \mathrm{E}-04 \\
2.94 \mathrm{E}-05\end{array}$ & $\begin{array}{l}1.15 \mathrm{E}-05 \\
3.13 \mathrm{E}-05 \\
2.61 \mathrm{E}-06\end{array}$ & $\begin{array}{l}3.80 \mathrm{E}-06 \\
6.73 \mathrm{E}-06 \\
1.26 \mathrm{E}-06\end{array}$ & - \\
\hline $002.6-03.4$ & M $1-37$ & $\begin{array}{l}6.17 \mathrm{E}+03:= \\
8.61 \mathrm{E}+03 \\
4.13 \mathrm{E}+03\end{array}$ & - & $\begin{array}{l}5703 \\
6111 \\
5003\end{array}$ & $\begin{array}{l}1.19 \mathrm{E}-02 \\
1.38 \mathrm{E}-02 \\
1.01 \mathrm{E}-02\end{array}$ & $\begin{array}{l}3.52 \mathrm{E}-04 ; \\
5.41 \mathrm{E}-04 \\
2.26 \mathrm{E}-04\end{array}$ & $\begin{array}{l}4.74 \mathrm{E}-04 \\
1.27 \mathrm{E}-03 \\
1.79 \mathrm{E}-04\end{array}$ & & $\begin{array}{l}3.70 \mathrm{E}-05 ; \\
6.23 \mathrm{E}-05 \\
2.29 \mathrm{E}-05\end{array}$ & $\begin{array}{l}3.20 \mathrm{E}-07 \\
6.27 \mathrm{E}-07 \\
1.52 \mathrm{E}-07\end{array}$ & - \\
\hline $002.6+04.2$ & Th $3-27$ & $\begin{array}{l}5.09 \mathrm{E}+03: \\
7.53 \mathrm{E}+03 \\
4.31 \mathrm{E}+03\end{array}$ & $\begin{array}{l}11084+ \\
11336 \\
10849\end{array}$ & $\begin{array}{l}11980 \\
12414 \\
11374\end{array}$ + & $\begin{array}{l}1.53 \mathrm{E}-01: \\
1.62 \mathrm{E}-01 \\
1.42 \mathrm{E}-01\end{array}$ & $\begin{array}{l}1.11 \mathrm{E}-03+ \\
1.29 \mathrm{E}-03 \\
9.62 \mathrm{E}-04\end{array}$ & $\begin{array}{l}4.13 \mathrm{E}-04+ \\
4.63 \mathrm{E}-04 \\
3.68 \mathrm{E}-04\end{array}$ & & $\begin{array}{l}1.45 \mathrm{E}-05 \\
1.86 \mathrm{E}-05 \\
1.15 \mathrm{E}-05\end{array}$ & $\begin{array}{l}6.02 \mathrm{E}-06+ \\
6.49 \mathrm{E}-06 \\
5.38 \mathrm{E}-06\end{array}$ & $\begin{array}{l}1.45 \mathrm{E}-06: \\
1.95 \mathrm{E}-06 \\
9.75 \mathrm{E}-07\end{array}$ \\
\hline $002.6+05.5$ & K $5-3$ & $\begin{array}{l}1.22 \mathrm{E}+03: \\
1.44 \mathrm{E}+03 \\
9.75 \mathrm{E}+02\end{array}$ & $\begin{array}{l}12814: \\
13242 \\
12168\end{array}$ & $\begin{array}{l}(11505): \\
(13835) \\
(7957)\end{array}$ & $\begin{array}{l}1.26 \mathrm{E}-01+ \\
1.31 \mathrm{E}-01 \\
1.19 \mathrm{E}-01\end{array}$ & $\begin{array}{l}5.89 \mathrm{E}-05: \\
7.43 \mathrm{E}-05 \\
4.92 \mathrm{E}-05\end{array}$ & $\begin{array}{l}1.93 \mathrm{E}-04: \\
2.35 \mathrm{E}-04 \\
1.67 \mathrm{E}-04\end{array}$ & $\begin{array}{l}5.38 \mathrm{E}-05+ \\
5.94 \mathrm{E}-05 \\
4.68 \mathrm{E}-05\end{array}$ & $\begin{array}{l}2.62 \mathrm{E}-06 \\
3.23 \mathrm{E}-06 \\
2.24 \mathrm{E}-06\end{array}$ & $\begin{array}{l}9.19 \mathrm{E}-07: \\
1.06 \mathrm{E}-06 \\
8.15 \mathrm{E}-07\end{array}$ & - \\
\hline $002.6+08.1$ & H $1-11$ & $\begin{array}{l}1.60 \mathrm{E}+03 \\
2.47 \mathrm{E}+03 \\
1.30 \mathrm{E}+03\end{array}$ & $\begin{array}{l}9264+ \\
9555 \\
9097\end{array}$ & & $\begin{array}{l}-1.09 \mathrm{E}-01: \\
1.15 \mathrm{E}-01 \\
1.00 \mathrm{E}-01\end{array}$ & $\begin{array}{l}3.42 \mathrm{E}-05+ \\
4.09 \mathrm{E}-05 \\
3.22 \mathrm{E}-05\end{array}$ & $\begin{array}{l}4.72 \mathrm{E}-04: \\
5.45 \mathrm{E}-04 \\
3.99 \mathrm{E}-04\end{array}$ & $\begin{array}{l}1.15 \mathrm{E}-04+ \\
1.29 \mathrm{E}-04 \\
1.00 \mathrm{E}-04\end{array}$ & $\begin{array}{l}5.11 \mathrm{E}-06+ \\
5.89 \mathrm{E}-06 \\
4.40 \mathrm{E}-06\end{array}$ & $\begin{array}{l}2.15 \mathrm{E}-06+ \\
2.32 \mathrm{E}-06 \\
1.90 \mathrm{E}-06\end{array}$ & - \\
\hline $002.7-04.8$ & M $1-42$ & $\begin{array}{l}9.16 \mathrm{E}+02+ \\
1.08 \mathrm{E}+03 \\
7.81 \mathrm{E}+02\end{array}$ & - & $\begin{array}{l}9209 \\
9747 \\
8829\end{array}$ & $\begin{array}{l}1.66 \mathrm{E}-01: \\
1.78 \mathrm{E}-01 \\
1.57 \mathrm{E}-01\end{array}$ & $\begin{array}{l}2.55 \mathrm{E}-04+ \\
2.82 \mathrm{E}-04 \\
2.31 \mathrm{E}-04\end{array}$ & $\begin{array}{l}3.13 \mathrm{E}-04: \\
4.26 \mathrm{E}-04 \\
2.63 \mathrm{E}-04\end{array}$ & - & $\begin{array}{l}5.85 \mathrm{E}-06: \\
7.66 \mathrm{E}-06 \\
4.49 \mathrm{E}-06\end{array}$ & $\begin{array}{l}3.09 \mathrm{E}-06: \\
3.81 \mathrm{E}-06 \\
2.69 \mathrm{E}-06\end{array}$ & $\begin{array}{l}5.10 \mathrm{E}-07 \\
8.31 \mathrm{E}-07 \\
2.68 \mathrm{E}-07\end{array}$ \\
\hline $002.8+01.8$ & $\mathrm{Te} 1567$ & $\begin{array}{l}5.27 \mathrm{E}+02: \\
6.09 \mathrm{E}+02 \\
4.18 \mathrm{E}+02\end{array}$ & - & $\begin{array}{r}9610 \\
10368 \\
8592\end{array}$ & $\begin{array}{l}1.50 \mathrm{E}-01: \\
1.61 \mathrm{E}-01 \\
1.36 \mathrm{E}-01\end{array}$ & $\begin{array}{l}2.88 \mathrm{E}-04+ \\
3.36 \mathrm{E}-04 \\
2.57 \mathrm{E}-04\end{array}$ & $\begin{array}{l}6.37 \mathrm{E}-04 \\
1.08 \mathrm{E}-03 \\
4.63 \mathrm{E}-04\end{array}$ & - & $\begin{array}{l}1.85 \mathrm{E}-05 \\
2.95 \mathrm{E}-05 \\
1.29 \mathrm{E}-05\end{array}$ & $\begin{array}{l}4.07 \mathrm{E}-06: \\
5.33 \mathrm{E}-06 \\
3.40 \mathrm{E}-06\end{array}$ & - \\
\hline $002.8-02.2$ & Pe $2-12$ & $\begin{array}{l}1.10 \mathrm{E}+03 \\
1.00 \mathrm{E}+05 \\
4.07 \mathrm{E}+02\end{array}$ & - & $\begin{array}{l}6897 \\
7072 \\
4401\end{array}$ & $\begin{array}{l}7.24 \mathrm{E}-02 \\
7.94 \mathrm{E}-02 \\
6.58 \mathrm{E}-02\end{array}$ & $\begin{array}{l}1.97 \mathrm{E}-04 \\
2.57 \mathrm{E}-03 \\
1.76 \mathrm{E}-04\end{array}$ & $\begin{array}{l}2.76 \mathrm{E}-04 \\
1.23 \mathrm{E}-02 \\
2.31 \mathrm{E}-04\end{array}$ & & $\begin{array}{l}1.36 \mathrm{E}-05 \\
6.46 \mathrm{E}-04 \\
1.09 \mathrm{E}-05\end{array}$ & $\begin{array}{l}1.33 \mathrm{E}-06 \\
5.89 \mathrm{E}-06 \\
1.12 \mathrm{E}-06\end{array}$ & - \\
\hline $002.9-03.9$ & H $2-39$ & $\begin{array}{l}2.38 \mathrm{E}+03+ \\
2.90 \mathrm{E}+03 \\
1.96 \mathrm{E}+03\end{array}$ & $\begin{array}{l}13197+ \\
13727 \\
12763\end{array}$ & $\begin{array}{l}(14648): \\
(18711) \\
(10222)\end{array}$ & $\begin{array}{l}1.05 \mathrm{E}-01: \\
1.12 \mathrm{E}-01 \\
1.01 \mathrm{E}-01\end{array}$ & $\begin{array}{l}7.98 \mathrm{E}-05: \\
8.85 \mathrm{E}-05 \\
6.33 \mathrm{E}-05\end{array}$ & $\begin{array}{l}2.58 \mathrm{E}-04+ \\
2.97 \mathrm{E}-04 \\
2.21 \mathrm{E}-04\end{array}$ & $\begin{array}{l}5.36 \mathrm{E}-05: \\
6.72 \mathrm{E}-05 \\
5.09 \mathrm{E}-05\end{array}$ & $\begin{array}{l}2.53 \mathrm{E}-06: \\
3.04 \mathrm{E}-06 \\
1.76 \mathrm{E}-06\end{array}$ & $\begin{array}{l}1.07 \mathrm{E}-06+ \\
1.19 \mathrm{E}-06 \\
9.52 \mathrm{E}-07\end{array}$ & $\begin{array}{l}1.80 \mathrm{E}-06: \\
2.16 \mathrm{E}-06 \\
1.06 \mathrm{E}-06\end{array}$ \\
\hline $003.0-02.6$ & KFL 4 & & $\begin{array}{l}\text { 11383: } \\
11961 \\
10118\end{array}$ & & $\begin{array}{l}1.59 \mathrm{E}-01: \\
1.72 \mathrm{E}-01 \\
1.44 \mathrm{E}-01\end{array}$ & & $\begin{array}{l}3.20 \mathrm{E}-04: \\
4.66 \mathrm{E}-04 \\
2.48 \mathrm{E}-04\end{array}$ & $\begin{array}{l}8.03 \mathrm{E}-05 \\
1.02 \mathrm{E}-04 \\
5.01 \mathrm{E}-05\end{array}$ & - & - & - \\
\hline $003.2-04.4$ & KFL 12 & $\begin{array}{l}1.00 \mathrm{E}+05+ \\
1.00 \mathrm{E}+05 \\
1.00 \mathrm{E}+05\end{array}$ & $\begin{array}{l}8453+ \\
8681 \\
8242\end{array}$ & & $\begin{array}{l}1.01 \mathrm{E}-01: \\
1.08 \mathrm{E}-01 \\
9.48 \mathrm{E}-02\end{array}$ & $\begin{array}{l}1.12 \mathrm{E}-05: \\
1.47 \mathrm{E}-05 \\
9.51 \mathrm{E}-06\end{array}$ & $\begin{array}{l}7.74 \mathrm{E}-04+ \\
9.06 \mathrm{E}-04 \\
6.64 \mathrm{E}-04\end{array}$ & $\begin{array}{l}1.78 \mathrm{E}-04+ \\
1.94 \mathrm{E}-04 \\
1.53 \mathrm{E}-04\end{array}$ & $\begin{array}{l}3.11 \mathrm{E}-06: \\
3.82 \mathrm{E}-06 \\
2.71 \mathrm{E}-06\end{array}$ & $\begin{array}{l}1.94 \mathrm{E}-06+ \\
2.16 \mathrm{E}-06 \\
1.73 \mathrm{E}-06\end{array}$ & - \\
\hline $003.3-04.6$ & Ap $1-12$ & $\begin{array}{l}3.95 \mathrm{E}+03: \\
4.78 \mathrm{E}+03 \\
2.90 \mathrm{E}+03\end{array}$ & - & $\begin{array}{l}6074 \\
6456 \\
5681\end{array}$ & $\begin{array}{l}5.92 \mathrm{E}-03 \\
6.94 \mathrm{E}-03 \\
4.39 \mathrm{E}-03\end{array}$ & $\begin{array}{l}1.95 \mathrm{E}-04: \\
2.46 \mathrm{E}-04 \\
1.41 \mathrm{E}-04\end{array}$ & $\begin{array}{l}1.50 \mathrm{E}-04 \\
2.38 \mathrm{E}-04 \\
8.22 \mathrm{E}-05\end{array}$ & & $\begin{array}{l}2.15 \mathrm{E}-05 \\
2.87 \mathrm{E}-05 \\
1.57 \mathrm{E}-05\end{array}$ & - & - \\
\hline $003.3-07.5$ & KFL 19 & $\begin{array}{l}3.00 \mathrm{E}+01+ \\
3.00 \mathrm{E}+01 \\
3.00 \mathrm{E}+01\end{array}$ & $\begin{array}{l}10596+ \\
10995 \\
10108\end{array}$ & & $\begin{array}{l}9.04 \mathrm{E}-02: \\
9.72 \mathrm{E}-02 \\
8.51 \mathrm{E}-02\end{array}$ & $\begin{array}{l}1.17 \mathrm{E}-05: \\
1.53 \mathrm{E}-05 \\
9.80 \mathrm{E}-06\end{array}$ & $\begin{array}{l}2.45 E-04: \\
3.03 E-04 \\
2.07 E-04\end{array}$ & $\begin{array}{l}7.78 \mathrm{E}-05: \\
9.13 \mathrm{E}-05 \\
6.79 \mathrm{E}-05\end{array}$ & $\begin{array}{l}3.62 \mathrm{E}-06: \\
5.22 \mathrm{E}-06 \\
2.72 \mathrm{E}-06\end{array}$ & $\begin{array}{l}7.86 \mathrm{E}-07+ \\
8.92 \mathrm{E}-07 \\
6.94 \mathrm{E}-07\end{array}$ & $\begin{array}{l}1.43 \mathrm{E}-05 \\
2.22 \mathrm{E}-05 \\
9.69 \mathrm{E}-06\end{array}$ \\
\hline $003.5-02.4$ & IC 4673 & $\begin{array}{l}1.02 \mathrm{E}+03+ \\
1.16 \mathrm{E}+03 \\
8.48 \mathrm{E}+02\end{array}$ & $\begin{array}{l}11089+ \\
11538 \\
10802\end{array}$ & $\begin{array}{l}(11622): \\
(12537) \\
(10270)\end{array}$ & $\begin{array}{l}8.69 \mathrm{E}-02+ \\
9.18 \mathrm{E}-02 \\
8.24 \mathrm{E}-02\end{array}$ & $\begin{array}{l}1.69 \mathrm{E}-04+ \\
1.97 \mathrm{E}-04 \\
1.47 \mathrm{E}-04\end{array}$ & $\begin{array}{l}2.99 \mathrm{E}-04: \\
3.42 \mathrm{E}-04 \\
2.49 \mathrm{E}-04\end{array}$ & $\begin{array}{l}6.80 \mathrm{E}-05+ \\
7.57 \mathrm{E}-05 \\
6.03 \mathrm{E}-05\end{array}$ & $\begin{array}{l}9.64 \mathrm{E}-06+ \\
1.08 \mathrm{E}-05 \\
8.06 \mathrm{E}-06\end{array}$ & $\begin{array}{l}3.76 \mathrm{E}-06+ \\
4.02 \mathrm{E}-06 \\
3.32 \mathrm{E}-06\end{array}$ & $\begin{array}{l}3.41 \mathrm{E}-06: \\
4.19 \mathrm{E}-06 \\
2.48 \mathrm{E}-06\end{array}$ \\
\hline $003.5-04.6$ & NGC 6565 & $\begin{array}{l}1.29 \mathrm{E}+03: \\
1.61 \mathrm{E}+03 \\
1.08 \mathrm{E}+03\end{array}$ & $\begin{array}{l}10351+ \\
10562 \\
10090\end{array}$ & $\begin{array}{l}10473 \\
10862 \\
10122\end{array}$ & $\begin{array}{l}1.17 \mathrm{E}-01: \\
1.24 \mathrm{E}-01 \\
1.09 \mathrm{E}-01\end{array}$ & $\begin{array}{l}3.17 \mathrm{E}-04+ \\
3.70 \mathrm{E}-04 \\
2.73 \mathrm{E}-04\end{array}$ & $\begin{array}{l}5.60 \mathrm{E}-04+ \\
6.33 \mathrm{E}-04 \\
5.05 \mathrm{E}-04\end{array}$ & $\begin{array}{l}1.78 \mathrm{E}-04+ \\
2.06 \mathrm{E}-04 \\
1.58 \mathrm{E}-04\end{array}$ & $\begin{array}{l}1.08 \mathrm{E}-05+ \\
1.23 \mathrm{E}-05 \\
9.47 \mathrm{E}-06\end{array}$ & $\begin{array}{l}2.77 \mathrm{E}-06+ \\
3.07 \mathrm{E}-06 \\
2.50 \mathrm{E}-06\end{array}$ & $\begin{array}{l}5.05 \mathrm{E}-07 \\
6.22 \mathrm{E}-07 \\
3.98 \mathrm{E}-07\end{array}$ \\
\hline $003.6-02.3$ & M $2-26$ & $\begin{array}{l}5.42 \mathrm{E}+02+ \\
6.46 \mathrm{E}+02 \\
4.64 \mathrm{E}+02\end{array}$ & $\begin{array}{l}9023: \\
9590 \\
8430\end{array}$ & $\begin{array}{l}8565+ \\
8809 \\
8365\end{array}$ & $\begin{array}{l}1.77 \mathrm{E}-01: \\
1.86 \mathrm{E}-01 \\
1.65 \mathrm{E}-01\end{array}$ & $\begin{array}{l}4.28 \mathrm{E}-04: \\
5.28 \mathrm{E}-04 \\
3.08 \mathrm{E}-04\end{array}$ & $\begin{array}{l}4.13 \mathrm{E}-04= \\
5.22 \mathrm{E}-04 \\
3.33 \mathrm{E}-04\end{array}$ & $\begin{array}{l}1.30 \mathrm{E}-04: \\
1.75 \mathrm{E}-04 \\
1.12 \mathrm{E}-04\end{array}$ & $\begin{array}{l}6.37 \mathrm{E}-06: \\
8.64 \mathrm{E}-06 \\
3.93 \mathrm{E}-06\end{array}$ & $\begin{array}{l}3.30 \mathrm{E}-06: \\
3.95 \mathrm{E}-06 \\
2.80 \mathrm{E}-06\end{array}$ & $\begin{array}{l}6.20 \mathrm{E}-07 \\
9.85 \mathrm{E}-07 \\
3.42 \mathrm{E}-07\end{array}$ \\
\hline $003.6+03.1$ & M $2-14$ & $\begin{array}{l}9.38 \mathrm{E}+03 \\
1.55 \mathrm{E}+04 \\
5.77 \mathrm{E}+03\end{array}$ & $\begin{array}{l}7983: \\
8357 \\
7331\end{array}$ & $\begin{array}{l}8184 \\
8555 \\
7549\end{array}$ & $\begin{array}{l}1.48 \mathrm{E}-01+ \\
1.57 \mathrm{E}-01 \\
1.38 \mathrm{E}-01\end{array}$ & $\begin{array}{l}2.45 \mathrm{E}-04: \\
3.35 \mathrm{E}-04 \\
2.18 \mathrm{E}-04\end{array}$ & $\begin{array}{l}3.64 \mathrm{E}-04: \\
5.19 \mathrm{E}-04 \\
3.11 \mathrm{E}-04\end{array}$ & $\begin{array}{l}6.04 \mathrm{E}-05 \\
9.18 \mathrm{E}-05 \\
4.33 \mathrm{E}-05\end{array}$ & $\begin{array}{l}9.83 \mathrm{E}-06 \\
1.70 \mathrm{E}-05 \\
7.79 \mathrm{E}-06\end{array}$ & $\begin{array}{l}6.06 \mathrm{E}-06: \\
7.76 \mathrm{E}-06 \\
5.21 \mathrm{E}-06\end{array}$ & $\begin{array}{l}1.46 \mathrm{E}-06 \\
2.66 \mathrm{E}-06 \\
8.99 \mathrm{E}-07\end{array}$ \\
\hline $003.6+04.9$ & K $5-6$ & $\begin{array}{l}9.33 \mathrm{E}+02 \\
3.45 \mathrm{E}+03 \\
2.51 \mathrm{E}+02\end{array}$ & $\begin{array}{l}\text { 15248: } \\
17317 \\
12811\end{array}$ & & $\begin{array}{l}1.07 \mathrm{E}-01: \\
1.23 \mathrm{E}-01 \\
9.37 \mathrm{E}-02\end{array}$ & $\begin{array}{l}4.32 \mathrm{E}-05 \\
1.32 \mathrm{E}-04 \\
2.90 \mathrm{E}-05\end{array}$ & $\begin{array}{l}2.62 \mathrm{E}-04 ; \\
4.89 \mathrm{E}-04 \\
1.70 \mathrm{E}-04\end{array}$ & - & $\begin{array}{l}2.79 \mathrm{E}-06 \\
6.98 \mathrm{E}-06 \\
1.14 \mathrm{E}-06\end{array}$ & $\begin{array}{l}5.40 \mathrm{E}-07: \\
7.44 \mathrm{E}-07 \\
4.05 \mathrm{E}-07\end{array}$ & - \\
\hline $003.7-04.6$ & M $2-30$ & $\begin{array}{l}3.10 \mathrm{E}+03+ \\
3.70 \mathrm{E}+03 \\
2.52 \mathrm{E}+03\end{array}$ & $\begin{array}{l}11042+ \\
11245 \\
10650\end{array}$ & $\begin{array}{l}12860 \\
13403 \\
12362\end{array}+$ & $\begin{array}{l}1.21 \mathrm{E}-01+ \\
1.25 \mathrm{E}-01 \\
1.13 \mathrm{E}-01\end{array}$ & $\begin{array}{l}1.37 \mathrm{E}-04: \\
1.64 \mathrm{E}-04 \\
1.10 \mathrm{E}-04\end{array}$ & $\begin{array}{l}4.46 \mathrm{E}-04+ \\
5.25 \mathrm{E}-04 \\
3.99 \mathrm{E}-04\end{array}$ & $\begin{array}{l}8.94 \mathrm{E}-05: \\
1.05 \mathrm{E}-04 \\
8.45 \mathrm{E}-05\end{array}$ & $\begin{array}{l}8.78 \mathrm{E}-06: \\
1.06 \mathrm{E}-05 \\
7.42 \mathrm{E}-06\end{array}$ & $\begin{array}{l}2.59 \mathrm{E}-06+ \\
2.88 \mathrm{E}-06 \\
2.37 \mathrm{E}-06\end{array}$ & $\begin{array}{l}1.07 \mathrm{E}-05: \\
1.48 \mathrm{E}-05 \\
8.26 \mathrm{E}-06\end{array}$ \\
\hline $003.8-04.3$ & H $1-59$ & $\begin{array}{l}1.73 \mathrm{E}+03+ \\
2.02 \mathrm{E}+03 \\
1.43 \mathrm{E}+03\end{array}$ & $\begin{array}{l}11161+ \\
11407 \\
10742\end{array}$ & $\begin{array}{l}10360 \\
10726 \\
10027\end{array}+$ & $\begin{array}{l}1.45 \mathrm{E}-01+ \\
1.53 \mathrm{E}-01 \\
1.36 \mathrm{E}-01\end{array}$ & $\begin{array}{l}3.33 \mathrm{E}-04: \\
4.14 \mathrm{E}-04 \\
2.67 \mathrm{E}-04\end{array}$ & $\begin{array}{l}4.32 \mathrm{E}-04: \\
5.16 \mathrm{E}-04 \\
3.80 \mathrm{E}-04\end{array}$ & $\begin{array}{l}8.54 \mathrm{E}-05: \\
1.05 \mathrm{E}-04 \\
8.49 \mathrm{E}-05\end{array}$ & $\begin{array}{l}1.03 \mathrm{E}-05: \\
1.28 \mathrm{E}-05 \\
8.74 \mathrm{E}-06\end{array}$ & $\begin{array}{l}4.15 \mathrm{E}-06+ \\
4.69 \mathrm{E}-06 \\
3.86 \mathrm{E}-06\end{array}$ & $\begin{array}{l}2.23 \mathrm{E}-06: \\
3.06 \mathrm{E}-06 \\
1.70 \mathrm{E}-06\end{array}$ \\
\hline $003.8-04.5$ & H $2-41$ & $\begin{array}{l}4.87 \mathrm{E}+02: \\
6.24 \mathrm{E}+02 \\
4.10 \mathrm{E}+02\end{array}$ & $\begin{array}{c}10384: \\
11033 \\
9579\end{array}$ & $\begin{array}{l}(21181): \\
(24762): \\
(17555)\end{array}$ & $\begin{array}{l}2.12 \mathrm{E}-01+ \\
2.25 \mathrm{E}-01 \\
1.98 \mathrm{E}-01\end{array}$ & $\begin{array}{l}2.50 \mathrm{E}-05+ \\
2.84 \mathrm{E}-05 \\
2.23 \mathrm{E}-05\end{array}$ & $\begin{array}{l}2.03 \mathrm{E}-04: \\
2.78 \mathrm{E}-04 \\
1.60 \mathrm{E}-04\end{array}$ & & $\begin{array}{l}1.90 \mathrm{E}-06: \\
2.83 \mathrm{E}-06 \\
1.46 \mathrm{E}-06\end{array}$ & $\begin{array}{l}1.38 \mathrm{E}-06: \\
1.83 \mathrm{E}-06 \\
1.20 \mathrm{E}-06\end{array}$ & - \\
\hline $003.9-02.3$ & M $1-35$ & $\begin{array}{l}2.79 \mathrm{E}+03: \\
3.34 \mathrm{E}+03 \\
2.21 \mathrm{E}+03\end{array}$ & $\begin{array}{l}\text { 7387: } \\
77966 \\
7006\end{array}$ & $\begin{array}{l}8953 \\
9212 \\
8670\end{array}+$ & $\begin{array}{l}1.46 \mathrm{E}-01+ \\
1.55 \mathrm{E}-01 \\
1.38 \mathrm{E}-01\end{array}$ & $\begin{array}{l}5.84 \mathrm{E}-04: \\
8.19 \mathrm{E}-04 \\
4.90 \mathrm{E}-04\end{array}$ & $\begin{array}{l}9.56 \mathrm{E}-04: \\
1.19 \mathrm{E}-03 \\
7.56 \mathrm{E}-04\end{array}$ & $\begin{array}{l}4.24 \mathrm{E}-04: \\
4.87 \mathrm{E}-04 \\
2.77 \mathrm{E}-04\end{array}$ & $\begin{array}{l}2.20 \mathrm{E}-05: \\
3.27 \mathrm{E}-05 \\
1.60 \mathrm{E}-05\end{array}$ & $\begin{array}{l}8.26 \mathrm{E}-06: \\
9.49 \mathrm{E}-06 \\
7.10 \mathrm{E}-06\end{array}$ & $\begin{array}{l}4.42 \mathrm{E}-06 ; \\
7.89 \mathrm{E}-06 \\
2.57 \mathrm{E}-06\end{array}$ \\
\hline $003.9+02.6$ & K $5-14$ & $\begin{array}{l}7.46 \mathrm{E}+03: \\
1.02 \mathrm{E}+04 \\
5.51 \mathrm{E}+03\end{array}$ & $\begin{array}{l}16763: \\
17872 \\
15889\end{array}$ & $\begin{array}{l}13343 \\
14339 \\
12377\end{array}$ & $\begin{array}{l}1.08 \mathrm{E}-01: \\
1.15 \mathrm{E}-01 \\
1.01 \mathrm{E}-01\end{array}$ & $\begin{array}{l}1.11 \mathrm{E}-04: \\
1.34 \mathrm{E}-04 \\
8.98 \mathrm{E}-05\end{array}$ & $\begin{array}{l}2.07 \mathrm{E}-04: \\
2.41 \mathrm{E}-04 \\
1.75 \mathrm{E}-04\end{array}$ & $\begin{array}{l}1.21 \mathrm{E}-05: \\
1.47 \mathrm{E}-05 \\
1.01 \mathrm{E}-05\end{array}$ & $\begin{array}{l}2.76 \mathrm{E}-06: \\
3.28 \mathrm{E}-06 \\
2.30 \mathrm{E}-06\end{array}$ & $\begin{array}{l}1.66 \mathrm{E}-06:= \\
1.82 \mathrm{E}-06 \\
1.45 \mathrm{E}-06\end{array}$ & - \\
\hline
\end{tabular}


Table A.1. continued.

\begin{tabular}{|c|c|c|c|c|c|c|c|c|c|c|c|}
\hline PN G & Main Name & $\mathrm{NE}$ (SII) & TRO3 & TRN2 & $\mathrm{HE} / \mathrm{H}$ & $\mathrm{N} / \mathrm{H}$ & $\mathrm{O} / \mathrm{H}$ & $\mathrm{NE} / \mathrm{H}$ & $\mathrm{S} / \mathrm{H}$ & $\mathrm{Ar} / \mathrm{H}$ & $\mathrm{Cl} / \mathrm{H}$ \\
\hline $003.9-03.1$ & KFL 7 & & $\begin{array}{l}13347: \\
16086 \\
10748\end{array}$ & & $\begin{array}{l}8.70 \mathrm{E}-02: \\
9.11 \mathrm{E}-02 \\
8.02 \mathrm{E}-02\end{array}$ & & $\begin{array}{l}1.41 \mathrm{E}-04 \\
2.38 \mathrm{E}-04 \\
8.48 \mathrm{E}-05\end{array}$ & $\begin{array}{l}2.11 \mathrm{E}-05 \\
3.57 \mathrm{E}-05 \\
1.17 \mathrm{E}-05\end{array}$ & & $\begin{array}{l}1.22 \mathrm{E}-06 \\
1.94 \mathrm{E}-06 \\
6.64 \mathrm{E}-07\end{array}$ & \\
\hline $004.0-05.8$ & Pe $1-12$ & $\begin{array}{l}5.60 \mathrm{E}+03 \\
1.00 \mathrm{E}+05 \\
1.25 \mathrm{E}+03\end{array}$ & $\begin{array}{l}14180: \\
14742 \\
12445\end{array}$ & & $\begin{array}{l}-1.21 \mathrm{E}-01: \\
\text { 1.31E-01: } \\
1.14 \mathrm{E}-01\end{array}$ & $\begin{array}{l}3.25 \mathrm{E}-05 \\
1.39 \mathrm{E}-04 \\
1.76 \mathrm{E}-05\end{array}$ & $\begin{array}{l}2.15 \mathrm{E}-04 ; \\
3.44 \mathrm{E}-04 \\
1.75 \mathrm{E}-04\end{array}$ & $\begin{array}{l}5.34 \mathrm{E}-05 ; \\
8.47 \mathrm{E}-05 \\
4.70 \mathrm{E}-05\end{array}$ & $\begin{array}{l}1.66 \mathrm{E}-06 \\
2.17 \mathrm{E}-05 \\
7.99 \mathrm{E}-07\end{array}$ & $\begin{array}{l}8.74 \mathrm{E}-07: \\
1.10 \mathrm{E}-06 \\
7.98 \mathrm{E}-07\end{array}$ & - \\
\hline $004.1-03.8$ & $\mathrm{KFL} 11$ & $\begin{array}{l}9.42 \mathrm{E}+02 \\
8.85 \mathrm{E}+03 \\
2.86 \mathrm{E}+02\end{array}$ & $\begin{array}{l}10929+ \\
11286 \\
10517\end{array}$ & $\begin{array}{l}13580 \\
14286 \\
12271\end{array}$ & $\begin{array}{l}1.09 \mathrm{E}-01: \\
1.16 \mathrm{E}-01 \\
9.66 \mathrm{E}-02\end{array}$ & $\begin{array}{l}8.07 \mathrm{E}-05:= \\
9.63 \mathrm{E}-05 \\
6.16 \mathrm{E}-05\end{array}$ & $\begin{array}{l}2.46 \mathrm{E}-04: \\
3.01 \mathrm{E}-04 \\
2.08 \mathrm{E}-04\end{array}$ & $\begin{array}{l}5.57 \mathrm{E}-05: \\
6.89 \mathrm{E}-05 \\
5.06 \mathrm{E}-05\end{array}$ & $\begin{array}{l}2.52 \mathrm{E}-06 \\
5.55 \mathrm{E}-06 \\
2.07 \mathrm{E}-06\end{array}$ & $\begin{array}{l}1.27 \mathrm{E}-06: \\
1.48 \mathrm{E}-06 \\
1.10 \mathrm{E}-06\end{array}$ & $\begin{array}{l}9.75 \mathrm{E}-07: \\
1.35 \mathrm{E}-06 \\
8.04 \mathrm{E}-07\end{array}$ \\
\hline $004.2+02.0$ & K $5-17$ & $\begin{array}{l}9.36 \mathrm{E}+03 \\
1.00 \mathrm{E}+05 \\
2.53 \mathrm{E}+03\end{array}$ & $\begin{array}{l}\text { 17391: } \\
20017 \\
13000\end{array}$ & & $\begin{array}{c}-7.24 \mathrm{E}-02: \\
9.19 \mathrm{E}-02 \\
6.02 \mathrm{E}-02\end{array}$ & $\begin{array}{l}5.51 \mathrm{E}-05 \\
1.74 \mathrm{E}-04 \\
3.35 \mathrm{E}-05\end{array}$ & $\begin{array}{l}1.01 \mathrm{E}-04 ; \\
2.25 \mathrm{E}-04 \\
7.58 \mathrm{E}-05\end{array}$ & & $\begin{array}{l}1.27 \mathrm{E}-06 \\
4.31 \mathrm{E}-06 \\
8.45 \mathrm{E}-07\end{array}$ & $\begin{array}{l}5.41 \mathrm{E}-07 \\
9.16 \mathrm{E}-07 \\
4.27 \mathrm{E}-07\end{array}$ & - \\
\hline $004.2-03.2$ & KFL 10 & $\begin{array}{l}1.19 \mathrm{E}+03+ \\
1.45 \mathrm{E}+03 \\
1.01 \mathrm{E}+03\end{array}$ & $\begin{array}{c}9681+ \\
10017 \\
9461\end{array}$ & $\begin{array}{l}(24839): \\
(26748): \\
(22744)\end{array}$ & $\begin{aligned}: & 1.74 \mathrm{E}-01+ \\
& 1.83 \mathrm{E}-01 \\
& 1.63 \mathrm{E}-01\end{aligned}$ & $\begin{array}{l}3.36 \mathrm{E}-05: \\
2.74 \mathrm{E}-05 \\
2.19 \mathrm{E}-05\end{array}$ & $\begin{aligned}= & 3.00 \mathrm{E}-04: \\
& 3.66 \mathrm{E}-04 \\
& 2.66 \mathrm{E}-04\end{aligned}$ & $\begin{array}{l}8.29 \mathrm{E}-05: \\
1.01 \mathrm{E}-04 \\
7.68 \mathrm{E}-05\end{array}$ & $\begin{array}{l}2.94 \mathrm{E}-06: \\
3.06 \mathrm{E}-06 \\
2.34 \mathrm{E}-06\end{array}$ & $\begin{array}{l}1.89 \mathrm{E}-06+ \\
2.06 \mathrm{E}-06 \\
1.71 \mathrm{E}-06\end{array}$ & $\begin{array}{l}1.66 \mathrm{E}-06+ \\
1.75 \mathrm{E}-06 \\
1.30 \mathrm{E}-06\end{array}$ \\
\hline $004.2-04.3$ & H $1-60$ & $\begin{array}{l}2.46 \mathrm{E}+03 \\
6.20 \mathrm{E}+03 \\
1.30 \mathrm{E}+03\end{array}$ & $\begin{array}{c}9876+ \\
10011 \\
9513\end{array}$ & & $\begin{aligned}-1.17 \mathrm{E}-01+ \\
1.24 \mathrm{E}-01 \\
1.10 \mathrm{E}-01\end{aligned}$ & $\begin{array}{l}2.89 \mathrm{E}-05: \\
4.05 \mathrm{E}-05 \\
2.19 \mathrm{E}-05\end{array}$ & $\begin{aligned}: & 3.78 \mathrm{E}-04: \\
& 4.71 \mathrm{E}-04 \\
& 3.45 \mathrm{E}-04\end{aligned}$ & & $\begin{array}{l}3.16 \mathrm{E}-06: \\
4.07 \mathrm{E}-06 \\
2.39 \mathrm{E}-06\end{array}$ & $\begin{array}{l}1.36 \mathrm{E}-06: \\
1.58 \mathrm{E}-06 \\
1.21 \mathrm{E}-06\end{array}$ & - \\
\hline $004.8+02.0$ & H $2-25$ & $\begin{array}{l}3.92 \mathrm{E}+02: \\
5.06 \mathrm{E}+02 \\
2.67 \mathrm{E}+02\end{array}$ & - & $\begin{array}{r}8829 \\
10750 \\
6461\end{array}$ & $\begin{aligned}: & 8.46 \mathrm{E}-02 \\
& 8.99 \mathrm{E}-02 \\
& 7.64 \mathrm{E}-02\end{aligned}$ & $\begin{array}{l}2.88 \mathrm{E}-05 \\
4.98 \mathrm{E}-05 \\
1.65 \mathrm{E}-05\end{array}$ & $\begin{array}{l}2.14 \mathrm{E}-04 \\
7.40 \mathrm{E}-04 \\
5.73 \mathrm{E}-05\end{array}$ & & $\begin{array}{l}4.27 \mathrm{E}-06 \\
1.18 \mathrm{E}-05 \\
1.40 \mathrm{E}-06\end{array}$ & $\begin{array}{l}1.21 \mathrm{E}-06 \\
2.08 \mathrm{E}-06 \\
6.55 \mathrm{E}-07\end{array}$ & - \\
\hline $004.8-05.0$ & м $3-26$ & $\begin{array}{l}1.03 \mathrm{E}+03+ \\
1.25 \mathrm{E}+03 \\
9.06 \mathrm{E}+02\end{array}$ & $\begin{array}{c}9818+ \\
10197 \\
9697\end{array}$ & $\begin{array}{l}(26251): \\
(28483): \\
(24251)\end{array}$ & $\begin{aligned}: & 1.73 \mathrm{E}-01+ \\
& 1.84 \mathrm{E}-01 \\
& 1.64 \mathrm{E}-01\end{aligned}$ & $\begin{array}{l}2.82 \mathrm{E}-05: \\
2.43 \mathrm{E}-05 \\
1.95 \mathrm{E}-05\end{array}$ & $\begin{array}{l}2.89 \mathrm{E}-04+ \\
3.31 \mathrm{E}-04 \\
2.49 \mathrm{E}-04\end{array}$ & $\begin{array}{l}7.83 \mathrm{E}-05: \\
9.52 \mathrm{E}-05 \\
7.02 \mathrm{E}-05\end{array}$ & $\begin{array}{l}2.62 \mathrm{E}-06: \\
2.97 \mathrm{E}-06 \\
1.84 \mathrm{E}-06\end{array}$ & $\begin{array}{l}1.82 \mathrm{E}-06: \\
1.95 \mathrm{E}-06 \\
1.58 \mathrm{E}-06\end{array}$ & $\begin{array}{l}1.50 \mathrm{E}-06: \\
1.70 \mathrm{E}-06 \\
9.53 \mathrm{E}-07\end{array}$ \\
\hline $004.9+04.9$ & M $1-25$ & $\begin{array}{l}4.85 \mathrm{E}+03: \\
6.50 \mathrm{E}+03 \\
3.63 \mathrm{E}+03\end{array}$ & $\begin{array}{l}8058+ \\
8267 \\
7903\end{array}$ & $\begin{array}{l}8672+ \\
8873 \\
8342\end{array}$ & $\begin{aligned}+ & 1.47 \mathrm{E}-01: \\
& 1.55 \mathrm{E}-01 \\
& 1.35 \mathrm{E}-01\end{aligned}$ & $\begin{array}{l}2.85 \mathrm{E}-04: \\
3.11 \mathrm{E}-04 \\
2.27 \mathrm{E}-04\end{array}$ & $\begin{array}{l}4.79 \mathrm{E}-04+ \\
5.49 \mathrm{E}-04 \\
4.35 \mathrm{E}-04\end{array}$ & $\begin{array}{l}3.09 \mathrm{E}-05: \\
4.08 \mathrm{E}-05 \\
2.89 \mathrm{E}-05\end{array}$ & $\begin{array}{l}1.49 \mathrm{E}-05+ \\
1.73 \mathrm{E}-05 \\
1.29 \mathrm{E}-05\end{array}$ & $\begin{array}{l}5.86 \mathrm{E}-06+ \\
6.36 \mathrm{E}-06 \\
5.16 \mathrm{E}-06\end{array}$ & $\begin{array}{l}2.34 \mathrm{E}-06 \\
2.87 \mathrm{E}-06 \\
1.55 \mathrm{E}-06\end{array}$ \\
\hline $005.0+03.0$ & Pe $1-9$ & $\begin{array}{l}4.73 \mathrm{E}+02 \\
2.79 \mathrm{E}+03 \\
4.55 \mathrm{E}+01\end{array}$ & - & $\begin{array}{c}11084 \\
11841 \\
9512\end{array}$ & 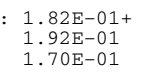 & $\begin{array}{l}1.76 \mathrm{E}-05 \\
2.81 \mathrm{E}-05 \\
1.64 \mathrm{E}-05\end{array}$ & $\begin{array}{l}8.21 \mathrm{E}-05 \\
1.31 \mathrm{E}-04 \\
5.76 \mathrm{E}-05\end{array}$ & $\begin{array}{l}\text { 2.11E-05; } \\
4.10 \mathrm{E}-05 \\
1.57 \mathrm{E}-05\end{array}$ & $\begin{array}{l}1.30 \mathrm{E}-06 \\
2.47 \mathrm{E}-06 \\
9.68 \mathrm{E}-07\end{array}$ & $\begin{array}{l}6.91 \mathrm{E}-07: \\
9.90 \mathrm{E}-07 \\
5.60 \mathrm{E}-07\end{array}$ & - \\
\hline $005.0+04.4$ & H $1-27$ & $\begin{array}{l}1.51 \mathrm{E}+04 \\
9.56 \mathrm{E}+04 \\
8.26 \mathrm{E}+03\end{array}$ & $\begin{array}{l}7604: \\
8506 \\
6424\end{array}$ & $\begin{array}{r}9449 \\
10443 \\
6087\end{array}$ & $\begin{array}{l}=1.62 \mathrm{E}-01: \\
1.71 \mathrm{E}-01 \\
1.51 \mathrm{E}-01\end{array}$ & $\begin{array}{l}7.44 \mathrm{E}-04 \\
1.15 \mathrm{E}-03 \\
3.97 \mathrm{E}-04\end{array}$ & $\begin{array}{l}7.60 \mathrm{E}-04 \\
2.04 \mathrm{E}-03 \\
4.62 \mathrm{E}-04\end{array}$ & & $\begin{array}{l}2.51 \mathrm{E}-05 \\
5.56 \mathrm{E}-05 \\
1.20 \mathrm{E}-05\end{array}$ & $\begin{array}{l}6.83 \mathrm{E}-06 \\
1.17 \mathrm{E}-05 \\
4.71 \mathrm{E}-06\end{array}$ & $\begin{array}{l}7.57 \mathrm{E}-06 ; \\
2.40 \mathrm{E}-05 \\
1.33 \mathrm{E}-06\end{array}$ \\
\hline $005.1+02.0$ & K $5-19$ & $\begin{array}{l}1.13 \mathrm{E}+03: \\
1.42 \mathrm{E}+03 \\
8.32 \mathrm{E}+02\end{array}$ & $\begin{array}{l}21118: \\
23821 \\
19175\end{array}$ & $\begin{array}{l}(16887): \\
(25153): \\
(8746)\end{array}$ & $\begin{aligned}: & 1.49 \mathrm{E}-01: \\
& 1.59 \mathrm{E}-01 \\
& 1.36 \mathrm{E}-01\end{aligned}$ & $\begin{array}{l}1.19 \mathrm{E}-04: \\
1.42 \mathrm{E}-04 \\
9.62 \mathrm{E}-05\end{array}$ & $\begin{array}{l}1.08 \mathrm{E}-04: \\
1.35 \mathrm{E}-04 \\
8.51 \mathrm{E}-05\end{array}$ & & $\begin{array}{l}3.36 \mathrm{E}-06+ \\
3.93 \mathrm{E}-06 \\
2.90 \mathrm{E}-06\end{array}$ & $\begin{array}{l}5.42 \mathrm{E}-07: \\
6.50 \mathrm{E}-07 \\
4.32 \mathrm{E}-07\end{array}$ & - \\
\hline $005.5-02.5$ & M $3-24$ & $\begin{array}{l}1.18 \mathrm{E}+03+ \\
1.45 \mathrm{E}+03 \\
9.69 \mathrm{E}+02\end{array}$ & - & $\begin{array}{r}9793 \\
10118 \\
9515\end{array}$ & $\begin{aligned}+ & 1.65 \mathrm{E}-01+ \\
& 1.71 \mathrm{E}-01 \\
& 1.56 \mathrm{E}-01\end{aligned}$ & $\begin{array}{l}2.18 \mathrm{E}-04+ \\
2.48 \mathrm{E}-04 \\
2.00 \mathrm{E}-04\end{array}$ & $\begin{array}{l}3.22 \mathrm{E}-04+ \\
3.55 \mathrm{E}-04 \\
2.80 \mathrm{E}-04\end{array}$ & $\begin{array}{l}1.02 \mathrm{E}-04: \\
1.18 \mathrm{E}-04 \\
8.09 \mathrm{E}-05\end{array}$ & $\begin{array}{l}5.33 \mathrm{E}-06+ \\
5.94 \mathrm{E}-06 \\
4.69 \mathrm{E}-06\end{array}$ & $\begin{array}{l}2.56 \mathrm{E}-06+ \\
2.86 \mathrm{E}-06 \\
2.26 \mathrm{E}-06\end{array}$ & $\begin{array}{l}1.10 \mathrm{E}-06+ \\
1.24 \mathrm{E}-06 \\
9.57 \mathrm{E}-07\end{array}$ \\
\hline $005.5+02.7$ & H $1-34$ & $\begin{array}{l}2.54 \mathrm{E}+03: \\
2.93 \mathrm{E}+03 \\
2.04 \mathrm{E}+03\end{array}$ & $\begin{array}{r}9309: \\
11139 \\
6182\end{array}$ & $\begin{array}{l}7501 \\
7800 \\
7194\end{array}$ & $\begin{aligned}+ & 1.40 \mathrm{E}-02 \\
& 1.50 \mathrm{E}-02 \\
& 1.31 \mathrm{E}-02\end{aligned}$ & $\begin{array}{l}9.57 \mathrm{E}-05 \\
1.51 \mathrm{E}-04 \\
7.03 \mathrm{E}-05\end{array}$ & $\begin{array}{l}3.03 \mathrm{E}-04 \\
4.64 \mathrm{E}-04 \\
2.22 \mathrm{E}-04\end{array}$ & - & $\begin{array}{l}8.89 \mathrm{E}-06 \\
2.63 \mathrm{E}-05 \\
4.22 \mathrm{E}-06\end{array}$ & $\begin{array}{l}7.07 \mathrm{E}-07 \\
1.32 \mathrm{E}-06 \\
4.46 \mathrm{E}-07\end{array}$ & - \\
\hline $005.6-04.7$ & KFL 16 & $\begin{array}{l}8.68 \mathrm{E}+02 \\
8.79 \mathrm{E}+03 \\
2.77 \mathrm{E}+02\end{array}$ & $\begin{array}{l}12471: \\
12857 \\
11500\end{array}$ & $\begin{array}{l}8685+ \\
8982 \\
8227\end{array}$ & $\begin{aligned}+ & 1.54 \mathrm{E}-01: \\
& 1.60 \mathrm{E}-01 \\
& 1.42 \mathrm{E}-01\end{aligned}$ & $\begin{array}{l}4.97 \mathrm{E}-05 \\
8.25 \mathrm{E}-05 \\
4.74 \mathrm{E}-05\end{array}$ & $\begin{array}{l}3.67 \mathrm{E}-04: \\
4.81 \mathrm{E}-04 \\
3.20 \mathrm{E}-04\end{array}$ & $\begin{array}{l}7.76 \mathrm{E}-05: \\
9.13 \mathrm{E}-05 \\
4.83 \mathrm{E}-05\end{array}$ & $\begin{array}{l}3.75 \mathrm{E}-06 \\
8.38 \mathrm{E}-06 \\
3.49 \mathrm{E}-06\end{array}$ & $\begin{array}{l}3.12 \mathrm{E}-06: \\
3.64 \mathrm{E}-06 \\
2.70 \mathrm{E}-06\end{array}$ & - \\
\hline $005.7-03.6$ & KFL 13 & $\begin{array}{l}1.62 \mathrm{E}+02: \\
2.13 \mathrm{E}+02 \\
1.11 \mathrm{E}+02\end{array}$ & $\begin{array}{l}8232: \\
8861 \\
7106\end{array}$ & $\begin{array}{l}8423 \\
8949 \\
7869\end{array}$ & $\begin{aligned}: & 1.69 \mathrm{E}-01: \\
& 1.79 \mathrm{E}-01 \\
& 1.57 \mathrm{E}-01\end{aligned}$ & $\begin{array}{l}1.75 \mathrm{E}-04 \\
3.32 \mathrm{E}-04 \\
1.36 \mathrm{E}-04\end{array}$ & $\begin{array}{l}4.87 \mathrm{E}-04 \\
9.11 \mathrm{E}-04 \\
3.76 \mathrm{E}-04\end{array}$ & & $\begin{array}{l}7.70 \mathrm{E}-06 \\
1.82 \mathrm{E}-05 \\
5.30 \mathrm{E}-06\end{array}$ & $\begin{array}{l}2.91 \mathrm{E}-06 \\
4.65 \mathrm{E}-06 \\
2.35 \mathrm{E}-06\end{array}$ & $\begin{array}{l}3.65 \mathrm{E}-07 ; \\
1.60 \mathrm{E}-06 \\
1.84 \mathrm{E}-07\end{array}$ \\
\hline $005.7-05.3$ & M $2-38$ & $\begin{array}{l}7.27 \mathrm{E}+02: \\
9.24 \mathrm{E}+02 \\
5.89 \mathrm{E}+02\end{array}$ & $\begin{array}{l}11889+ \\
12334 \\
11508\end{array}$ & $\begin{array}{l}(17252): \\
(22103): \\
(12489)\end{array}$ & $\begin{aligned}: & 1.56 \mathrm{E}-01: \\
& 1.63 \mathrm{E}-01 \\
& 1.44 \mathrm{E}-01\end{aligned}$ & $\begin{array}{l}6.98 \mathrm{E}-05+ \\
7.89 \mathrm{E}-05 \\
6.12 \mathrm{E}-05\end{array}$ & $\begin{array}{l}3.15 \mathrm{E}-04+ \\
3.69 \mathrm{E}-04 \\
2.74 \mathrm{E}-04\end{array}$ & $\begin{array}{l}6.05 \mathrm{E}-05+ \\
6.88 \mathrm{E}-05 \\
5.25 \mathrm{E}-05\end{array}$ & $\begin{array}{l}1.03 \mathrm{E}-05: \\
1.13 \mathrm{E}-05 \\
8.32 \mathrm{E}-06\end{array}$ & $\begin{array}{l}4.56 \mathrm{E}-06: \\
5.07 \mathrm{E}-06 \\
3.94 \mathrm{E}-06\end{array}$ & - \\
\hline $005.8-06.1$ & NGC 6620 & $\begin{array}{l}1.79 \mathrm{E}+03: \\
2.31 \mathrm{E}+03 \\
1.50 \mathrm{E}+03\end{array}$ & $\begin{array}{l}9664+ \\
9851 \\
9401\end{array}$ & $\begin{array}{l}9217+ \\
9456 \\
8870\end{array}$ & $\begin{aligned}+ & 1.30 \mathrm{E}-01+ \\
& 1.36 \mathrm{E}-01 \\
& 1.23 \mathrm{E}-01\end{aligned}$ & $\begin{array}{l}3.47 \mathrm{E}-04: \\
4.48 \mathrm{E}-04 \\
3.16 \mathrm{E}-04\end{array}$ & $\begin{array}{l}7.06 \mathrm{E}-04+ \\
7.95 \mathrm{E}-04 \\
6.55 \mathrm{E}-04\end{array}$ & $\begin{array}{l}2.33 \mathrm{E}-04: \\
2.46 \mathrm{E}-04 \\
1.87 \mathrm{E}-04\end{array}$ & $\begin{array}{l}1.28 \mathrm{E}-05+ \\
1.53 \mathrm{E}-05 \\
1.16 \mathrm{E}-05\end{array}$ & $\begin{array}{l}4.00 \mathrm{E}-06+ \\
4.33 \mathrm{E}-06 \\
3.62 \mathrm{E}-06\end{array}$ & $\begin{array}{l}9.79 \mathrm{E}-07 \\
1.30 \mathrm{E}-06 \\
7.92 \mathrm{E}-07\end{array}$ \\
\hline $005.9-02.6$ & MaC $1-10$ & $\begin{array}{l}1.88 \mathrm{E}+03+ \\
2.20 \mathrm{E}+03 \\
1.58 \mathrm{E}+03\end{array}$ & $\begin{array}{l}25874: \\
28926 \\
22922\end{array}$ & & $\begin{array}{c}-6.75 \mathrm{E}-02: \\
7.63 \mathrm{E}-02 \\
5.88 \mathrm{E}-02\end{array}$ & $\begin{array}{l}1.35 \mathrm{E}-05: \\
1.65 \mathrm{E}-05 \\
1.14 \mathrm{E}-05\end{array}$ & $\begin{array}{l}1.34 \mathrm{E}-05: \\
1.86 \mathrm{E}-05 \\
1.01 \mathrm{E}-05\end{array}$ & & $\begin{array}{l}1.08 \mathrm{E}-06: \\
1.45 \mathrm{E}-06 \\
8.25 \mathrm{E}-07\end{array}$ & $\begin{array}{l}3.80 \mathrm{E}-07: \\
4.71 \mathrm{E}-07 \\
3.02 \mathrm{E}-07\end{array}$ & - \\
\hline $006.0+02.8$ & Th $4-3$ & $\begin{array}{l}6.78 \mathrm{E}+03 \\
1.00 \mathrm{E}+05 \\
1.24 \mathrm{E}+03\end{array}$ & - & $\begin{array}{l}8679 \\
9478 \\
5212\end{array}$ & $\begin{aligned} &= 1.09 \mathrm{E}-02 \\
& 1.20 \mathrm{E}-02 \\
& \\
& 1.01 \mathrm{E}-02\end{aligned}$ & $\begin{array}{l}5.27 \mathrm{E}-05 \\
8.18 \mathrm{E}-04 \\
3.41 \mathrm{E}-05\end{array}$ & $\begin{array}{l}2.32 \mathrm{E}-04 \\
2.19 \mathrm{E}-02 \\
1.55 \mathrm{E}-04\end{array}$ & & $\begin{array}{l}8.77 \mathrm{E}-06 \\
4.28 \mathrm{E}-04 \\
3.84 \mathrm{E}-06\end{array}$ & $\begin{array}{l}2.53 \mathrm{E}-07 \\
1.32 \mathrm{E}-06 \\
1.78 \mathrm{E}-07\end{array}$ & - \\
\hline $006.0+03.1$ & M $1-28$ & $\begin{array}{l}1.64 \mathrm{E}+02 \\
1.97 \mathrm{E}+03 \\
3.00 \mathrm{E}+01\end{array}$ & $\begin{array}{l}11094: \\
11276 \\
10443\end{array}$ & $\begin{array}{r}9844 \\
10134 \\
9173\end{array}$ & $\begin{aligned}+ & 1.72 \mathrm{E}-01: \\
& 1.87 \mathrm{E}-01 \\
& 1.46 \mathrm{E}-01\end{aligned}$ & $\begin{array}{l}9.00 \mathrm{E}-04 \\
1.38 \mathrm{E}-03 \\
7.85 \mathrm{E}-04\end{array}$ & $\begin{array}{l}3.24 \mathrm{E}-04: \\
4.82 \mathrm{E}-04 \\
3.00 \mathrm{E}-04\end{array}$ & $\begin{array}{l}2.07 \mathrm{E}-04: \\
2.86 \mathrm{E}-04 \\
1.80 \mathrm{E}-04\end{array}$ & $\begin{array}{l}2.49 \mathrm{E}-05 \\
5.02 \mathrm{E}-05 \\
1.97 \mathrm{E}-05\end{array}$ & $\begin{array}{l}4.03 \mathrm{E}-06: \\
5.37 \mathrm{E}-06 \\
3.21 \mathrm{E}-06\end{array}$ & - \\
\hline $006.0-03.6$ & M $2-31$ & $\begin{array}{l}4.09 \mathrm{E}+03: \\
5.90 \mathrm{E}+03 \\
3.38 \mathrm{E}+03\end{array}$ & $\begin{array}{c}9732: \\
10184 \\
9615\end{array}$ & $\begin{array}{l}12397+ \\
12945 \\
11786\end{array}$ & $\begin{aligned}+ & 1.21 \mathrm{E}-01: \\
& 1.28 \mathrm{E}-01 \\
& 1.11 \mathrm{E}-01\end{aligned}$ & $\begin{array}{l}2.62 \mathrm{E}-04: \\
3.06 \mathrm{E}-04 \\
2.02 \mathrm{E}-04\end{array}$ & $\begin{array}{l}4.74 \mathrm{E}-04: \\
5.15 \mathrm{E}-04 \\
3.71 \mathrm{E}-04\end{array}$ & $\begin{array}{l}1.13 \mathrm{E}-04: \\
1.16 \mathrm{E}-04 \\
8.72 \mathrm{E}-05\end{array}$ & $\begin{array}{l}1.26 \mathrm{E}-05: \\
1.43 \mathrm{E}-05 \\
9.44 \mathrm{E}-06\end{array}$ & $\begin{array}{l}2.05 \mathrm{E}-06: \\
2.19 \mathrm{E}-06 \\
1.79 \mathrm{E}-06\end{array}$ & $\begin{array}{l}3.09 \mathrm{E}-06: \\
3.71 \mathrm{E}-06 \\
1.95 \mathrm{E}-06\end{array}$ \\
\hline $006.2-03.7$ & KFL 15 & $\begin{array}{l}4.92 \mathrm{E}+02 \\
4.01 \mathrm{E}+03 \\
3.00 \mathrm{E}+01\end{array}$ & $\begin{array}{l}\text { 14141: } \\
14588 \\
13197\end{array}$ & & $\begin{array}{l}-1.05 \mathrm{E}-01: \\
1.11 \mathrm{E}-01 \\
9.59 \mathrm{E}-02\end{array}$ & $\begin{array}{l}7.81 \mathrm{E}-05: \\
1.08 \mathrm{E}-04 \\
5.92 \mathrm{E}-05\end{array}$ & $\begin{array}{l}3.18 \mathrm{E}-04: \\
4.40 \mathrm{E}-04 \\
2.69 \mathrm{E}-04\end{array}$ & $\begin{array}{l}7.09 \mathrm{E}-05: \\
8.72 \mathrm{E}-05 \\
5.50 \mathrm{E}-05\end{array}$ & $\begin{array}{l}5.12 \mathrm{E}-06: \\
7.17 \mathrm{E}-06 \\
2.97 \mathrm{E}-06\end{array}$ & $\begin{array}{l}1.99 \mathrm{E}-06: \\
2.27 \mathrm{E}-06 \\
1.76 \mathrm{E}-06\end{array}$ & - \\
\hline $006.3+03.3$ & H $2-22$ & $\begin{array}{l}4.91 \mathrm{E}+02 \\
2.41 \mathrm{E}+03 \\
7.83 \mathrm{E}+01\end{array}$ & - & $\begin{array}{l}6630 \\
7497 \\
5486\end{array}$ & $\begin{array}{l}1.10 \mathrm{E}-01 \\
\quad 1.21 \mathrm{E}-01 \\
9.91 \mathrm{E}-02\end{array}$ & $\begin{array}{l}2.14 \mathrm{E}-04 ; \\
5.11 \mathrm{E}-04 \\
1.46 \mathrm{E}-04\end{array}$ & $\begin{array}{l}3.37 \mathrm{E}-04 \\
1.80 \mathrm{E}-03 \\
1.43 \mathrm{E}-04\end{array}$ & & $\begin{array}{l}1.73 \mathrm{E}-05 \\
4.17 \mathrm{E}-05 \\
1.10 \mathrm{E}-05\end{array}$ & $\begin{array}{l}2.00 \mathrm{E}-06 \\
4.65 \mathrm{E}-06 \\
1.35 \mathrm{E}-06\end{array}$ & - \\
\hline $006.3+04.4$ & H $2-18$ & $\begin{array}{l}2.26 \mathrm{E}+03+ \\
2.72 \mathrm{E}+03 \\
1.87 \mathrm{E}+03\end{array}$ & $\begin{array}{l}10928+ \\
11201 \\
10564\end{array}$ & $\begin{array}{l}(13871): \\
(16891) \\
(10749)\end{array}$ & $\begin{aligned}: & 1.10 \mathrm{E}-01: \\
& 1.18 \mathrm{E}-01 \\
& 1.04 \mathrm{E}-01\end{aligned}$ & $\begin{array}{l}6.10 \mathrm{E}-05+ \\
7.03 \mathrm{E}-05 \\
5.10 \mathrm{E}-05\end{array}$ & $\begin{array}{l}3.67 \mathrm{E}-04: \\
4.36 \mathrm{E}-04 \\
3.19 \mathrm{E}-04\end{array}$ & $\begin{array}{l}8.10 \mathrm{E}-05+ \\
8.76 \mathrm{E}-05 \\
7.17 \mathrm{E}-05\end{array}$ & $\begin{array}{l}4.27 \mathrm{E}-06: \\
5.14 \mathrm{E}-06 \\
3.32 \mathrm{E}-06\end{array}$ & $\begin{array}{l}1.10 \mathrm{E}-06: \\
1.25 \mathrm{E}-06 \\
1.01 \mathrm{E}-06\end{array}$ & $\begin{array}{l}2.22 \mathrm{E}-06 \\
3.35 \mathrm{E}-06 \\
1.42 \mathrm{E}-06\end{array}$ \\
\hline $006.4+02.0$ & м $1-31$ & $\begin{array}{l}8.66 \mathrm{E}+03 \\
1.40 \mathrm{E}+04 \\
5.93 \mathrm{E}+03\end{array}$ & $\begin{array}{l}7639+ \\
7980 \\
7264\end{array}$ & $\begin{array}{c}10738 \\
11414 \\
9533\end{array}$ & $\begin{aligned}: & 1.54 \mathrm{E}-01: \\
& 1.67 \mathrm{E}-01 \\
& 1.45 \mathrm{E}-01\end{aligned}$ & $\begin{array}{l}7.37 \mathrm{E}-04: \\
9.09 \mathrm{E}-04 \\
4.77 \mathrm{E}-04\end{array}$ & $\begin{array}{l}8.05 \mathrm{E}-04: \\
1.06 \mathrm{E}-03 \\
6.54 \mathrm{E}-04\end{array}$ & $\begin{array}{l}2.27 \mathrm{E}-04: \\
3.20 \mathrm{E}-04 \\
1.95 \mathrm{E}-04\end{array}$ & $\begin{array}{l}2.80 \mathrm{E}-05: \\
3.89 \mathrm{E}-05 \\
1.95 \mathrm{E}-05\end{array}$ & $\begin{array}{l}6.80 \mathrm{E}-06: \\
8.09 \mathrm{E}-06 \\
5.80 \mathrm{E}-06\end{array}$ & $\begin{array}{l}8.05 \mathrm{E}-06 ; \\
1.37 \mathrm{E}-05 \\
3.81 \mathrm{E}-06\end{array}$ \\
\hline $006.4-04.6$ & Pe $2-13$ & $\begin{array}{l}2.02 \mathrm{E}+03+ \\
2.36 \mathrm{E}+03 \\
1.71 \mathrm{E}+03\end{array}$ & $\begin{array}{l}11814+ \\
12196 \\
11540\end{array}$ & & $\begin{aligned}- & 1.56 \mathrm{E}-01+ \\
& 1.65 \mathrm{E}-01 \\
& 1.48 \mathrm{E}-01\end{aligned}$ & & $\begin{array}{l}4.66 \mathrm{E}-04+ \\
5.23 \mathrm{E}-04 \\
4.00 \mathrm{E}-04\end{array}$ & - & & $\begin{array}{l}3.51 \mathrm{E}-06: \\
3.94 \mathrm{E}-06 \\
2.96 \mathrm{E}-06\end{array}$ & - \\
\hline
\end{tabular}


Table A.1. continued.

\begin{tabular}{|c|c|c|c|c|c|c|c|c|c|c|c|}
\hline PN G & Main Name & $\mathrm{NE}$ (SII) & TRO3 & TRN2 & $\mathrm{HE} / \mathrm{H}$ & $\mathrm{N} / \mathrm{H}$ & $0 / \mathrm{H}$ & $\mathrm{NE} / \mathrm{H}$ & $\mathrm{S} / \mathrm{H}$ & $\mathrm{Ar} / \mathrm{H}$ & $\mathrm{Cl} / \mathrm{H}$ \\
\hline $006.5-03.1$ & H $1-61$ & $\begin{array}{l}4.91 \mathrm{E}+03 \\
7.35 \mathrm{E}+04 \\
2.23 \mathrm{E}+03\end{array}$ & & $\begin{array}{r}12108 \\
13061 \\
6642\end{array}$ & $\begin{array}{l}1.26 \mathrm{E}-01: \\
1.39 \mathrm{E}-01 \\
1.20 \mathrm{E}-01\end{array}$ & $\begin{array}{l}9.65 \mathrm{E}-05 \\
4.82 \mathrm{E}-04 \\
7.42 \mathrm{E}-05\end{array}$ & $\begin{array}{l}1.13 \mathrm{E}-04 \\
1.18 \mathrm{E}-03 \\
9.59 \mathrm{E}-05\end{array}$ & & $\begin{array}{l}4.02 \mathrm{E}-06 \\
4.09 \mathrm{E}-05 \\
3.25 \mathrm{E}-06\end{array}$ & $\begin{array}{l}3.03 \mathrm{E}-06 \\
1.18 \mathrm{E}-05 \\
2.65 \mathrm{E}-06\end{array}$ & \\
\hline $006.8+02.3$ & Th $4-7$ & $\begin{array}{l}2.07 \mathrm{E}+03+ \\
2.48 \mathrm{E}+03 \\
1.78 \mathrm{E}+03\end{array}$ & $\begin{array}{l}14514: \\
15294 \\
14165\end{array}$ & $\begin{array}{l}(15076): \\
(16954): \\
(12944)\end{array}$ & $\begin{array}{l}1.18 \mathrm{E}-01+ \\
1.25 \mathrm{E}-01 \\
1.11 \mathrm{E}-01\end{array}$ & $\begin{array}{l}1.07 \mathrm{E}-04+ \\
1.26 \mathrm{E}-04 \\
9.33 \mathrm{E}-05\end{array}$ & $\begin{array}{l}2.84 \mathrm{E}-04: \\
3.12 \mathrm{E}-04 \\
2.30 \mathrm{E}-04\end{array}$ & $\begin{array}{l}4.46 \mathrm{E}-05: \\
4.80 \mathrm{E}-05 \\
3.52 \mathrm{E}-05\end{array}$ & $\begin{array}{l}2.91 \mathrm{E}-06: \\
3.30 \mathrm{E}-06 \\
2.43 \mathrm{E}-06\end{array}$ & $\begin{array}{l}9.04 \mathrm{E}-07: \\
1.08 \mathrm{E}-06 \\
6.79 \mathrm{E}-07\end{array}$ & - \\
\hline $006.8-03.4$ & H $2-45$ & $\begin{array}{l}1.06 \mathrm{E}+04 \\
1.76 \mathrm{E}+04 \\
7.17 \mathrm{E}+03\end{array}$ & $\begin{array}{l}11654+ \\
11866 \\
11302\end{array}$ & $\begin{array}{l}(17005): \\
(21259): \\
(10342)\end{array}$ & $\begin{array}{l}1.03 \mathrm{E}-01: \\
1.10 \mathrm{E}-01 \\
9.68 \mathrm{E}-02\end{array}$ & $\begin{array}{l}7.02 \mathrm{E}-05: \\
9.33 \mathrm{E}-05 \\
6.15 \mathrm{E}-05\end{array}$ & $\begin{array}{l}2.45 \mathrm{E}-04+ \\
2.81 \mathrm{E}-04 \\
2.22 \mathrm{E}-04\end{array}$ & & $\begin{array}{l}3.37 \mathrm{E}-06+ \\
3.91 \mathrm{E}-06 \\
3.06 \mathrm{E}-06\end{array}$ & $\begin{array}{l}6.92 \mathrm{E}-07+ \\
7.71 \mathrm{E}-07 \\
6.45 \mathrm{E}-07\end{array}$ & $\begin{array}{l}3.15 \mathrm{E}-06+ \\
3.64 \mathrm{E}-06 \\
2.73 \mathrm{E}-06\end{array}$ \\
\hline $006.8+04.1$ & M $3-15$ & $\begin{array}{l}5.40 \mathrm{E}+03 \\
8.14 \mathrm{E}+03 \\
4.07 \mathrm{E}+03\end{array}$ & $\begin{array}{l}8431+ \\
8584 \\
8235\end{array}$ & $\begin{array}{l}10644 \\
11056 \\
10119\end{array}$ & $\begin{array}{l}1.31 \mathrm{E}-01: \\
1.38 \mathrm{E}-01 \\
1.21 \mathrm{E}-01\end{array}$ & $\begin{array}{l}3.51 \mathrm{E}-04+ \\
4.08 \mathrm{E}-04 \\
3.10 \mathrm{E}-04\end{array}$ & $\begin{array}{l}6.44 \mathrm{E}-04+ \\
7.17 \mathrm{E}-04 \\
5.79 \mathrm{E}-04\end{array}$ & & $\begin{array}{l}1.77 \mathrm{E}-05+ \\
2.10 \mathrm{E}-05 \\
1.53 \mathrm{E}-05\end{array}$ & $\begin{array}{l}4.09 \mathrm{E}-06: \\
5.11 \mathrm{E}-06 \\
3.36 \mathrm{E}-06\end{array}$ & $\begin{array}{l}6.73 \mathrm{E}-06: \\
8.57 \mathrm{E}-06 \\
4.90 \mathrm{E}-06\end{array}$ \\
\hline $007.0-06.8$ & VY $2-1$ & $\begin{array}{l}2.21 \mathrm{E}+03+ \\
2.67 \mathrm{E}+03 \\
1.82 \mathrm{E}+03\end{array}$ & $\begin{array}{l}7797+ \\
7983 \\
7645\end{array}$ & $\begin{array}{l}9601+ \\
9884 \\
9367\end{array}$ & $\begin{array}{l}1.25 \mathrm{E}-01: \\
1.33 \mathrm{E}-01 \\
1.19 \mathrm{E}-01\end{array}$ & $\begin{array}{l}2.20 \mathrm{E}-04+ \\
2.50 \mathrm{E}-04 \\
1.84 \mathrm{E}-04\end{array}$ & $\begin{array}{l}6.38 \mathrm{E}-04+ \\
7.13 \mathrm{E}-04 \\
5.65 \mathrm{E}-04\end{array}$ & $\begin{array}{l}1.68 \mathrm{E}-04: \\
1.97 \mathrm{E}-04 \\
1.57 \mathrm{E}-04\end{array}$ & $\begin{array}{l}1.51 \mathrm{E}-05+ \\
1.77 \mathrm{E}-05 \\
1.30 \mathrm{E}-05\end{array}$ & $\begin{array}{l}3.58 \mathrm{E}-06+ \\
3.97 \mathrm{E}-06 \\
3.26 \mathrm{E}-06\end{array}$ & $\begin{array}{l}3.64 \mathrm{E}-06+ \\
4.61 \mathrm{E}-06 \\
2.89 \mathrm{E}-06\end{array}$ \\
\hline $007.8-03.7$ & M $2-34$ & $\begin{array}{l}3.08 \mathrm{E}+02: \\
3.82 \mathrm{E}+02 \\
2.38 \mathrm{E}+02\end{array}$ & $\begin{array}{l}8424: \\
8830 \\
7937\end{array}$ & $\begin{array}{l}8726+ \\
8966 \\
8489\end{array}$ & $\begin{array}{l}1.78 \mathrm{E}-01: \\
1.90 \mathrm{E}-01 \\
1.68 \mathrm{E}-01\end{array}$ & $\begin{array}{l}5.46 \mathrm{E}-04: \\
7.25 \mathrm{E}-04 \\
4.41 \mathrm{E}-04\end{array}$ & $\begin{array}{l}4.73 \mathrm{E}-04: \\
5.91 \mathrm{E}-04 \\
3.98 \mathrm{E}-04\end{array}$ & & $\begin{array}{l}1.31 \mathrm{E}-05 \\
1.92 \mathrm{E}-05 \\
9.75 \mathrm{E}-06\end{array}$ & $\begin{array}{l}4.16 \mathrm{E}-06: \\
4.94 \mathrm{E}-06 \\
3.58 \mathrm{E}-06\end{array}$ & $\begin{array}{l}9.28 \mathrm{E}-07 \\
1.49 \mathrm{E}-06 \\
5.56 \mathrm{E}-07\end{array}$ \\
\hline $007.8-04.4$ & H $1-65$ & $\begin{array}{l}6.07 \mathrm{E}+03 \\
9.38 \mathrm{E}+03 \\
4.16 \mathrm{E}+03\end{array}$ & - & $\begin{array}{l}5804+ \\
5946 \\
5532\end{array}$ & $\begin{array}{l}9.06 \mathrm{E}-03 \\
9.66 \mathrm{E}-03 \\
8.57 \mathrm{E}-03\end{array}$ & $\begin{array}{l}2.50 \mathrm{E}-04: \\
3.45 \mathrm{E}-04 \\
2.03 \mathrm{E}-04\end{array}$ & $\begin{array}{l}1.85 \mathrm{E}-04 \\
2.98 \mathrm{E}-04 \\
1.40 \mathrm{E}-04\end{array}$ & & $\begin{array}{l}4.19 \mathrm{E}-05 \\
6.80 \mathrm{E}-05 \\
3.09 \mathrm{E}-05\end{array}$ & $\begin{array}{l}3.26 \mathrm{E}-07 \\
4.13 \mathrm{E}-07 \\
2.84 \mathrm{E}-07\end{array}$ & - \\
\hline $008.1-04.7$ & M $2-39$ & $\begin{array}{l}4.94 \mathrm{E}+03+ \\
6.10 \mathrm{E}+03 \\
4.15 \mathrm{E}+03\end{array}$ & $\begin{array}{l}26960: \\
29447 \\
25568\end{array}$ & $\begin{array}{c}10267 \\
10659 \\
9764\end{array}$ & $\begin{array}{l}6.52 \mathrm{E}-02: \\
6.97 \mathrm{E}-02 \\
5.87 \mathrm{E}-02\end{array}$ & $\begin{array}{l}6.07 \mathrm{E}-06+ \\
7.00 \mathrm{E}-06 \\
5.08 \mathrm{E}-06\end{array}$ & $\begin{array}{l}2.38 \mathrm{E}-05: \\
2.69 \mathrm{E}-05 \\
1.99 \mathrm{E}-05\end{array}$ & $\begin{array}{l}6.20 \mathrm{E}-06: \\
6.60 \mathrm{E}-06 \\
4.62 \mathrm{E}-06\end{array}$ & $\begin{array}{l}2.20 \mathrm{E}-07+ \\
2.55 \mathrm{E}-07 \\
1.86 \mathrm{E}-07\end{array}$ & $\begin{array}{l}2.06 \mathrm{E}-07+ \\
2.29 \mathrm{E}-07 \\
1.82 \mathrm{E}-07\end{array}$ & $\begin{array}{l}1.91 \mathrm{E}-08 ; \\
2.24 \mathrm{E}-08 \\
1.56 \mathrm{E}-08\end{array}$ \\
\hline $008.2-04.8$ & M $2-42$ & $\begin{array}{l}2.15 \mathrm{E}+03+ \\
2.63 \mathrm{E}+03 \\
1.78 \mathrm{E}+03\end{array}$ & $\begin{array}{l}8280: \\
8655 \\
8161\end{array}$ & $\begin{array}{l}10836 \\
11336 \\
10424\end{array}$ & $\begin{array}{l}1.13 \mathrm{E}-01+ \\
1.19 \mathrm{E}-01 \\
1.06 \mathrm{E}-01\end{array}$ & $\begin{array}{l}2.14 \mathrm{E}-04: \\
2.66 \mathrm{E}-04 \\
1.64 \mathrm{E}-04\end{array}$ & $\begin{array}{l}6.12 \mathrm{E}-04: \\
6.73 \mathrm{E}-04 \\
4.80 \mathrm{E}-04\end{array}$ & $\begin{array}{l}1.65 \mathrm{E}-04: \\
1.67 \mathrm{E}-04 \\
1.26 \mathrm{E}-04\end{array}$ & $\begin{array}{l}1.37 \mathrm{E}-05: \\
1.54 \mathrm{E}-05 \\
1.02 \mathrm{E}-05\end{array}$ & $\begin{array}{l}2.18 \mathrm{E}-06: \\
2.31 \mathrm{E}-06 \\
1.88 \mathrm{E}-06\end{array}$ & $\begin{array}{l}5.46 \mathrm{E}-06: \\
6.64 \mathrm{E}-06 \\
3.31 \mathrm{E}-06\end{array}$ \\
\hline $008.4-03.6$ & H $1-64$ & $\begin{array}{l}3.19 \mathrm{E}+02 \\
1.32 \mathrm{E}+03 \\
3.00 \mathrm{E}+01\end{array}$ & - & $\begin{array}{l}6562 \\
6703 \\
6232\end{array}$ & $\begin{array}{l}1.35 \mathrm{E}-01 \\
1.43 \mathrm{E}-01 \\
1.22 \mathrm{E}-01\end{array}$ & $\begin{array}{l}1.91 \mathrm{E}-04: \\
2.77 \mathrm{E}-04 \\
1.61 \mathrm{E}-04\end{array}$ & $\begin{array}{l}5.89 \mathrm{E}-04 \\
1.00 \mathrm{E}-03 \\
5.51 \mathrm{E}-04\end{array}$ & & $\begin{array}{l}1.97 \mathrm{E}-05 \\
3.17 \mathrm{E}-05 \\
1.58 \mathrm{E}-05\end{array}$ & $\begin{array}{l}2.60 \mathrm{E}-06 \\
3.56 \mathrm{E}-06 \\
2.27 \mathrm{E}-06\end{array}$ & - \\
\hline $009.0+04.1$ & Th $4-5$ & $\begin{array}{l}1.56 \mathrm{E}+03+ \\
1.91 \mathrm{E}+03 \\
1.33 \mathrm{E}+03\end{array}$ & $\begin{array}{l}10399+ \\
10637 \\
10187\end{array}$ & $\begin{array}{l}10878+ \\
11176 \\
10570\end{array}$ & $\begin{array}{l}1.62 \mathrm{E}-01+ \\
1.71 \mathrm{E}-01 \\
1.53 \mathrm{E}-01\end{array}$ & $\begin{array}{l}2.84 \mathrm{E}-04+ \\
3.28 \mathrm{E}-04 \\
2.49 \mathrm{E}-04\end{array}$ & $\begin{array}{l}3.43 \mathrm{E}-04+ \\
3.76 \mathrm{E}-04 \\
3.07 \mathrm{E}-04\end{array}$ & & $\begin{array}{l}7.28 \mathrm{E}-06+ \\
8.41 \mathrm{E}-06 \\
6.28 \mathrm{E}-06\end{array}$ & $\begin{array}{l}2.80 \mathrm{E}-06+ \\
3.04 \mathrm{E}-06 \\
2.53 \mathrm{E}-06\end{array}$ & $\begin{array}{l}2.17 \mathrm{E}-06+ \\
2.60 \mathrm{E}-06 \\
1.77 \mathrm{E}-06\end{array}$ \\
\hline $351.9-01.9$ & Wray $16-286$ & $\begin{array}{l}5.44 \mathrm{E}+03: \\
7.13 \mathrm{E}+03 \\
4.10 \mathrm{E}+03\end{array}$ & $\begin{array}{l}9273+ \\
9523 \\
9008\end{array}$ & $\begin{array}{l}12751 \\
13323 \\
12036\end{array}+$ & $\begin{array}{l}1.23 \mathrm{E}-01: \\
1.31 \mathrm{E}-01 \\
1.17 \mathrm{E}-01\end{array}$ & $\begin{array}{l}1.87 \mathrm{E}-04= \\
2.25 \mathrm{E}-04 \\
1.45 \mathrm{E}-04\end{array}$ & $\begin{array}{l}5.47 E-04: \\
6.47 E-04 \\
4.77 E-04\end{array}$ & $\begin{array}{l}1.71 \mathrm{E}-04+ \\
1.88 \mathrm{E}-04 \\
1.52 \mathrm{E}-04\end{array}$ & $\begin{array}{l}1.05 \mathrm{E}-05: \\
1.21 \mathrm{E}-05 \\
8.74 \mathrm{E}-06\end{array}$ & $\begin{array}{l}2.77 \mathrm{E}-06: \\
3.06 \mathrm{E}-06 \\
2.40 \mathrm{E}-06\end{array}$ & - \\
\hline $352.0-04.6$ & H $1-30$ & $\begin{array}{l}3.11 \mathrm{E}+03: \\
3.98 \mathrm{E}+03 \\
2.57 \mathrm{E}+03\end{array}$ & $\begin{array}{c}9848+ \\
10074 \\
9567\end{array}$ & $\begin{array}{l}9471+ \\
9766 \\
9125\end{array}$ & $\begin{array}{l}1.60 \mathrm{E}-01+ \\
1.70 \mathrm{E}-01 \\
1.51 \mathrm{E}-01\end{array}$ & $\begin{array}{l}8.49 \mathrm{E}-04+ \\
1.00 \mathrm{E}-03 \\
7.02 \mathrm{E}-04\end{array}$ & $\begin{array}{l}5.54 \mathrm{E}-04+ \\
6.34 \mathrm{E}-04 \\
4.98 \mathrm{E}-04\end{array}$ & $\begin{array}{l}1.73 \mathrm{E}-04+ \\
1.87 \mathrm{E}-04 \\
1.54 \mathrm{E}-04\end{array}$ & $\begin{array}{l}1.51 \mathrm{E}-05+ \\
1.80 \mathrm{E}-05 \\
1.32 \mathrm{E}-05\end{array}$ & $\begin{array}{l}5.52 \mathrm{E}-06: \\
6.32 \mathrm{E}-06 \\
5.15 \mathrm{E}-06\end{array}$ & $\begin{array}{l}1.02 \mathrm{E}-06: \\
1.32 \mathrm{E}-06 \\
8.22 \mathrm{E}-07\end{array}$ \\
\hline $352.1+05.1$ & M $2-8$ & $\begin{array}{l}2.73 \mathrm{E}+03: \\
3.31 \mathrm{E}+03 \\
2.19 \mathrm{E}+03\end{array}$ & $\begin{array}{l}9324+ \\
9564 \\
9124\end{array}$ & $\begin{array}{l}9390+ \\
9653 \\
9050\end{array}$ & $\begin{array}{l}1.43 \mathrm{E}-01+ \\
1.50 \mathrm{E}-01 \\
1.35 \mathrm{E}-01\end{array}$ & $\begin{array}{l}3.70 \mathrm{E}-04: \\
4.22 \mathrm{E}-04 \\
3.04 \mathrm{E}-04\end{array}$ & $\begin{array}{l}5.13 \mathrm{E}-04+ \\
5.91 \mathrm{E}-04 \\
4.54 \mathrm{E}-04\end{array}$ & $\begin{array}{l}1.57 \mathrm{E}-04: \\
1.80 \mathrm{E}-04 \\
1.33 \mathrm{E}-04\end{array}$ & $\begin{array}{l}1.13 \mathrm{E}-05+ \\
1.23 \mathrm{E}-05 \\
9.71 \mathrm{E}-06\end{array}$ & $\begin{array}{l}4.51 \mathrm{E}-06+ \\
5.04 \mathrm{E}-06 \\
4.04 \mathrm{E}-06\end{array}$ & $\begin{array}{l}1.75 \mathrm{E}-06: \\
2.13 \mathrm{E}-06 \\
1.31 \mathrm{E}-06\end{array}$ \\
\hline $352.6+03.0$ & H $1-8$ & $\begin{array}{l}2.70 \mathrm{E}+03: \\
3.23 \mathrm{E}+03 \\
2.18 \mathrm{E}+03\end{array}$ & - & $\begin{array}{l}8414+ \\
8724+ \\
8068\end{array}$ & $\begin{array}{l}1.52 \mathrm{E}-01: \\
1.71 \mathrm{E}-01 \\
1.35 \mathrm{E}-01\end{array}$ & $\begin{array}{l}4.83 \mathrm{E}-04+ \\
5.66 \mathrm{E}-04 \\
4.25 \mathrm{E}-04\end{array}$ & $\begin{array}{l}5.76 \mathrm{E}-04: \\
7.50 \mathrm{E}-04 \\
4.62 \mathrm{E}-04\end{array}$ & & $\begin{array}{l}1.11 \mathrm{E}-05: \\
1.39 \mathrm{E}-05 \\
8.41 \mathrm{E}-06\end{array}$ & $\begin{array}{l}6.36 \mathrm{E}-06: \\
8.38 \mathrm{E}-06 \\
4.56 \mathrm{E}-06\end{array}$ & - \\
\hline $352.6-04.9$ & SB 37 & $\begin{array}{l}3.12 \mathrm{E}+02 \\
1.50 \mathrm{E}+03 \\
3.00 \mathrm{E}+01\end{array}$ & $\begin{array}{l}\text { 14075: } \\
15497 \\
12784\end{array}$ & & $\begin{array}{l}1.25 \mathrm{E}-01: \\
1.33 \mathrm{E}-01 \\
1.19 \mathrm{E}-01\end{array}$ & $\begin{array}{l}1.25 \mathrm{E}-04 ; \\
2.17 \mathrm{E}-04 \\
6.59 \mathrm{E}-05\end{array}$ & $\begin{array}{l}1.61 \mathrm{E}-04: \\
2.20 \mathrm{E}-04 \\
1.18 \mathrm{E}-04\end{array}$ & $\begin{array}{l}1.39 \mathrm{E}-05: \\
1.70 \mathrm{E}-05 \\
1.03 \mathrm{E}-05\end{array}$ & $\begin{array}{l}7.30 \mathrm{E}-06 \\
1.11 \mathrm{E}-05 \\
4.01 \mathrm{E}-06\end{array}$ & - & - \\
\hline $353.3+06.3$ & M $2-6$ & $\begin{array}{l}4.99 \mathrm{E}+03: \\
6.90 \mathrm{E}+03 \\
4.05 \mathrm{E}+03\end{array}$ & $\begin{array}{c}10136+ \\
10393 \\
9772\end{array}$ & $\begin{array}{l}12116 \\
12758 \\
11475\end{array}+$ & $\begin{array}{l}9.94 \mathrm{E}-02+ \\
1.05 \mathrm{E}-01 \\
9.34 \mathrm{E}-02\end{array}$ & $\begin{array}{l}7.21 \mathrm{E}-05: \\
8.79 \mathrm{E}-05 \\
6.05 \mathrm{E}-05\end{array}$ & $\begin{array}{l}2.58 \mathrm{E}-04+ \\
3.03 \mathrm{E}-04 \\
2.26 \mathrm{E}-04\end{array}$ & $\begin{array}{l}4.84 \mathrm{E}-05+ \\
5.35 \mathrm{E}-05 \\
4.24 \mathrm{E}-05\end{array}$ & $\begin{array}{l}4.33 \mathrm{E}-06: \\
5.21 \mathrm{E}-06 \\
3.69 \mathrm{E}-06\end{array}$ & $\begin{array}{l}7.87 \mathrm{E}-07+ \\
8.56 \mathrm{E}-07 \\
7.27 \mathrm{E}-07\end{array}$ & $\begin{array}{l}1.72 \mathrm{E}-06: \\
2.37 \mathrm{E}-06 \\
1.31 \mathrm{E}-06\end{array}$ \\
\hline $353.4-03.3$ & K $5-12$ & $\begin{array}{l}3.82 \mathrm{E}+03 \\
8.95 \mathrm{E}+03 \\
2.24 \mathrm{E}+03\end{array}$ & $\begin{array}{l}9247: \\
9811: \\
8605\end{array}$ & $\begin{array}{l}(13585): \\
(18217): \\
(7328)\end{array}$ & $\begin{array}{l}1.03 \mathrm{E}-01+ \\
1.08 \mathrm{E}-01 \\
9.71 \mathrm{E}-02\end{array}$ & $\begin{array}{l}1.33 \mathrm{E}-04: \\
1.85 \mathrm{E}-04 \\
1.04 \mathrm{E}-04\end{array}$ & $\begin{array}{l}9.82 \mathrm{E}-04: \\
1.38 \mathrm{E}-03 \\
7.72 \mathrm{E}-04\end{array}$ & $\begin{array}{l}4.49 \mathrm{E}-05: \\
6.26 \mathrm{E}-05 \\
3.53 \mathrm{E}-05\end{array}$ & $\begin{array}{l}1.23 \mathrm{E}-05 \\
1.86 \mathrm{E}-05 \\
8.71 \mathrm{E}-06\end{array}$ & $\begin{array}{l}1.62 \mathrm{E}-05: \\
1.98 \mathrm{E}-05 \\
1.41 \mathrm{E}-05\end{array}$ & - \\
\hline $353.5-04.9$ & H $1-36$ & $\begin{array}{l}9.87 \mathrm{E}+03: \\
1.22 \mathrm{E}+04 \\
6.66 \mathrm{E}+03\end{array}$ & $\begin{array}{l}36563: \\
38094 \\
31360\end{array}$ & & $\begin{array}{l}-8.78 \mathrm{E}-02: \\
9.13 \mathrm{E}-02 \\
8.10 \mathrm{E}-02\end{array}$ & $\begin{array}{l}5.92 \mathrm{E}-05: \\
6.75 \mathrm{E}-05 \\
4.73 \mathrm{E}-05\end{array}$ & $\begin{array}{l}7.04 \mathrm{E}-05: \\
8.46 \mathrm{E}-05 \\
6.01 \mathrm{E}-05\end{array}$ & $\begin{array}{l}1.55 \mathrm{E}-05: \\
1.80 \mathrm{E}-05 \\
1.30 \mathrm{E}-05\end{array}$ & $\begin{array}{l}1.34 \mathrm{E}-06: \\
1.62 \mathrm{E}-06 \\
1.14 \mathrm{E}-06\end{array}$ & $\begin{array}{l}4.59 \mathrm{E}-07: \\
5.39 \mathrm{E}-07 \\
4.21 \mathrm{E}-07\end{array}$ & $\begin{array}{l}8.42 \mathrm{E}-08: \\
1.10 \mathrm{E}-07 \\
6.50 \mathrm{E}-08\end{array}$ \\
\hline $353.7+06.3$ & M $2-7$ & $\begin{array}{l}5.78 \mathrm{E}+02+ \\
6.41 \mathrm{E}+02 \\
4.72 \mathrm{E}+02\end{array}$ & - & $\begin{array}{l}7737+ \\
7988 \\
7390\end{array}$ & $\begin{array}{l}1.44 \mathrm{E}-01+ \\
1.53 \mathrm{E}-01 \\
1.35 \mathrm{E}-01\end{array}$ & $\begin{array}{l}8.07 \mathrm{E}-05+ \\
9.28 \mathrm{E}-05 \\
7.08 \mathrm{E}-05\end{array}$ & $\begin{array}{l}4.13 \mathrm{E}-04: \\
4.77 \mathrm{E}-04 \\
3.22 \mathrm{E}-04\end{array}$ & $\begin{array}{l}6.90 \mathrm{E}-05: \\
8.13 \mathrm{E}-05 \\
4.69 \mathrm{E}-05\end{array}$ & $\begin{array}{l}3.71 \mathrm{E}-06: \\
4.59 \mathrm{E}-06 \\
2.83 \mathrm{E}-06\end{array}$ & $\begin{array}{l}2.81 \mathrm{E}-06: \\
3.22 \mathrm{E}-06 \\
2.37 \mathrm{E}-06\end{array}$ & - \\
\hline $353.8-01.2$ & K $6-3$ & $\begin{array}{l}1.65 \mathrm{E}+03: \\
2.06 \mathrm{E}+03 \\
1.29 \mathrm{E}+03\end{array}$ & $\begin{array}{c}13115: \\
18153 \\
7801\end{array}$ & $\begin{array}{l}7783: \\
8529 \\
6501\end{array}$ & $\begin{array}{l}1.31 \mathrm{E}-01 \\
1.39 \mathrm{E}-01 \\
1.11 \mathrm{E}-01\end{array}$ & $\begin{array}{l}6.52 \mathrm{E}-05 \\
2.08 \mathrm{E}-04 \\
4.11 \mathrm{E}-05\end{array}$ & $\begin{array}{l}1.24 \mathrm{E}-04 \\
6.03 \mathrm{E}-04 \\
6.40 \mathrm{E}-05\end{array}$ & & $\begin{array}{l}1.86 \mathrm{E}-06 \\
9.07 \mathrm{E}-06 \\
1.04 \mathrm{E}-06\end{array}$ & $\begin{array}{l}8.35 \mathrm{E}-07 \\
2.54 \mathrm{E}-06 \\
4.72 \mathrm{E}-07\end{array}$ & - \\
\hline $354.2+04.3$ & M $2-10$ & $\begin{array}{l}1.27 \mathrm{E}+03+ \\
1.51 \mathrm{E}+03 \\
1.07 \mathrm{E}+03\end{array}$ & - & $\begin{array}{l}7291 \\
7439 \\
7126\end{array}$ & $\begin{array}{l}1.41 \mathrm{E}-01+ \\
1.50 \mathrm{E}-01 \\
1.32 \mathrm{E}-01\end{array}$ & $\begin{array}{l}2.99 \mathrm{E}-04+ \\
3.33 \mathrm{E}-04 \\
2.68 \mathrm{E}-04\end{array}$ & $\begin{array}{l}2.73 \mathrm{E}-04+ \\
3.18 \mathrm{E}-04 \\
2.36 \mathrm{E}-04\end{array}$ & & $\begin{array}{l}7.93 \mathrm{E}-06+ \\
9.01 \mathrm{E}-06 \\
6.96 \mathrm{E}-06\end{array}$ & $\begin{array}{l}3.58 \mathrm{E}-06: \\
4.13 \mathrm{E}-06 \\
3.15 \mathrm{E}-06\end{array}$ & $\begin{array}{l}7.69 \mathrm{E}-07 \\
8.78 \mathrm{E}-07 \\
6.66 \mathrm{E}-07\end{array}$ \\
\hline $354.5+03.3$ & Th $3-4$ & $\begin{array}{l}1.57 \mathrm{E}+04 \\
3.99 \mathrm{E}+04 \\
1.02 \mathrm{E}+04\end{array}$ & - & $\begin{array}{l}16346 \\
18569 \\
14543\end{array}$ & $\begin{array}{l}1.09 \mathrm{E}-01: \\
1.28 \mathrm{E}-01 \\
1.03 \mathrm{E}-01\end{array}$ & $\begin{array}{l}1.28 \mathrm{E}-04 ; \\
2.63 \mathrm{E}-04 \\
9.83 \mathrm{E}-05\end{array}$ & $\begin{array}{l}1.64 \mathrm{E}-04 \\
3.91 \mathrm{E}-04 \\
1.32 \mathrm{E}-04\end{array}$ & $\begin{array}{l}3.38 \mathrm{E}-05 ; \\
8.47 \mathrm{E}-05 \\
2.45 \mathrm{E}-05\end{array}$ & $\begin{array}{l}2.98 \mathrm{E}-06 \\
9.66 \mathrm{E}-06 \\
2.25 \mathrm{E}-06\end{array}$ & $\begin{array}{l}1.57 \mathrm{E}-06 \\
3.03 \mathrm{E}-06 \\
1.37 \mathrm{E}-06\end{array}$ & - \\
\hline $354.6-01.7$ & K $6-5$ & $\begin{array}{l}9.96 \mathrm{E}+02+ \\
1.21 \mathrm{E}+03 \\
8.56 \mathrm{E}+02\end{array}$ & - & $\begin{array}{r}10667 \\
12480 \\
9029\end{array}$ & $\begin{array}{l}1.61 \mathrm{E}-01: \\
1.81 \mathrm{E}-01 \\
1.41 \mathrm{E}-01\end{array}$ & $\begin{array}{l}8.91 \mathrm{E}-04+ \\
1.06 \mathrm{E}-03 \\
7.46 \mathrm{E}-04\end{array}$ & $\begin{array}{l}2.58 \mathrm{E}-04: \\
3.80 \mathrm{E}-04 \\
1.61 \mathrm{E}-04\end{array}$ & & $\begin{array}{l}1.47 \mathrm{E}-05: \\
2.16 \mathrm{E}-05 \\
1.01 \mathrm{E}-05\end{array}$ & $\begin{array}{l}4.81 \mathrm{E}-06: \\
6.86 \mathrm{E}-06 \\
3.47 \mathrm{E}-06\end{array}$ & - \\
\hline $355.1-02.9$ & H $1-31$ & $\begin{array}{l}1.02 \mathrm{E}+04 \\
3.22 \mathrm{E}+04 \\
5.99 \mathrm{E}+03\end{array}$ & $\begin{array}{l}10865+ \\
11101 \\
10423\end{array}$ & $\begin{array}{l}(15599): \\
(17561) \\
(12987)\end{array}$ & $\begin{array}{l}1.15 \mathrm{E}-01: \\
1.24 \mathrm{E}-01 \\
1.08 \mathrm{E}-01\end{array}$ & $\begin{array}{l}9.53 \mathrm{E}-05 ; \\
1.63 \mathrm{E}-04 \\
7.98 \mathrm{E}-05\end{array}$ & $\begin{array}{l}5.37 \mathrm{E}-04: \\
6.59 \mathrm{E}-04 \\
4.88 \mathrm{E}-04\end{array}$ & & $\begin{array}{l}6.28 \mathrm{E}-06: \\
8.30 \mathrm{E}-06 \\
5.52 \mathrm{E}-06\end{array}$ & $\begin{array}{l}9.86 \mathrm{E}-07: \\
1.18 \mathrm{E}-06 \\
8.63 \mathrm{E}-07\end{array}$ & $\begin{array}{l}1.02 \mathrm{E}-06 ; \\
1.74 \mathrm{E}-06 \\
5.13 \mathrm{E}-07\end{array}$ \\
\hline $355.1-06.9$ & M $3-21$ & $\begin{array}{l}7.11 \mathrm{E}+03: \\
9.20 \mathrm{E}+03 \\
5.34 \mathrm{E}+03\end{array}$ & $\begin{array}{c}10023+ \\
10258 \\
9701\end{array}$ & $\begin{array}{l}14063 \\
14822 \\
12885\end{array}$ & $\begin{array}{l}1.19 \mathrm{E}-01: \\
1.27 \mathrm{E}-01 \\
1.12 \mathrm{E}-01\end{array}$ & $\begin{array}{l}\text { 3. } 77 \mathrm{E}-04: \\
4.47 \mathrm{E}-04 \\
2.86 \mathrm{E}-04\end{array}$ & $\begin{array}{l}6.19 \mathrm{E}-04: \\
7.30 \mathrm{E}-04 \\
5.40 \mathrm{E}-04\end{array}$ & $\begin{array}{l}1.67 \mathrm{E}-04: \\
2.04 \mathrm{E}-04 \\
1.56 \mathrm{E}-04\end{array}$ & $\begin{array}{l}1.30 \mathrm{E}-05+ \\
1.53 \mathrm{E}-05 \\
1.12 \mathrm{E}-05\end{array}$ & $\begin{array}{l}3.10 \mathrm{E}-06+ \\
3.40 \mathrm{E}-06 \\
2.83 \mathrm{E}-06\end{array}$ & $\begin{array}{l}2.94 \mathrm{E}-06: \\
4.05 \mathrm{E}-06 \\
2.19 \mathrm{E}-06\end{array}$ \\
\hline $355.2-02.5$ & H $1-29$ & $\begin{array}{l}3.36 \mathrm{E}+03: \\
4.19 \mathrm{E}+03 \\
2.76 \mathrm{E}+03\end{array}$ & $\begin{array}{l}11614+ \\
12064 \\
11311\end{array}$ & $\begin{array}{l}11333 \\
11846 \\
10822\end{array}+$ & $\begin{array}{l}1.15 \mathrm{E}-01: \\
1.23 \mathrm{E}-01 \\
1.08 \mathrm{E}-01\end{array}$ & $\begin{array}{l}7.32 \mathrm{E}-05: \\
8.0 \mathrm{E}-05 \\
5.98 \mathrm{E}-05\end{array}$ & $\begin{array}{l}2.70 \mathrm{E}-04+ \\
3.08 \mathrm{E}-04 \\
2.37 \mathrm{E}-04\end{array}$ & $\begin{array}{l}5.86 \mathrm{E}-05: \\
7.73 \mathrm{E}-05 \\
5.44 \mathrm{E}-05\end{array}$ & $\begin{array}{l}2.99 \mathrm{E}-06: \\
3.49 \mathrm{E}-06 \\
2.46 \mathrm{E}-06\end{array}$ & $\begin{array}{l}1.71 \mathrm{E}-06: \\
1.87 \mathrm{E}-06 \\
1.48 \mathrm{E}-06\end{array}$ & $\begin{array}{l}3.65 \mathrm{E}-07: \\
4.75 \mathrm{E}-07 \\
2.33 \mathrm{E}-07\end{array}$ \\
\hline
\end{tabular}


Table A.1. continued.

\begin{tabular}{|c|c|c|c|c|c|c|c|c|c|c|c|}
\hline$-\quad \mathrm{PNG}^{-}$ & Main Name & $\mathrm{NE}$ (SII) & TRO3 & TRN2 & $\mathrm{HE} / \mathrm{H}$ & $\mathrm{N} / \mathrm{H}$ & $\mathrm{O} / \mathrm{H}$ & $\mathrm{NE} / \mathrm{H}$ & $\mathrm{S} / \mathrm{H}$ & $\mathrm{Ar} / \mathrm{H}$ & $\mathrm{Cl} / \mathrm{H}$ \\
\hline $355.4-02.4$ & M $3-14$ & $\begin{array}{l}2.58 \mathrm{E}+03: \\
3.08 \mathrm{E}+03 \\
2.04 \mathrm{E}+03\end{array}$ & $\begin{array}{l}8682: \\
9715 \\
7230\end{array}$ & $\begin{array}{l}8938 \\
9357 \\
8313\end{array}$ & $\begin{array}{l}+1.59 \mathrm{E}-01: \\
+1.64 \mathrm{E}-01 \\
1.47 \mathrm{E}-01\end{array}$ & $\begin{array}{l}4.97 \mathrm{E}-04 \\
9.76 \mathrm{E}-04 \\
3.35 \mathrm{E}-04\end{array}$ & $\begin{array}{l}6.17 \mathrm{E}-04 ; \\
1.09 \mathrm{E}-03 \\
4.45 \mathrm{E}-04\end{array}$ & & $\begin{array}{l}1.28 \mathrm{E}-05 \\
3.19 \mathrm{E}-05 \\
7.33 \mathrm{E}-06\end{array}$ & $\begin{array}{l}5.93 \mathrm{E}-06 \\
9.45 \mathrm{E}-06 \\
4.48 \mathrm{E}-06\end{array}$ & $\begin{array}{l}1.86 \mathrm{E}-06 \\
8.77 \mathrm{E}-06 \\
6.64 \mathrm{E}-07\end{array}$ \\
\hline $355.4-04.0$ & Hf $2-1$ & $\begin{array}{l}6.96 \mathrm{E}+02+ \\
8.25 \mathrm{E}+02 \\
5.74 \mathrm{E}+02\end{array}$ & $\begin{array}{l}11710+ \\
12064 \\
11414\end{array}$ & $\begin{array}{r}10514 \\
+11501 \\
9579\end{array}$ & $\begin{aligned}: & 1.35 \mathrm{E}-01+ \\
& 1.43 \mathrm{E}-01 \\
& 1.28 \mathrm{E}-01\end{aligned}$ & $\begin{array}{l}5.19 \mathrm{E}-04: \\
7.01 \mathrm{E}-04 \\
3.51 \mathrm{E}-04\end{array}$ & $\begin{array}{l}5.36 \mathrm{E}-04+ \\
5.99 \mathrm{E}-04 \\
4.74 \mathrm{E}-04\end{array}$ & & $\begin{array}{l}-1.56 \mathrm{E}-05: \\
1.80 \mathrm{E}-05 \\
1.28 \mathrm{E}-05\end{array}$ & $\begin{array}{l}3.40 \mathrm{E}-06+ \\
3.65 \mathrm{E}-06 \\
3.07 \mathrm{E}-06\end{array}$ & $\begin{array}{l}3.16 \mathrm{E}-06: \\
3.98 \mathrm{E}-06 \\
2.12 \mathrm{E}-06\end{array}$ \\
\hline $355.5-01.4$ & K $5-9$ & $\begin{array}{l}2.61 \mathrm{E}+03 \\
6.83 \mathrm{E}+03 \\
1.53 \mathrm{E}+03\end{array}$ & - & $\begin{array}{r}10941 \\
14935 \\
5695\end{array}$ & - & - & - & - & - & - & - \\
\hline $355.6-02.7$ & H $1-32$ & $\begin{array}{l}5.50 \mathrm{E}+03 \\
1.24 \mathrm{E}+04 \\
3.42 \mathrm{E}+03\end{array}$ & $\begin{array}{l}10138: \\
10628 \\
9511\end{array}$ & $\begin{aligned}= & (16239): \\
& (18306): \\
& (12902)\end{aligned}$ & $\begin{aligned} &: 1.13 \mathrm{E}-01+ \\
& 1.18 \mathrm{E}-01 \\
& 1.06 \mathrm{E}-01\end{aligned}$ & $\begin{array}{l}2.39 \mathrm{E}-05: \\
3.25 \mathrm{E}-05 \\
2.05 \mathrm{E}-05\end{array}$ & $\begin{array}{l}3.91 \mathrm{E}-04= \\
5.16 \mathrm{E}-04 \\
3.29 \mathrm{E}-04\end{array}$ & & $\begin{array}{c}-4.36 \mathrm{E}-06: \\
6.05 \mathrm{E}-06 \\
3.60 \mathrm{E}-06\end{array}$ & $\begin{array}{l}1.79 \mathrm{E}-06: \\
2.25 \mathrm{E}-06 \\
1.48 \mathrm{E}-06\end{array}$ & $\begin{array}{l}\text { 1.56E-06; } \\
2.60 \mathrm{E}-06 \\
7.55 \mathrm{E}-07\end{array}$ \\
\hline $355.7-03.0$ & H $1-33$ & $\begin{array}{l}2.57 \mathrm{E}+03: \\
2.99 \mathrm{E}+03 \\
2.07 \mathrm{E}+03\end{array}$ & $\begin{array}{l}8375: \\
8905 \\
7715\end{array}$ & $: \begin{array}{r}10714 \\
11467 \\
9560\end{array}$ & 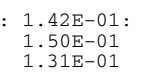 & $\begin{array}{l}4.57 \mathrm{E}-04: \\
6.52 \mathrm{E}-04 \\
3.14 \mathrm{E}-04\end{array}$ & $\begin{array}{l}6.24 \mathrm{E}-04= \\
8.48 \mathrm{E}-04 \\
5.02 \mathrm{E}-04\end{array}$ & & $\begin{array}{l}-1.63 \mathrm{E}-05 \\
2.55 \mathrm{E}-05 \\
1.10 \mathrm{E}-05\end{array}$ & $\begin{array}{l}3.34 \mathrm{E}-06: \\
4.34 \mathrm{E}-06 \\
2.78 \mathrm{E}-06\end{array}$ & $\begin{array}{l}3.75 \mathrm{E}-06 ; \\
8.03 \mathrm{E}-06 \\
1.75 \mathrm{E}-06\end{array}$ \\
\hline $355.7-03.4$ & H $2-23$ & $\begin{array}{l}\text { 3. } 41 E+03:= \\
4.75 E+03 \\
2.88 E+03\end{array}$ & $\begin{array}{l}10061+ \\
10350 \\
9855\end{array}$ & & $\begin{array}{l}-1.19 \mathrm{E}-01: \\
\text { 1.27E-01: } \\
1.11 \mathrm{E}-01\end{array}$ & $\begin{array}{l}\text { 6. } 32 \mathrm{E}-05: \\
8.70 \mathrm{E}-05 \\
5.11 \mathrm{E}-05\end{array}$ & $\begin{array}{l}4.41 \mathrm{E}-04+ \\
4.97 \mathrm{E}-04 \\
3.82 \mathrm{E}-04\end{array}$ & & $\begin{array}{c}-7.46 \mathrm{E}-06+ \\
8.71 \mathrm{E}-06 \\
6.38 \mathrm{E}-06\end{array}$ & $\begin{array}{l}1.39 \mathrm{E}-06+ \\
1.55 \mathrm{E}-06 \\
1.24 \mathrm{E}-06\end{array}$ & - \\
\hline $355.7-03.5$ & H $1-35$ & $\begin{array}{l}1.83 \mathrm{E}+04 ; \\
1.00 \mathrm{E}+05 \\
9.05 \mathrm{E}+03\end{array}$ & $\begin{array}{l}9438: \\
9691 \\
8799\end{array}$ & $\begin{aligned}: & (14253): \\
& (16118): \\
& (8979)\end{aligned}$ & $\begin{aligned}: & 1.14 \mathrm{E}-01: \\
& 1.22 \mathrm{E}-01 \\
& 1.08 \mathrm{E}-01\end{aligned}$ & $\begin{array}{l}2.84 \mathrm{E}-05 \\
5.91 \mathrm{E}-05 \\
2.38 \mathrm{E}-05\end{array}$ & $\begin{array}{l}4.42 \mathrm{E}-04: \\
6.61 \mathrm{E}-04 \\
3.77 \mathrm{E}-04\end{array}$ & $\begin{array}{l}5.80 \mathrm{E}-05: \\
8.40 \mathrm{E}-05 \\
5.28 \mathrm{E}-05\end{array}$ & $\begin{array}{l}=6.28 \mathrm{E}-06: \\
8.73 \mathrm{E}-06 \\
5.37 \mathrm{E}-06\end{array}$ & $\begin{array}{l}1.93 \mathrm{E}-06: \\
2.28 \mathrm{E}-06 \\
1.79 \mathrm{E}-06\end{array}$ & $\begin{array}{l}1.31 \mathrm{E}-06 ; \\
1.70 \mathrm{E}-06 \\
9.47 \mathrm{E}-07\end{array}$ \\
\hline $355.9+03.6$ & H $1-9$ & $\begin{array}{l}1.00 \mathrm{E}+05: \\
1.00 \mathrm{E}+05 \\
2.70 \mathrm{E}+04\end{array}$ & $\begin{array}{l}11230: \\
12653 \\
10649\end{array}$ & $\begin{aligned} &:(10189) ; \\
&(18659) ; \\
&(9974)\end{aligned}$ & $\begin{array}{c}\text {; } 7.32 \mathrm{E}-02 ; \\
7.71 \mathrm{E}-02 \\
6.74 \mathrm{E}-02\end{array}$ & $\begin{array}{l}2.59 \mathrm{E}-05: \\
2.95 \mathrm{E}-05 \\
1.47 \mathrm{E}-05\end{array}$ & $\begin{array}{l}1.98 \mathrm{E}-04= \\
2.41 \mathrm{E}-04 \\
8.26 \mathrm{E}-05\end{array}$ & $\begin{array}{l}6.88 \mathrm{E}-06: \\
8.10 \mathrm{E}-06 \\
2.45 \mathrm{E}-06\end{array}$ & $\begin{array}{l}=3.23 \mathrm{E}-06 ; \\
3.84 \mathrm{E}-06 \\
2.00 \mathrm{E}-06\end{array}$ & $\begin{array}{l}7.03 \mathrm{E}-07 \\
7.94 \mathrm{E}-07 \\
5.21 \mathrm{E}-07\end{array}$ & - \\
\hline $355.9-04.2$ & м $1-30$ & $\begin{array}{l}3.61 \mathrm{E}+03: \text { : } \\
5.08 \mathrm{E}+03 \\
2.73 \mathrm{E}+03\end{array}$ & $\begin{array}{l}6494: \\
6915 \\
5822\end{array}$ & $\begin{array}{l}7064+ \\
7217 \\
6857\end{array}$ & $\begin{aligned} &+ 1.45 \mathrm{E}-01: \\
&+1.54 \mathrm{E}-01 \\
& 1.33 \mathrm{E}-01\end{aligned}$ & $\begin{array}{l}5.40 \mathrm{E}-04: \\
7.75 \mathrm{E}-04 \\
4.23 \mathrm{E}-04\end{array}$ & $\begin{array}{l}4.79 \mathrm{E}-04 \\
7.61 \mathrm{E}-04 \\
3.90 \mathrm{E}-04\end{array}$ & & $\begin{array}{l}1.65 \mathrm{E}-05 \\
3.34 \mathrm{E}-05 \\
1.08 \mathrm{E}-05\end{array}$ & $\begin{array}{l}7.59 \mathrm{E}-06 \\
1.14 \mathrm{E}-05 \\
5.89 \mathrm{E}-06\end{array}$ & $\begin{array}{l}2.81 \mathrm{E}-06 ; \\
8.63 \mathrm{E}-06 \\
1.49 \mathrm{E}-06\end{array}$ \\
\hline $356.1+02.7$ & Th $3-13$ & $\begin{array}{l}3.73 \mathrm{E}+03+ \\
4.34 \mathrm{E}+03 \\
3.16 \mathrm{E}+03\end{array}$ & - & $\begin{array}{r}26949 \\
29504 \\
23777\end{array}$ & $\begin{array}{l}: \quad 8.03 \mathrm{E}-02: \\
8.84 \mathrm{E}-02 \\
7.44 \mathrm{E}-02\end{array}$ & $\begin{array}{l}1.03 \mathrm{E}-05+ \\
1.16 \mathrm{E}-05 \\
9.31 \mathrm{E}-06\end{array}$ & $\begin{array}{l}2.67 \mathrm{E}-05: \\
3.19 \mathrm{E}-05 \\
2.33 \mathrm{E}-05\end{array}$ & & $\begin{array}{c}-8.25 \mathrm{E}-07+ \\
9.87 \mathrm{E}-07 \\
7.03 \mathrm{E}-07\end{array}$ & $\begin{array}{l}7.09 \mathrm{E}-07: \\
8.15 \mathrm{E}-07 \\
6.16 \mathrm{E}-07\end{array}$ & - \\
\hline $356.2-04.4$ & Cn $2-1$ & $\begin{array}{l}\text { 4. } 30 \mathrm{E}+03: \text { : } \\
5.81 \mathrm{E}+03 \\
3.48 \mathrm{E}+03\end{array}$ & $\begin{array}{l}10438+ \\
10842 \\
10276\end{array}$ & $\begin{array}{r}12887 \\
+13391 \\
12251\end{array}$ & $\begin{aligned}+ & 1.19 \mathrm{E}-01+ \\
& 1.25 \mathrm{E}-01 \\
& 1.12 \mathrm{E}-01\end{aligned}$ & $\begin{array}{l}1.73 \mathrm{E}-04: \\
1.93 \mathrm{E}-04 \\
1.37 \mathrm{E}-04\end{array}$ & $\begin{array}{l}4.71 \mathrm{E}-04: \\
5.20 \mathrm{E}-04 \\
3.90 \mathrm{E}-04\end{array}$ & $\begin{array}{l}\text { 1. } 39 \mathrm{E}-04: \\
1.40 \mathrm{E}-04 \\
1.03 \mathrm{E}-04\end{array}$ & 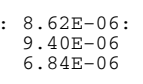 & $\begin{array}{l}2.00 \mathrm{E}-06+ \\
2.12 \mathrm{E}-06 \\
1.76 \mathrm{E}-06\end{array}$ & $\begin{array}{l}3.35 \mathrm{E}-06: \\
3.88 \mathrm{E}-06 \\
2.32 \mathrm{E}-06\end{array}$ \\
\hline $356.3-00.3$ & Th $3-34$ & $\begin{array}{l}\text { 5. } 19 \mathrm{E}+03: \text { : } \\
\text { 7.11E+03 } \\
3.99 \mathrm{E}+03\end{array}$ & $\begin{array}{l}20112: \\
24628 \\
11648\end{array}$ & $\begin{array}{l}31221 \\
34305 \\
27119\end{array}$ & $\begin{array}{l}: 2.20 \mathrm{E}-01: \\
2.54 \mathrm{E}-01 \\
1.93 \mathrm{E}-01\end{array}$ & $\begin{array}{l}7.80 \mathrm{E}-04 ; \\
2.04 \mathrm{E}-03 \\
5.53 \mathrm{E}-04\end{array}$ & $\begin{array}{l}9.89 \mathrm{E}-05 \\
2.88 \mathrm{E}-04 \\
6.22 \mathrm{E}-05\end{array}$ & & $\begin{array}{r}-8.89 \mathrm{E}-06 ; \\
4.18 \mathrm{E}-05 \\
4.21 \mathrm{E}-06\end{array}$ & $\begin{array}{l}2.75 \mathrm{E}-06 \\
7.08 \mathrm{E}-06 \\
1.71 \mathrm{E}-06\end{array}$ & - \\
\hline $356.5-02.3$ & M $1-27$ & $\begin{array}{l}5.06 \mathrm{E}+03 \\
8.17 \mathrm{E}+03 \\
3.71 \mathrm{E}+03\end{array}$ & - & $\begin{array}{l}6737 \\
-7050 \\
6020\end{array}$ & $\begin{array}{l}: 8.91 \mathrm{E}-03 ; \\
9.90 \mathrm{E}-03 \\
7.62 \mathrm{E}-03\end{array}$ & $\begin{array}{l}1.32 \mathrm{E}-04 ; \\
2.21 \mathrm{E}-04 \\
1.03 \mathrm{E}-04\end{array}$ & $\begin{array}{l}3.81 \mathrm{E}-04 ; \\
8.95 \mathrm{E}-04 \\
2.16 \mathrm{E}-04\end{array}$ & & $\begin{array}{l}2.45 \mathrm{E}-05 \\
4.40 \mathrm{E}-05 \\
1.77 \mathrm{E}-05\end{array}$ & $\begin{array}{l}2.54 \mathrm{E}-07 \\
3.80 \mathrm{E}-07 \\
2.06 \mathrm{E}-07\end{array}$ & - \\
\hline $356.5-03.9$ & H $1-39$ & $\begin{array}{l}\text { 5. } 87 \mathrm{E}+03: \\
8.04 \mathrm{E}+03 \\
4.32 \mathrm{E}+03\end{array}$ & - & $\begin{array}{l}8317 \\
-8742 \\
7535\end{array}$ & $\begin{array}{l}: \quad 4.67 \mathrm{E}-02 ; \\
5.07 \mathrm{E}-02 \\
4.49 \mathrm{E}-02\end{array}$ & $\begin{array}{l}5.58 \mathrm{E}-05: \\
7.25 \mathrm{E}-05 \\
4.54 \mathrm{E}-05\end{array}$ & $\begin{array}{l}2.75 \mathrm{E}-04 \\
4.22 \mathrm{E}-04 \\
1.79 \mathrm{E}-04\end{array}$ & & $\begin{aligned} &- 4.41 \mathrm{E}-06 ; \\
& 6.61 \mathrm{E}-06 \\
& 2.97 \mathrm{E}-06\end{aligned}$ & $\begin{array}{l}8.04 \mathrm{E}-07 \\
9.71 \mathrm{E}-07 \\
6.38 \mathrm{E}-07\end{array}$ & $\begin{array}{l}2.04 \mathrm{E}-07 ; \\
5.14 \mathrm{E}-07 \\
8.74 \mathrm{E}-08\end{array}$ \\
\hline $356.7-04.8$ & H $1-41$ & $\begin{array}{l}9.31 \mathrm{E}+02: \\
1.06 \mathrm{E}+03 \\
7.55 \mathrm{E}+02\end{array}$ & $\begin{array}{l}9715+ \\
9971 \\
9470\end{array}$ & $\begin{array}{r}9902 \\
+10245 \\
9576\end{array}$ & $\begin{aligned}+ & 1.16 \mathrm{E}-01+ \\
& 1.22 \mathrm{E}-01 \\
& 1.09 \mathrm{E}-01\end{aligned}$ & $\begin{array}{l}7.49 \mathrm{E}-05: \\
8.83 \mathrm{E}-05 \\
6.13 \mathrm{E}-05\end{array}$ & $\begin{array}{l}4.23 \mathrm{E}-04+ \\
4.85 \mathrm{E}-04 \\
3.72 \mathrm{E}-04\end{array}$ & $\begin{array}{c}1.04 \mathrm{E}-04+ \\
1.15 \mathrm{E}-04 \\
9.06 \mathrm{E}-05\end{array}$ & $\begin{array}{r}5.00 \mathrm{E}-06+ \\
5.86 \mathrm{E}-06 \\
4.19 \mathrm{E}-06\end{array}$ & $\begin{array}{l}1.43 \mathrm{E}-06+ \\
1.56 \mathrm{E}-06 \\
1.29 \mathrm{E}-06\end{array}$ & $\begin{array}{l}2.48 \mathrm{E}-06: \\
3.19 \mathrm{E}-06 \\
1.93 \mathrm{E}-06\end{array}$ \\
\hline $356.7-06.4$ & H $1-51$ & $\begin{array}{l}1.79 \mathrm{E}+02: \text { : } \\
2.33 \mathrm{E}+02 \\
1.20 \mathrm{E}+02\end{array}$ & $\begin{array}{l}\text { 13253: } \\
\text { 14109: } \\
12307\end{array}$ & $\begin{array}{l}8238 \\
8629 \\
7462\end{array}$ & 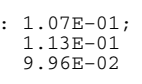 & $\begin{array}{l}1.26 \mathrm{E}-04: \\
1.55 \mathrm{E}-04 \\
1.14 \mathrm{E}-04\end{array}$ & $\begin{array}{l}4.48 \mathrm{E}-04 ; \\
8.08 \mathrm{E}-04 \\
3.16 \mathrm{E}-04\end{array}$ & $\begin{array}{l}1.28 \mathrm{E}-04 ; \\
2.49 \mathrm{E}-04 \\
6.75 \mathrm{E}-05\end{array}$ & $\begin{array}{l}3.15 \mathrm{E}-05 \\
3.89 \mathrm{E}-05 \\
2.70 \mathrm{E}-05\end{array}$ & $\begin{array}{l}1.37 \mathrm{E}-06 \\
1.65 \mathrm{E}-06 \\
1.18 \mathrm{E}-06\end{array}$ & - \\
\hline $356.8-03.0$ & K $5-20$ & $\begin{array}{l}4.43 \mathrm{E}+02 \\
1.57 \mathrm{E}+03 \\
3.00 \mathrm{E}+01\end{array}$ & $\begin{array}{c}10880: \\
12402 \\
9137\end{array}$ & & $\begin{array}{l}-1.34 \mathrm{E}-01: \\
\text { 1.41E-01: } \\
1.19 \mathrm{E}-01\end{array}$ & $\begin{array}{l}9.04 \mathrm{E}-06: \\
1.10 \mathrm{E}-05 \\
6.82 \mathrm{E}-06\end{array}$ & $\begin{array}{l}\text { 2. } 46 \mathrm{E}-04 \\
4.44 \mathrm{E}-04 \\
1.48 \mathrm{E}-04\end{array}$ & $\begin{array}{l}6.72 \mathrm{E}-05 \\
1.33 \mathrm{E}-04 \\
3.96 \mathrm{E}-05\end{array}$ & $\begin{array}{c}1.44 \mathrm{E}-06 ; \\
3.10 \mathrm{E}-06 \\
3.62 \mathrm{E}-07\end{array}$ & $\begin{array}{l}9.78 \mathrm{E}-07: \\
1.39 \mathrm{E}-06 \\
7.30 \mathrm{E}-07\end{array}$ & - \\
\hline $356.9+04.4$ & M $3-38$ & $\begin{array}{l}\text { 3. } .06 \mathrm{E}+03: \\
3.53 \mathrm{E}+03 \\
2.45 \mathrm{E}+03\end{array}$ & $\begin{array}{l}\text { 14015: } \\
14579 \\
13310\end{array}$ & $\begin{array}{l}17800: \\
18900 \\
16697\end{array}$ & 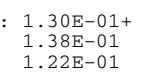 & $\begin{array}{l}3.81 \mathrm{E}-04= \\
5.02 \mathrm{E}-04 \\
3.41 \mathrm{E}-04\end{array}$ & $\begin{array}{l}2.47 \mathrm{E}-04+ \\
2.88 \mathrm{E}-04 \\
2.13 \mathrm{E}-04\end{array}$ & $\begin{array}{r}6.36 \mathrm{E}-05+ \\
7.19 \mathrm{E}-05 \\
5.77 \mathrm{E}-05\end{array}$ & $\begin{array}{r}7.50 \mathrm{E}-06: \\
+9.32 \mathrm{E}-06 \\
6.36 \mathrm{E}-06\end{array}$ & $\begin{array}{l}2.82 \mathrm{E}-06+ \\
3.14 \mathrm{E}-06 \\
2.56 \mathrm{E}-06\end{array}$ & $\begin{array}{l}8.25 \mathrm{E}-07: \\
1.16 \mathrm{E}-06 \\
6.20 \mathrm{E}-07\end{array}$ \\
\hline $356.9+04.5$ & M $2-11$ & $\begin{array}{l}2.15 \mathrm{E}+03+ \\
2.55 \mathrm{E}+03 \\
1.77 \mathrm{E}+03\end{array}$ & $\begin{array}{l}14427+ \\
14976 \\
13905\end{array}$ & $\begin{array}{r}+\begin{array}{l}14610 \\
15254 \\
13893\end{array} \\
1389\end{array}$ & $\begin{array}{r}+1.43 \mathrm{E}-01: \\
+1.51 \mathrm{E}-01 \\
\\
1.33 \mathrm{E}-01\end{array}$ & $\begin{array}{l}1.63 \mathrm{E}-04: \\
2.00 \mathrm{E}-04 \\
1.37 \mathrm{E}-04\end{array}$ & $\begin{array}{l}2.75 \mathrm{E}-04+ \\
3.20 \mathrm{E}-04 \\
2.43 \mathrm{E}-04\end{array}$ & $\begin{array}{r}5.77 \mathrm{E}-05+ \\
6.57 \mathrm{E}-05 \\
5.36 \mathrm{E}-05\end{array}$ & $\begin{aligned} &+ 4.81 \mathrm{E}-06+ \\
& 5.72 \mathrm{E}-06 \\
& 4.07 \mathrm{E}-06\end{aligned}$ & $\begin{array}{l}1.41 \mathrm{E}-06+ \\
1.55 \mathrm{E}-06 \\
1.27 \mathrm{E}-06\end{array}$ & $\begin{array}{l}6.56 \mathrm{E}-08: \\
8.54 \mathrm{E}-08 \\
5.06 \mathrm{E}-08\end{array}$ \\
\hline $356.9-05.8$ & M $2-24$ & $\begin{array}{l}1.14 \mathrm{E}+03+ \\
1.29 \mathrm{E}+03 \\
9.36 \mathrm{E}+02\end{array}$ & - & $\begin{array}{r}10520 \\
10917 \\
10145\end{array}$ & $\begin{aligned}+ & 1.18 \mathrm{E}-01: \\
& 1.26 \mathrm{E}-01 \\
& 1.10 \mathrm{E}-01\end{aligned}$ & $\begin{array}{l}9.60 \mathrm{E}-05+ \\
1.13 \mathrm{E}-04 \\
8.85 \mathrm{E}-05\end{array}$ & $\begin{array}{l}1.32 \mathrm{E}-04+ \\
1.49 \mathrm{E}-04 \\
1.17 \mathrm{E}-04\end{array}$ & $\begin{array}{l}1.18 \mathrm{E}-04:= \\
1.32 \mathrm{E}-04 \\
8.93 \mathrm{E}-05\end{array}$ & 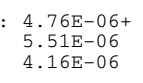 & $\begin{array}{l}1.10 \mathrm{E}-06+ \\
1.24 \mathrm{E}-06 \\
9.78 \mathrm{E}-07\end{array}$ & $\begin{array}{l}4.04 \mathrm{E}-07: \\
5.16 \mathrm{E}-07 \\
3.37 \mathrm{E}-07\end{array}$ \\
\hline $357.0+02.4$ & M $4-4$ & $\begin{array}{l}\text { 7. } .43 \mathrm{E}+02+ \\
9.22 \mathrm{E}+02 \\
6.17 \mathrm{E}+02\end{array}$ & - & $\begin{array}{r}9532 \\
10948 \\
7817\end{array}$ & $\begin{aligned} &: 1.55 \mathrm{E}-01+ \\
& 1.64 \mathrm{E}-01 \\
& 1.46 \mathrm{E}-01\end{aligned}$ & $\begin{array}{l}3.86 \mathrm{E}-04+ \\
4.33 \mathrm{E}-04 \\
3.45 \mathrm{E}-04\end{array}$ & $\begin{array}{l}5.89 \mathrm{E}-04 \\
1.15 \mathrm{E}-03 \\
3.55 \mathrm{E}-04\end{array}$ & & $\begin{array}{r}-1.30 \mathrm{E}-05 ; \\
2.51 \mathrm{E}-05 \\
7.87 \mathrm{E}-06\end{array}$ & $\begin{array}{l}3.74 \mathrm{E}-06 \\
5.72 \mathrm{E}-06 \\
2.61 \mathrm{E}-06\end{array}$ & - \\
\hline $357.1+03.6$ & M $3-7$ & $\begin{array}{l}3.40 \mathrm{E}+03: \\
4.53 \mathrm{E}+03 \\
2.78 \mathrm{E}+03\end{array}$ & $\begin{array}{l}7753+ \\
7964 \\
7609\end{array}$ & $\begin{array}{l}8600 \\
8858 \\
8335\end{array}$ & $\begin{aligned}+ & 1.19 \mathrm{E}-01: \\
& 1.27 \mathrm{E}-01 \\
& 1.12 \mathrm{E}-01\end{aligned}$ & $\begin{array}{l}1.29 \mathrm{E}-04: \\
1.46 \mathrm{E}-04 \\
1.00 \mathrm{E}-04\end{array}$ & $\begin{array}{l}4.76 \mathrm{E}-04+ \\
5.30 \mathrm{E}-04 \\
4.19 \mathrm{E}-04\end{array}$ & $\begin{array}{l}8.49 \mathrm{E}-05+ \\
9.80 \mathrm{E}-05 \\
7.92 \mathrm{E}-05\end{array}$ & $\begin{array}{r}9.87 \mathrm{E}-06: \\
+1.10 \mathrm{E}-05 \\
7.86 \mathrm{E}-06\end{array}$ & $\begin{array}{l}2.91 \mathrm{E}-06: \\
3.15 \mathrm{E}-06 \\
2.54 \mathrm{E}-06\end{array}$ & $\begin{array}{l}4.10 \mathrm{E}-06: \\
5.12 \mathrm{E}-06 \\
2.81 \mathrm{E}-06\end{array}$ \\
\hline $357.1-04.7$ & H $1-43$ & $\begin{array}{l}8.86 \mathrm{E}+03 \\
1.52 \mathrm{E}+04 \\
5.42 \mathrm{E}+03\end{array}$ & - & $\begin{array}{l}6137 \\
6474 \\
5580\end{array}$ & 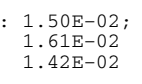 & $\begin{array}{l}2.05 \mathrm{E}-04= \\
2.80 \mathrm{E}-04 \\
1.47 \mathrm{E}-04\end{array}$ & $\begin{array}{l}1.32 \mathrm{E}-04 \\
2.03 \mathrm{E}-04 \\
8.43 \mathrm{E}-05\end{array}$ & & $\begin{array}{rl}- & 2.49 \mathrm{E}-05 \\
4 & 4.66 \mathrm{E}-05 \\
1.53 \mathrm{E}-05\end{array}$ & $\begin{array}{l}3.03 \mathrm{E}-07 \\
3.73 \mathrm{E}-07 \\
2.36 \mathrm{E}-07\end{array}$ & - \\
\hline $357.2-04.5$ & H $1-42$ & $\begin{array}{l}\text { 4. } .73 \mathrm{E}+03: \\
6.53 \mathrm{E}+03 \\
3.68 \mathrm{E}+03\end{array}$ & $\begin{array}{l}10605+ \\
10863 \\
10222\end{array}$ & $\begin{array}{l}12432 \\
+13075 \\
11874\end{array}$ & $\begin{array}{r}+1.05 \mathrm{E}-01: \\
+1.13 \mathrm{E}-01 \\
\quad 9.83 \mathrm{E}-02\end{array}$ & $\begin{array}{l}6.67 \mathrm{E}-05: \\
8.39 \mathrm{E}-05 \\
5.74 \mathrm{E}-05\end{array}$ & $\begin{array}{l}2.86 \mathrm{E}-04= \\
3.37 \mathrm{E}-04 \\
2.48 \mathrm{E}-04\end{array}$ & $\begin{array}{l}7.46 \mathrm{E}-05+ \\
8.13 \mathrm{E}-05 \\
6.65 \mathrm{E}-05\end{array}$ & $\begin{array}{r}+4.75 \mathrm{E}-06: \\
+5.85 \mathrm{E}-06 \\
4.08 \mathrm{E}-06\end{array}$ & $\begin{array}{l}1.03 \mathrm{E}-06: \\
1.19 \mathrm{E}-06 \\
9.49 \mathrm{E}-07\end{array}$ & $\begin{array}{l}2.07 \mathrm{E}-06: \\
2.83 \mathrm{E}-06 \\
1.54 \mathrm{E}-06\end{array}$ \\
\hline $357.3+03.3$ & M $3-41$ & $\begin{array}{l}2.14 \mathrm{E}+03: \\
2.67 \mathrm{E}+03 \\
1.72 \mathrm{E}+03\end{array}$ & - & $\begin{array}{l}7267+ \\
7427 \\
7103\end{array}$ & $\begin{array}{r}+4.73 \mathrm{E}-02 ; \\
4.98 \mathrm{E}-02 \\
4.39 \mathrm{E}-02\end{array}$ & $\begin{array}{l}1.01 \mathrm{E}-04+ \\
1.15 \mathrm{E}-04 \\
9.17 \mathrm{E}-05\end{array}$ & $\begin{array}{l}1.53 \mathrm{E}-04: \\
1.92 \mathrm{E}-04 \\
1.34 \mathrm{E}-04\end{array}$ & & $\begin{aligned}-5.14 \mathrm{E}-06 ; \\
5.96 \mathrm{E}-06 \\
4.64 \mathrm{E}-06\end{aligned}$ & $\begin{array}{l}9.41 \mathrm{E}-07 \\
1.06 \mathrm{E}-06 \\
8.52 \mathrm{E}-07\end{array}$ & $\begin{array}{l}2.57 \mathrm{E}-07 \\
3.77 \mathrm{E}-07 \\
1.49 \mathrm{E}-07\end{array}$ \\
\hline $357.4-03.2$ & M $2-16$ & $\begin{array}{l}3.77 \mathrm{E}+03: \text { : } \\
4.70 \mathrm{E}+03 \\
2.89 \mathrm{E}+03\end{array}$ & $\begin{array}{l}8864: \\
9418 \\
7708\end{array}$ & $\begin{array}{l}9042 \\
9475 \\
8325\end{array}$ & $\begin{aligned} &: 1.42 \mathrm{E}-01+ \\
& 1.49 \mathrm{E}-01 \\
& 1.34 \mathrm{E}-01\end{aligned}$ & $\begin{array}{l}8.02 \mathrm{E}-04 ; \\
1.44 \mathrm{E}-03 \\
5.64 \mathrm{E}-04\end{array}$ & $\begin{array}{l}6.71 \mathrm{E}-04 ; \\
1.13 \mathrm{E}-03 \\
5.36 \mathrm{E}-04\end{array}$ & & $\begin{array}{l}1.63 \mathrm{E}-05 \\
3.32 \mathrm{E}-05 \\
1.07 \mathrm{E}-05\end{array}$ & $\begin{array}{l}4.35 \mathrm{E}-06 \\
6.98 \mathrm{E}-06 \\
3.62 \mathrm{E}-06\end{array}$ & $\begin{array}{l}2.37 \mathrm{E}-06 ; \\
8.03 \mathrm{E}-06 \\
9.58 \mathrm{E}-07\end{array}$ \\
\hline $357.4-03.5$ & M $2-18$ & $\begin{array}{l}4.85 \mathrm{E}+03 \\
8.90 \mathrm{E}+03 \\
3.24 \mathrm{E}+03\end{array}$ & $\begin{array}{lll}- & - & -\end{array}$ & $\begin{array}{r}10467 \\
11291 \\
8675\end{array}$ & $\begin{aligned}: & 1.15 \mathrm{E}-01: \\
& 1.23 \mathrm{E}-01 \\
& 1.05 \mathrm{E}-01\end{aligned}$ & $\begin{array}{l}3.03 \mathrm{E}-05: \\
3.95 \mathrm{E}-05 \\
2.45 \mathrm{E}-05\end{array}$ & $\begin{array}{l}2.21 \mathrm{E}-04 \\
3.69 \mathrm{E}-04 \\
1.41 \mathrm{E}-04\end{array}$ & & $\begin{array}{r}-2.60 \mathrm{E}-06 \\
4.05 \mathrm{E}-06 \\
1.68 \mathrm{E}-06\end{array}$ & $\begin{array}{l}1.53 \mathrm{E}-06: \\
2.01 \mathrm{E}-06 \\
1.11 \mathrm{E}-06\end{array}$ & $\begin{array}{l}7.47 \mathrm{E}-07 \\
1.32 \mathrm{E}-06 \\
3.75 \mathrm{E}-07\end{array}$ \\
\hline
\end{tabular}


Table A.1. continued.

\begin{tabular}{|c|c|c|c|c|c|c|c|c|c|c|c|}
\hline PN G & Main Name & NE (SII) & TRO3 & TRN2 & $\mathrm{HE} / \mathrm{H}$ & $\mathrm{N} / \mathrm{H}$ & $0 / \mathrm{H}$ & $\mathrm{NE} / \mathrm{H}$ & $\mathrm{S} / \mathrm{H}$ & $\mathrm{Ar} / \mathrm{H}$ & $\mathrm{Cl} / \mathrm{H}$ \\
\hline $357.4-04.6$ & M $2-22$ & $\begin{array}{l}1.37 \mathrm{E}+03+ \\
1.69 \mathrm{E}+03 \\
1.17 \mathrm{E}+03\end{array}$ & $\begin{array}{l}9661+ \\
9857 \\
9430\end{array}$ & $\begin{array}{l}9097 \\
9282 \\
8826\end{array}$ & $\begin{array}{l}1.66 \mathrm{E}-01+ \\
1.76 \mathrm{E}-01 \\
1.56 \mathrm{E}-01\end{array}$ & $\begin{array}{l}4.68 \mathrm{E}-04+ \\
5.50 \mathrm{E}-04 \\
3.98 \mathrm{E}-04\end{array}$ & $\begin{array}{l}4.28 \mathrm{E}-04+ \\
4.85 \mathrm{E}-04 \\
3.85 \mathrm{E}-04\end{array}$ & & $\begin{array}{l}9.44 \mathrm{E}-06+ \\
1.08 \mathrm{E}-05 \\
8.31 \mathrm{E}-06\end{array}$ & $\begin{array}{l}3.59 \mathrm{E}-06+ \\
3.97 \mathrm{E}-06 \\
3.19 \mathrm{E}-06\end{array}$ & $\begin{array}{l}1.20 \mathrm{E}-06+ \\
1.45 \mathrm{E}-06 \\
1.02 \mathrm{E}-06\end{array}$ \\
\hline $357.5+03.2$ & M $3-42$ & $\begin{array}{l}1.03 \mathrm{E}+03 \\
1.71 \mathrm{E}+04 \\
2.68 \mathrm{E}+02\end{array}$ & $\begin{array}{l}10862: \\
11063 \\
10087\end{array}$ & $\begin{array}{l}9312 \\
9552 \\
8701\end{array}$ & $\begin{array}{l}1.42 \mathrm{E}-01: \\
1.50 \mathrm{E}-01 \\
1.31 \mathrm{E}-01\end{array}$ & $\begin{array}{l}5.47 \mathrm{E}-04 \\
9.44 \mathrm{E}-04 \\
4.47 \mathrm{E}-04\end{array}$ & $\begin{array}{l}6.73 \mathrm{E}-04 \\
1.11 \mathrm{E}-03 \\
6.37 \mathrm{E}-04\end{array}$ & $\begin{array}{l}1.66 \mathrm{E}-04: \\
2.45 \mathrm{E}-04 \\
1.30 \mathrm{E}-04\end{array}$ & $\begin{array}{l}2.08 \mathrm{E}-05 \\
8.27 \mathrm{E}-05 \\
1.73 \mathrm{E}-05\end{array}$ & $\begin{array}{l}7.03 \mathrm{E}-06: \\
8.05 \mathrm{E}-06 \\
6.48 \mathrm{E}-06\end{array}$ & $\begin{array}{l}1.50 \mathrm{E}-06: \\
2.07 \mathrm{E}-06 \\
1.18 \mathrm{E}-06\end{array}$ \\
\hline $357.6-03.3$ & H $2-29$ & $\begin{array}{l}2.17 \mathrm{E}+02 \\
1.29 \mathrm{E}+03 \\
3.00 \mathrm{E}+01\end{array}$ & - & $\begin{array}{l}7550 \\
7874 \\
6700\end{array}$ & $\begin{array}{l}1.71 \mathrm{E}-01 \\
1.85 \mathrm{E}-01 \\
1.57 \mathrm{E}-01\end{array}$ & $\begin{array}{l}1.13 \mathrm{E}-04: \\
1.61 \mathrm{E}-04 \\
9.42 \mathrm{E}-05\end{array}$ & $\begin{array}{l}2.39 \mathrm{E}-04 \\
5.44 \mathrm{E}-04 \\
1.67 \mathrm{E}-04\end{array}$ & $\begin{array}{l}5.18 \mathrm{E}-05 ; \\
1.33 \mathrm{E}-04 \\
3.34 \mathrm{E}-05\end{array}$ & $\begin{array}{l}9.48 \mathrm{E}-06 \\
1.68 \mathrm{E}-05 \\
7.65 \mathrm{E}-06\end{array}$ & $\begin{array}{l}1.77 \mathrm{E}-06 \\
2.71 \mathrm{E}-06 \\
1.43 \mathrm{E}-06\end{array}$ & - \\
\hline $358.2+03.5$ & H $2-10$ & $\begin{array}{l}6.91 \mathrm{E}+03 \\
1.54 \mathrm{E}+04 \\
4.06 \mathrm{E}+03\end{array}$ & $\begin{array}{l}\text { 10851: } \\
11184 \\
10299\end{array}$ & $\begin{array}{l}(13075): \\
(16156) \\
(8537)\end{array}$ & $\begin{array}{l}1.03 \mathrm{E}-01: \\
1.12 \mathrm{E}-01 \\
9.59 \mathrm{E}-02\end{array}$ & $\begin{array}{l}6.31 \mathrm{E}-05: \\
9.06 \mathrm{E}-05 \\
5.13 \mathrm{E}-05\end{array}$ & $\begin{array}{l}3.49 \mathrm{E}-04: \\
4.33 \mathrm{E}-04 \\
3.05 \mathrm{E}-04\end{array}$ & & $\begin{array}{l}4.14 \mathrm{E}-06: \\
5.32 \mathrm{E}-06 \\
3.57 \mathrm{E}-06\end{array}$ & $\begin{array}{l}6.97 \mathrm{E}-07: \\
9.08 \mathrm{E}-07 \\
5.73 \mathrm{E}-07\end{array}$ & $\begin{array}{l}1.05 \mathrm{E}-06 \\
1.62 \mathrm{E}-06 \\
5.15 \mathrm{E}-07\end{array}$ \\
\hline $358.2+03.6$ & M $3-10$ & $\begin{array}{l}6.55 \mathrm{E}+03: \\
9.69 \mathrm{E}+03 \\
4.78 \mathrm{E}+03\end{array}$ & $\begin{array}{l}10739+ \\
11018 \\
10463\end{array}$ & $\begin{array}{l}(14103): \\
(15403)) \\
(12561)\end{array}$ & $\begin{array}{l}1.15 \mathrm{E}-01: \\
1.23 \mathrm{E}-01 \\
1.08 \mathrm{E}-01\end{array}$ & $\begin{array}{l}1.00 \mathrm{E}-04: \\
1.23 \mathrm{E}-04 \\
8.81 \mathrm{E}-05\end{array}$ & $\begin{array}{l}5.08 \mathrm{E}-04: \\
5.70 \mathrm{E}-04 \\
4.35 \mathrm{E}-04\end{array}$ & & $\begin{array}{l}5.80 \mathrm{E}-06+ \\
6.58 \mathrm{E}-06 \\
5.31 \mathrm{E}-06\end{array}$ & $\begin{array}{l}2.47 \mathrm{E}-06+ \\
2.74 \mathrm{E}-06 \\
2.26 \mathrm{E}-06\end{array}$ & $\begin{array}{l}1.04 \mathrm{E}-06: \\
1.40 \mathrm{E}-06 \\
6.38 \mathrm{E}-07\end{array}$ \\
\hline $358.2+04.2$ & M $3-8$ & $\begin{array}{l}5.41 \mathrm{E}+03 \\
3.57 \mathrm{E}+04 \\
3.19 \mathrm{E}+03\end{array}$ & - & $\begin{array}{r}10105 \\
12042 \\
5430\end{array}$ & $\begin{array}{l}1.35 \mathrm{E}-01: \\
1.43 \mathrm{E}-01 \\
1.24 \mathrm{E}-01\end{array}$ & $\begin{array}{l}1.31 \mathrm{E}-04 ; \\
4.14 \mathrm{E}-04 \\
1.06 \mathrm{E}-04\end{array}$ & $\begin{array}{l}2.38 \mathrm{E}-04 \\
1.79 \mathrm{E}-03 \\
1.27 \mathrm{E}-04\end{array}$ & & $\begin{array}{l}3.47 \mathrm{E}-06 ; \\
2.74 \mathrm{E}-05 \\
1.49 \mathrm{E}-06\end{array}$ & $\begin{array}{l}2.53 \mathrm{E}-06 \\
8.19 \mathrm{E}-06 \\
1.64 \mathrm{E}-06\end{array}$ & - \\
\hline $358.3-02.5$ & A1 $2-0$ & $\begin{array}{l}3.42 \mathrm{E}+02: \\
4.34 \mathrm{E}+02 \\
2.51 \mathrm{E}+02\end{array}$ & $\begin{array}{l}\text { 13690: } \\
15551 \\
12922\end{array}$ & $\begin{array}{r}9099 \\
10100 \\
8195\end{array}$ & $\begin{array}{l}1.62 \mathrm{E}-01: \\
1.74 \mathrm{E}-01 \\
1.55 \mathrm{E}-01\end{array}$ & $\begin{array}{l}1.65 \mathrm{E}-04: \\
1.87 \mathrm{E}-04 \\
1.26 \mathrm{E}-04\end{array}$ & $\begin{array}{l}3.63 \mathrm{E}-04: \\
5.24 \mathrm{E}-04 \\
2.78 \mathrm{E}-04\end{array}$ & $\begin{array}{l}4.13 \mathrm{E}-05 \\
7.95 \mathrm{E}-05 \\
2.68 \mathrm{E}-05\end{array}$ & $\begin{array}{l}3.67 \mathrm{E}-06: \\
4.35 \mathrm{E}-06 \\
2.59 \mathrm{E}-06\end{array}$ & $\begin{array}{l}3.10 \mathrm{E}-06: \\
3.55 \mathrm{E}-06 \\
2.31 \mathrm{E}-06\end{array}$ & - \\
\hline $358.3+03.0$ & H $1-17$ & $\begin{array}{l}1.27 \mathrm{E}+04 \\
2.36 \mathrm{E}+04 \\
7.87 \mathrm{E}+03\end{array}$ & $\begin{array}{l}11915+ \\
12226 \\
11325\end{array}$ & $\begin{array}{l}(19168): \\
(21042) \\
(15488)\end{array}$ & $\begin{array}{l}1.18 \mathrm{E}-01: \\
1.26 \mathrm{E}-01 \\
1.10 \mathrm{E}-01\end{array}$ & $\begin{array}{l}1.10 \mathrm{E}-04: \\
1.36 \mathrm{E}-04 \\
8.88 \mathrm{E}-05\end{array}$ & $\begin{array}{l}3.81 \mathrm{E}-04: \\
4.81 \mathrm{E}-04 \\
3.43 \mathrm{E}-04\end{array}$ & $\begin{array}{l}1.01 \mathrm{E}-04: \\
1.19 \mathrm{E}-04 \\
9.30 \mathrm{E}-05\end{array}$ & $\begin{array}{l}6.59 \mathrm{E}-06: \\
7.99 \mathrm{E}-06 \\
5.72 \mathrm{E}-06\end{array}$ & $\begin{array}{l}2.38 \mathrm{E}-06+ \\
2.67 \mathrm{E}-06 \\
2.20 \mathrm{E}-06\end{array}$ & $\begin{array}{l}1.00 \mathrm{E}-06+ \\
1.22 \mathrm{E}-06 \\
8.34 \mathrm{E}-07\end{array}$ \\
\hline $358.3-07.3$ & SB 52 & $\begin{array}{l}9.49 \mathrm{E}+02 \\
2.55 \mathrm{E}+03 \\
3.71 \mathrm{E}+02\end{array}$ & $\begin{array}{l}13458: \\
13978 \\
12625\end{array}$ & $\begin{array}{l}(14214) ; \\
(22965) ; \\
(4085)\end{array}$ & $\begin{array}{l}1.34 \mathrm{E}-01: \\
1.42 \mathrm{E}-01 \\
1.24 \mathrm{E}-01\end{array}$ & $\begin{array}{l}2.69 \mathrm{E}-05: \\
3.10 \mathrm{E}-05 \\
1.85 \mathrm{E}-05\end{array}$ & $\begin{array}{l}2.52 \mathrm{E}-04: \\
3.37 \mathrm{E}-04 \\
2.16 \mathrm{E}-04\end{array}$ & $\begin{array}{l}4.54 \mathrm{E}-05: \\
5.78 \mathrm{E}-05 \\
3.79 \mathrm{E}-05\end{array}$ & $\begin{array}{l}2.28 \mathrm{E}-06 \\
3.58 \mathrm{E}-06 \\
1.09 \mathrm{E}-06\end{array}$ & $\begin{array}{l}8.89 \mathrm{E}-07: \\
1.04 \mathrm{E}-06 \\
8.25 \mathrm{E}-07\end{array}$ & - \\
\hline $358.5-02.5$ & M $4-7$ & $\begin{array}{l}1.57 \mathrm{E}+03+ \\
1.82 \mathrm{E}+03 \\
1.32 \mathrm{E}+03\end{array}$ & $\begin{array}{l}14518: \\
15649 \\
13313\end{array}$ & $\begin{array}{l}(13945): \\
(20019) \\
(9642)\end{array}$ & $\begin{array}{l}1.01 \mathrm{E}-01: \\
1.10 \mathrm{E}-01 \\
9.48 \mathrm{E}-02\end{array}$ & $\begin{array}{l}7.49 \mathrm{E}-05+ \\
8.35 \mathrm{E}-05 \\
6.55 \mathrm{E}-05\end{array}$ & $\begin{array}{l}1.83 \mathrm{E}-04: \\
2.39 \mathrm{E}-04 \\
1.57 \mathrm{E}-04\end{array}$ & $\begin{array}{l}4.46 \mathrm{E}-05 \\
6.80 \mathrm{E}-05 \\
3.73 \mathrm{E}-05\end{array}$ & $\begin{array}{l}2.39 \mathrm{E}-06: \\
3.29 \mathrm{E}-06 \\
1.85 \mathrm{E}-06\end{array}$ & $\begin{array}{l}5.50 \mathrm{E}-07: \\
6.80 \mathrm{E}-07 \\
4.62 \mathrm{E}-07\end{array}$ & - \\
\hline $358.5-04.2$ & H $1-46$ & $\begin{array}{l}3.75 \mathrm{E}+03: \\
4.72 \mathrm{E}+03 \\
3.09 \mathrm{E}+03\end{array}$ & $\begin{array}{c}9992+ \\
10243 \\
9781\end{array}$ & $\begin{array}{l}15848 \\
16352 \\
14847\end{array}+$ & $\begin{array}{l}1.10 \mathrm{E}-01+ \\
1.17 \mathrm{E}-01 \\
1.03 \mathrm{E}-01\end{array}$ & $\begin{array}{l}6.20 \mathrm{E}-05+ \\
7.26 \mathrm{E}-05 \\
5.42 \mathrm{E}-05\end{array}$ & $\begin{array}{l}1.87 \mathrm{E}-04+ \\
2.10 \mathrm{E}-04 \\
1.65 \mathrm{E}-04\end{array}$ & $\begin{array}{l}3.18 \mathrm{E}-05: \\
3.36 \mathrm{E}-05 \\
2.53 \mathrm{E}-05\end{array}$ & $\begin{array}{l}5.81 \mathrm{E}-06+ \\
6.63 \mathrm{E}-06 \\
4.92 \mathrm{E}-06\end{array}$ & $\begin{array}{l}1.28 \mathrm{E}-06+ \\
1.38 \mathrm{E}-06 \\
1.13 \mathrm{E}-06\end{array}$ & $\begin{array}{l}3.45 \mathrm{E}-07+ \\
4.30 \mathrm{E}-07 \\
2.67 \mathrm{E}-07\end{array}$ \\
\hline $358.6+01.8$ & M $4-6$ & $\begin{array}{l}4.51 \mathrm{E}+03: \\
6.04 \mathrm{E}+03 \\
3.39 \mathrm{E}+03\end{array}$ & $\begin{array}{l}10701: \\
11405 \\
10264\end{array}$ & $\begin{array}{l}13998 \\
14623 \\
12846\end{array}$ & $\begin{array}{l}1.22 \mathrm{E}-01+ \\
1.28 \mathrm{E}-01 \\
1.14 \mathrm{E}-01\end{array}$ & $\begin{array}{l}2.67 \mathrm{E}-04: \\
3.18 \mathrm{E}-04 \\
1.81 \mathrm{E}-04\end{array}$ & $\begin{array}{l}4.96 \mathrm{E}-04: \\
5.80 \mathrm{E}-04 \\
3.71 \mathrm{E}-04\end{array}$ & $\begin{array}{l}1.71 \mathrm{E}-04: \\
1.77 \mathrm{E}-04 \\
1.10 \mathrm{E}-04\end{array}$ & $\begin{array}{l}8.79 \mathrm{E}-06: \\
1.03 \mathrm{E}-05 \\
6.01 \mathrm{E}-06\end{array}$ & $\begin{array}{l}2.95 \mathrm{E}-06: \\
3.35 \mathrm{E}-06 \\
2.36 \mathrm{E}-06\end{array}$ & - \\
\hline $358.7-05.1$ & SB 53 & $\begin{array}{l}6.27 \mathrm{E}+02 \\
1.01 \mathrm{E}+03 \\
4.32 \mathrm{E}+02\end{array}$ & $\begin{array}{l}16384: \\
17185 \\
15598\end{array}$ & ${ }^{-1-}$ & $\begin{array}{l}1.27 \mathrm{E}-01: \\
1.36 \mathrm{E}-01 \\
1.17 \mathrm{E}-01\end{array}$ & $\begin{array}{l}1.26 \mathrm{E}-04: \\
1.64 \mathrm{E}-04 \\
1.01 \mathrm{E}-04\end{array}$ & $\begin{array}{l}3.02 \mathrm{E}-04: \\
3.65 \mathrm{E}-04 \\
2.54 \mathrm{E}-04\end{array}$ & $\begin{array}{l}4.35 \mathrm{E}-05: \\
5.24 \mathrm{E}-05 \\
3.64 \mathrm{E}-05\end{array}$ & $\begin{array}{l}5.92 \mathrm{E}-06: \\
7.63 \mathrm{E}-06 \\
4.92 \mathrm{E}-06\end{array}$ & $\begin{array}{l}9.77 \mathrm{E}-07+ \\
1.09 \mathrm{E}-06 \\
9.04 \mathrm{E}-07\end{array}$ & - \\
\hline $358.7-05.2$ & H $1-50$ & $\begin{array}{l}4.87 \mathrm{E}+03: \\
6.31 \mathrm{E}+03 \\
3.57 \mathrm{E}+03\end{array}$ & $\begin{array}{l}11052+ \\
11514 \\
10788\end{array}$ & $\begin{array}{l}12847 \\
13405 \\
12201\end{array}$ & $\begin{array}{l}1.17 \mathrm{E}-01: \\
1.25 \mathrm{E}-01 \\
1.09 \mathrm{E}-01\end{array}$ & $\begin{array}{l}1.92 \mathrm{E}-04: \\
2.24 \mathrm{E}-04 \\
1.57 \mathrm{E}-04\end{array}$ & $\begin{array}{l}4.54 \mathrm{E}-04: \\
5.12 \mathrm{E}-04 \\
3.84 \mathrm{E}-04\end{array}$ & $\begin{array}{l}1.31 \mathrm{E}-04: \\
1.39 \mathrm{E}-04 \\
1.06 \mathrm{E}-04\end{array}$ & $\begin{array}{l}7.36 \mathrm{E}-06+ \\
8.42 \mathrm{E}-06 \\
6.18 \mathrm{E}-06\end{array}$ & $\begin{array}{l}2.35 \mathrm{E}-06+ \\
2.59 \mathrm{E}-06 \\
2.09 \mathrm{E}-06\end{array}$ & $\begin{array}{l}1.63 \mathrm{E}-06: \\
2.08 \mathrm{E}-06 \\
1.22 \mathrm{E}-06\end{array}$ \\
\hline $358.8+04.0$ & Th 3-15 & $\begin{array}{l}4.95 \mathrm{E}+02+ \\
6.13 \mathrm{E}+02 \\
4.17 \mathrm{E}+02\end{array}$ & $\begin{array}{l}11876: \\
13450 \\
10673\end{array}$ & & $\begin{array}{l}-1.09 \mathrm{E}-01+ \\
1.15 \mathrm{E}-01 \\
1.02 \mathrm{E}-01\end{array}$ & $\begin{array}{l}2.19 \mathrm{E}-05: \\
2.63 \mathrm{E}-05 \\
1.93 \mathrm{E}-05\end{array}$ & $\begin{array}{l}1.36 \mathrm{E}-04: \\
1.98 \mathrm{E}-04 \\
8.83 \mathrm{E}-05\end{array}$ & & $\begin{array}{l}1.27 \mathrm{E}-06 \\
2.20 \mathrm{E}-06 \\
8.59 \mathrm{E}-07\end{array}$ & $\begin{array}{l}7.54 \mathrm{E}-07: \\
9.90 \mathrm{E}-07 \\
5.75 \mathrm{E}-07\end{array}$ & - \\
\hline $358.9+03.2$ & H $1-20$ & $\begin{array}{l}3.73 \mathrm{E}+03: \\
4.84 \mathrm{E}+03 \\
2.96 \mathrm{E}+03\end{array}$ & - & $\begin{array}{r}9899 \\
10571 \\
9104\end{array}$ & $\begin{array}{l}1.43 \mathrm{E}-01+ \\
1.52 \mathrm{E}-01 \\
1.34 \mathrm{E}-01\end{array}$ & $\begin{array}{l}3.20 \mathrm{E}-04+ \\
3.78 \mathrm{E}-04 \\
2.81 \mathrm{E}-04\end{array}$ & $\begin{array}{l}4.05 \mathrm{E}-04: \\
5.08 \mathrm{E}-04 \\
3.22 \mathrm{E}-04\end{array}$ & & $\begin{array}{l}7.51 \mathrm{E}-06: \\
9.93 \mathrm{E}-06 \\
6.06 \mathrm{E}-06\end{array}$ & $\begin{array}{l}3.98 \mathrm{E}-06: \\
4.69 \mathrm{E}-06 \\
3.41 \mathrm{E}-06\end{array}$ & $\begin{array}{l}1.14 \mathrm{E}-06: \\
1.59 \mathrm{E}-06 \\
4.67 \mathrm{E}-07\end{array}$ \\
\hline $358.9+03.4$ & H $1-19$ & $\begin{array}{l}1.29 \mathrm{E}+04 \\
4.74 \mathrm{E}+04 \\
7.39 \mathrm{E}+03\end{array}$ & - & $\begin{array}{r}10165 \\
10907 \\
6156\end{array}$ & $\begin{array}{l}1.40 \mathrm{E}-01: \\
1.49 \mathrm{E}-01 \\
1.32 \mathrm{E}-01\end{array}$ & $\begin{array}{l}1.79 \mathrm{E}-04 \\
3.59 \mathrm{E}-04 \\
1.37 \mathrm{E}-04\end{array}$ & $\begin{array}{l}1.82 \mathrm{E}-04 \\
5.89 \mathrm{E}-04 \\
1.34 \mathrm{E}-04\end{array}$ & & $\begin{array}{l}4.09 \mathrm{E}-06 \\
1.40 \mathrm{E}-05 \\
2.79 \mathrm{E}-06\end{array}$ & $\begin{array}{l}3.57 \mathrm{E}-06 \\
7.09 \mathrm{E}-06 \\
2.79 \mathrm{E}-06\end{array}$ & - \\
\hline $359.0-04.1$ & M $3-48$ & $\begin{array}{l}5.21 \mathrm{E}+02 \\
2.59 \mathrm{E}+03 \\
6.85 \mathrm{E}+01\end{array}$ & $\begin{array}{l}\text { 8884: } \\
9161 \\
8117\end{array}$ & $\begin{array}{l}9266+ \\
9624 \\
8779\end{array}$ & $\begin{array}{l}1.66 \mathrm{E}-01: \\
1.79 \mathrm{E}-01 \\
1.53 \mathrm{E}-01\end{array}$ & $\begin{array}{l}5.58 \mathrm{E}-04: \\
7.84 \mathrm{E}-04 \\
4.75 \mathrm{E}-04\end{array}$ & $\begin{array}{l}5.55 \mathrm{E}-04: \\
7.69 \mathrm{E}-04 \\
5.09 \mathrm{E}-04\end{array}$ & $\begin{array}{l}2.20 \mathrm{E}-04 ; \\
3.44 \mathrm{E}-04 \\
2.10 \mathrm{E}-04\end{array}$ & $\begin{array}{l}2.80 \mathrm{E}-05 \\
4.14 \mathrm{E}-05 \\
2.40 \mathrm{E}-05\end{array}$ & $\begin{array}{l}6.07 \mathrm{E}-06: \\
8.11 \mathrm{E}-06 \\
5.10 \mathrm{E}-06\end{array}$ & $\begin{array}{l}1.30 \mathrm{E}-06 \\
2.01 \mathrm{E}-06 \\
1.12 \mathrm{E}-06\end{array}$ \\
\hline $359.0-04.8$ & M $2-25$ & $\begin{array}{l}2.76 \mathrm{E}+02: \\
3.49 \mathrm{E}+02 \\
2.08 \mathrm{E}+02\end{array}$ & $\begin{array}{l}9528+ \\
9643 \\
9286\end{array}$ & $\begin{array}{r}10009 \\
10302 \\
9695\end{array}$ & $\begin{array}{l}1.47 \mathrm{E}-01: \\
1.57 \mathrm{E}-01 \\
1.41 \mathrm{E}-01\end{array}$ & $\begin{array}{l}4.35 \mathrm{E}-04+ \\
5.18 \mathrm{E}-04 \\
4.09 \mathrm{E}-04\end{array}$ & $\begin{array}{l}4.47 \mathrm{E}-04+ \\
5.10 \mathrm{E}-04 \\
4.21 \mathrm{E}-04\end{array}$ & & $\begin{array}{l}9.87 \mathrm{E}-06+ \\
1.14 \mathrm{E}-05 \\
9.12 \mathrm{E}-06\end{array}$ & $\begin{array}{l}3.68 \mathrm{E}-06: \\
4.56 \mathrm{E}-06 \\
2.93 \mathrm{E}-06\end{array}$ & $\begin{array}{l}4.32 \mathrm{E}-07: \\
5.56 \mathrm{E}-07 \\
3.49 \mathrm{E}-07\end{array}$ \\
\hline $359.1-01.7$ & M $1-29$ & $\begin{array}{l}2.41 \mathrm{E}+03:= \\
2.94 \mathrm{E}+03 \\
1.93 \mathrm{E}+03\end{array}$ & $\begin{array}{l}10933+ \\
11269 \\
10685\end{array}$ & $\begin{array}{c}9644 \\
10022 \\
9342\end{array}+$ & $\begin{array}{l}1.50 \mathrm{E}-01+ \\
1.58 \mathrm{E}-01 \\
1.43 \mathrm{E}-01\end{array}$ & $\begin{array}{l}4.78 \mathrm{E}-04: \\
5.36 \mathrm{E}-04 \\
3.75 \mathrm{E}-04\end{array}$ & $\begin{array}{l}5.15 \mathrm{E}-04+ \\
5.68 \mathrm{E}-04 \\
4.44 \mathrm{E}-04\end{array}$ & $\begin{array}{l}1.34 \mathrm{E}-04: \\
1.61 \mathrm{E}-04 \\
1.17 \mathrm{E}-04\end{array}$ & $\begin{array}{l}1.07 \mathrm{E}-05+ \\
1.19 \mathrm{E}-05 \\
9.09 \mathrm{E}-06\end{array}$ & $\begin{array}{l}3.63 \mathrm{E}-06+ \\
3.93 \mathrm{E}-06 \\
3.25 \mathrm{E}-06\end{array}$ & $\begin{array}{l}8.01 \mathrm{E}-07: \\
9.35 \mathrm{E}-07 \\
5.87 \mathrm{E}-07\end{array}$ \\
\hline $359.1-02.3$ & м $3-16$ & $\begin{array}{l}9.15 \mathrm{E}+02+ \\
1.08 \mathrm{E}+03 \\
7.91 \mathrm{E}+02\end{array}$ & - & $\begin{array}{r}9725 \\
12276 \\
7740\end{array}$ & $\begin{array}{l}1.06 \mathrm{E}-01: \\
1.12 \mathrm{E}-01 \\
9.84 \mathrm{E}-02\end{array}$ & $\begin{array}{l}1.09 \mathrm{E}-04 \\
2.36 \mathrm{E}-04 \\
5.49 \mathrm{E}-05\end{array}$ & $\begin{array}{l}7.10 \mathrm{E}-04 \\
2.37 \mathrm{E}-03 \\
3.48 \mathrm{E}-04\end{array}$ & & $\begin{array}{l}1.17 \mathrm{E}-05 \\
3.41 \mathrm{E}-05 \\
3.94 \mathrm{E}-06\end{array}$ & $\begin{array}{l}2.62 \mathrm{E}-06 \\
5.02 \mathrm{E}-06 \\
1.42 \mathrm{E}-06\end{array}$ & - \\
\hline $359.1-02.9$ & M $3-46$ & $\begin{array}{l}5.04 \mathrm{E}+02 \\
1.48 \mathrm{E}+03 \\
6.34 \mathrm{E}+01\end{array}$ & $\begin{array}{l}7425: \\
7762 \\
6965\end{array}$ & $\begin{array}{l}8160+ \\
8387 \\
7839\end{array}$ & $\begin{array}{l}2.00 \mathrm{E}-01: \\
2.17 \mathrm{E}-01 \\
1.79 \mathrm{E}-01\end{array}$ & $\begin{array}{l}6.45 \mathrm{E}-04: \\
8.98 \mathrm{E}-04 \\
5.43 \mathrm{E}-04\end{array}$ & $\begin{array}{l}8.52 \mathrm{E}-04: \\
1.19 \mathrm{E}-03 \\
7.47 \mathrm{E}-04\end{array}$ & $\begin{array}{l}3.73 \mathrm{E}-04: \\
5.49 \mathrm{E}-04 \\
2.96 \mathrm{E}-04\end{array}$ & $\begin{array}{l}2.73 \mathrm{E}-05: \\
3.89 \mathrm{E}-05 \\
2.28 \mathrm{E}-05\end{array}$ & $\begin{array}{l}6.94 \mathrm{E}-06: \\
9.12 \mathrm{E}-06 \\
5.80 \mathrm{E}-06\end{array}$ & $\begin{array}{l}9.34 \mathrm{E}-07 \\
1.67 \mathrm{E}-06 \\
5.50 \mathrm{E}-07\end{array}$ \\
\hline $359.3-01.8$ & M $3-44$ & $\begin{array}{l}5.26 \mathrm{E}+03 \\
8.42 \mathrm{E}+03 \\
3.92 \mathrm{E}+03\end{array}$ & - & $\begin{array}{l}6978+ \\
7207 \\
6738\end{array}$ & $\begin{array}{l}8.24 \mathrm{E}-03 \\
8.96 \mathrm{E}-03 \\
7.19 \mathrm{E}-03\end{array}$ & $\begin{array}{l}1.22 \mathrm{E}-04: \\
1.71 \mathrm{E}-04 \\
1.01 \mathrm{E}-04\end{array}$ & $\begin{array}{l}1.23 \mathrm{E}-04 \\
2.30 \mathrm{E}-04 \\
8.85 \mathrm{E}-05\end{array}$ & & $\begin{array}{l}2.32 \mathrm{E}-05 \\
3.80 \mathrm{E}-05 \\
1.86 \mathrm{E}-05\end{array}$ & $\begin{array}{l}1.71 \mathrm{E}-07 \\
2.30 \mathrm{E}-07 \\
1.46 \mathrm{E}-07\end{array}$ & - \\
\hline $359.3-03.1$ & M $3-17$ & $\begin{array}{l}2.72 \mathrm{E}+03: \\
3.49 \mathrm{E}+03 \\
1.98 \mathrm{E}+03\end{array}$ & - & $\begin{array}{l}7891: \\
8980 \\
6540\end{array}$ & $\begin{array}{l}9.59 \mathrm{E}-02 \\
1.02 \mathrm{E}-01 \\
8.91 \mathrm{E}-02\end{array}$ & $\begin{array}{l}7.46 \mathrm{E}-05 \\
1.15 \mathrm{E}-04 \\
5.74 \mathrm{E}-05\end{array}$ & $\begin{array}{l}2.39 \mathrm{E}-04 \\
8.65 \mathrm{E}-04 \\
1.17 \mathrm{E}-04\end{array}$ & & $\begin{array}{l}5.93 \mathrm{E}-06 \\
1.44 \mathrm{E}-05 \\
3.12 \mathrm{E}-06\end{array}$ & $\begin{array}{l}1.75 \mathrm{E}-06 \\
2.91 \mathrm{E}-06 \\
1.24 \mathrm{E}-06\end{array}$ & $\begin{array}{l}6.27 \mathrm{E}-07 \\
1.96 \mathrm{E}-06 \\
2.21 \mathrm{E}-07\end{array}$ \\
\hline $359.4-03.4$ & H $2-33$ & $\begin{array}{l}9.64 \mathrm{E}+02 \\
1.00 \mathrm{E}+05 \\
3.13 \mathrm{E}+02\end{array}$ & $\begin{array}{l}\text { 8636: } \\
8845 \\
8104\end{array}$ & $\begin{array}{l}(21816): \\
(26143): \\
(11324)\end{array}$ & $\begin{array}{l}1.59 \mathrm{E}-01+ \\
1.63 \mathrm{E}-01 \\
1.49 \mathrm{E}-01\end{array}$ & $\begin{array}{l}1.75 \mathrm{E}-05 \\
6.72 \mathrm{E}-05 \\
1.56 \mathrm{E}-05\end{array}$ & $\begin{array}{l}5.47 \mathrm{E}-04: \\
7.34 \mathrm{E}-04 \\
4.50 \mathrm{E}-04\end{array}$ & $\begin{array}{l}1.53 \mathrm{E}-04: \\
1.91 \mathrm{E}-04 \\
1.29 \mathrm{E}-04\end{array}$ & $\begin{array}{l}3.69 \mathrm{E}-06 \\
6.79 \mathrm{E}-06 \\
3.30 \mathrm{E}-06\end{array}$ & $\begin{array}{l}2.86 \mathrm{E}-06:= \\
3.41 \mathrm{E}-06 \\
2.59 \mathrm{E}-06\end{array}$ & - \\
\hline $359.4-08.5$ & SB 55 & $\begin{array}{l}2.23 \mathrm{E}+03 \\
1.00 \mathrm{E}+05 \\
3.00 \mathrm{E}+01\end{array}$ & $\begin{array}{l}26163: \\
27462 \\
21615\end{array}$ & & $\begin{array}{l}1.56 \mathrm{E}-01: \\
1.82 \mathrm{E}-01 \\
1.41 \mathrm{E}-01\end{array}$ & $\begin{array}{l}\text { 3.13E-06; } \\
1.14 \mathrm{E}-05 \\
1.43 \mathrm{E}-06\end{array}$ & $\begin{array}{l}3.55 \mathrm{E}-05 \\
6.16 \mathrm{E}-05 \\
2.74 \mathrm{E}-05\end{array}$ & $\begin{array}{l}1.23 \mathrm{E}-05 \\
2.00 \mathrm{E}-05 \\
9.64 \mathrm{E}-06\end{array}$ & $\begin{array}{l}9.08 \mathrm{E}-08 \\
1.27 \mathrm{E}-06 \\
5.99 \mathrm{E}-08\end{array}$ & $\begin{array}{l}1.42 \mathrm{E}-07: \\
1.85 \mathrm{E}-07 \\
1.29 \mathrm{E}-07\end{array}$ & - \\
\hline $359.6-04.8$ & H $2-36$ & $\begin{array}{l}2.93 \mathrm{E}+02: \\
3.74 \mathrm{E}+02 \\
2.31 \mathrm{E}+02\end{array}$ & $\begin{array}{l}12336+ \\
12660 \\
11917\end{array}$ & & $\begin{array}{l}2.21 \mathrm{E}-01+ \\
2.31 \mathrm{E}-01 \\
2.11 \mathrm{E}-01\end{array}$ & $\begin{array}{l}1.71 \mathrm{E}-05: \\
2.19 \mathrm{E}-05 \\
1.45 \mathrm{E}-05\end{array}$ & $\begin{array}{l}1.70 \mathrm{E}-04+ \\
1.98 \mathrm{E}-04 \\
1.47 \mathrm{E}-04\end{array}$ & $\begin{array}{l}4.26 \mathrm{E}-05: \\
4.51 \mathrm{E}-05 \\
3.49 \mathrm{E}-05\end{array}$ & $\begin{array}{l}2.07 \mathrm{E}-06: \\
2.70 \mathrm{E}-06 \\
1.69 \mathrm{E}-06\end{array}$ & $\begin{array}{l}1.22 \mathrm{E}-06: \\
1.45 \mathrm{E}-06 \\
1.05 \mathrm{E}-06\end{array}$ & $\begin{array}{l}1.11 \mathrm{E}-06+ \\
1.41 \mathrm{E}-06 \\
8.90 \mathrm{E}-07\end{array}$ \\
\hline
\end{tabular}


C. Chiappini et al.: Abundance patterns in the Galactic bulge, Online Material $p 7$

Table A.1. continued.

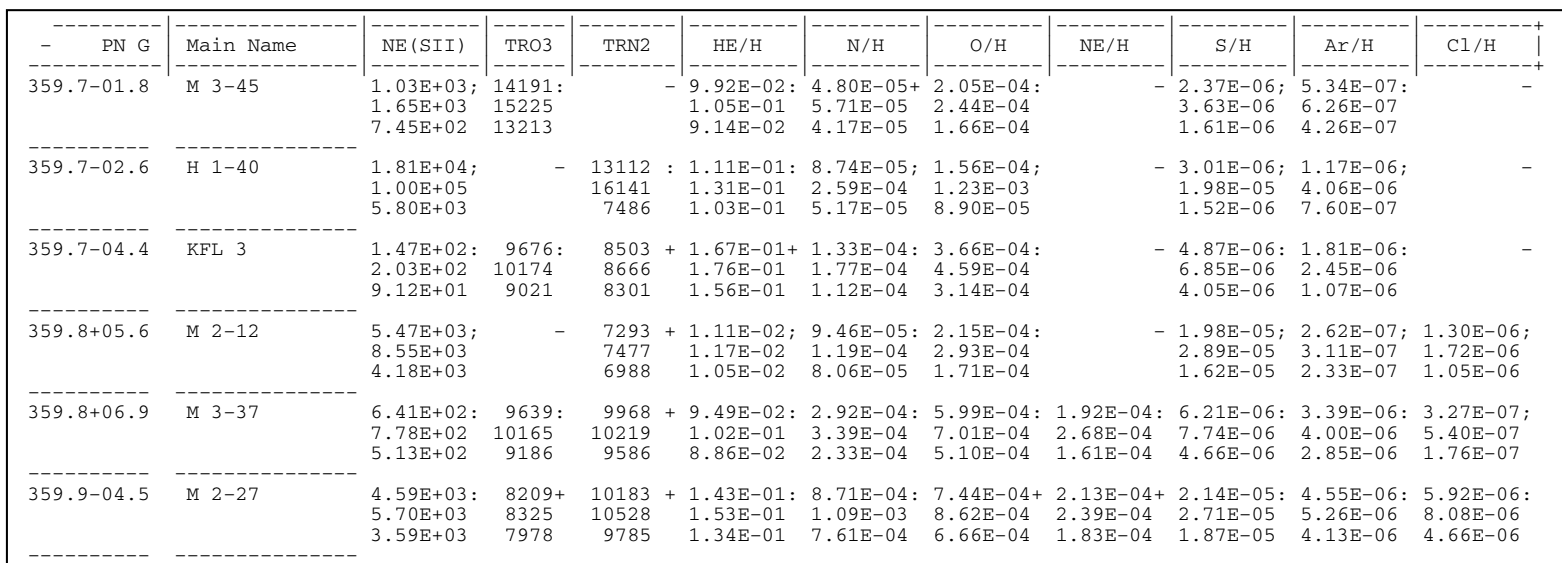


C. Chiappini et al.: Abundance patterns in the Galactic bulge, Online Material p 8

Table B.1. Plasma parameters and chemical abundances (Galactic inner-disk sample).

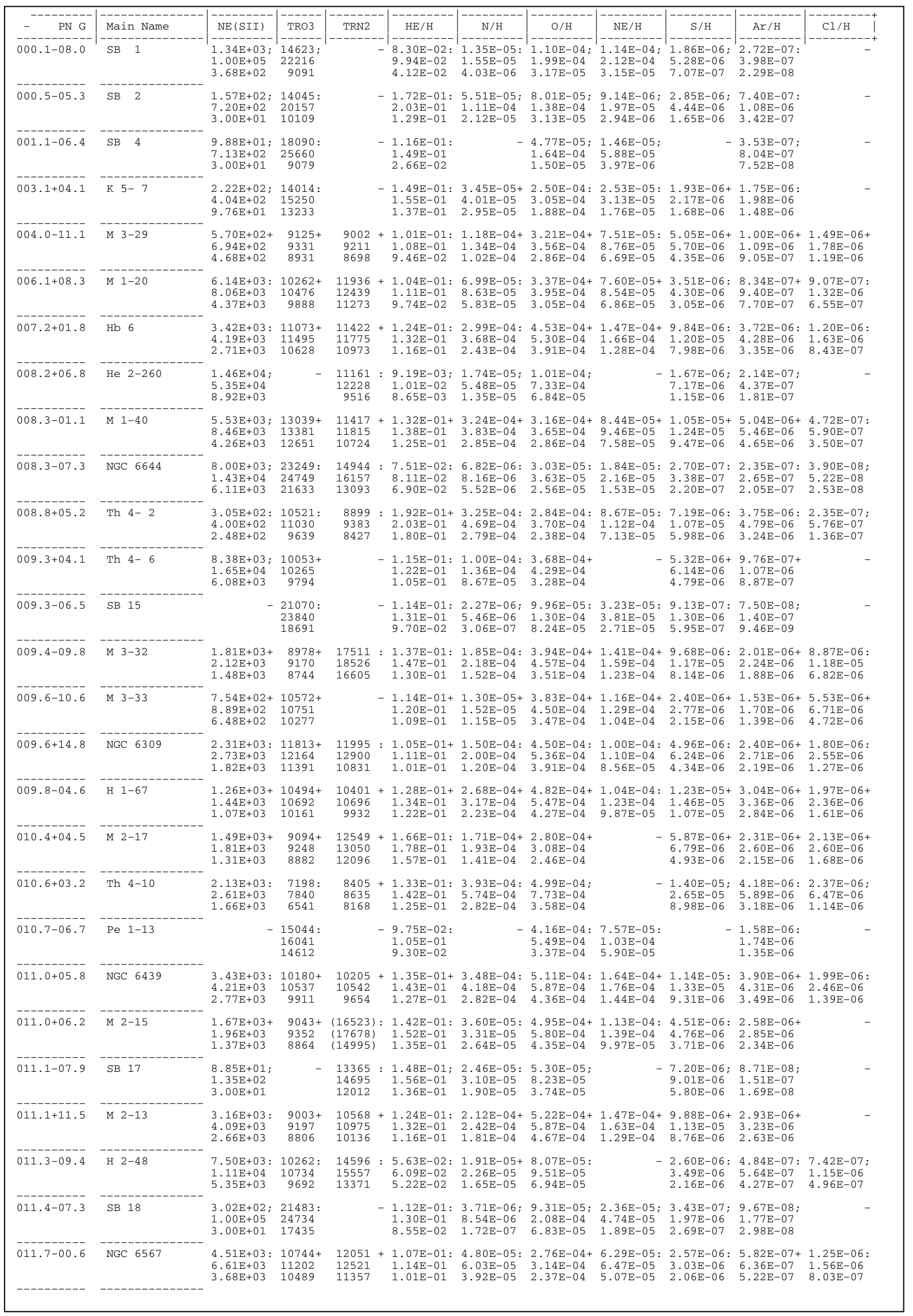


Table B.1. continued.

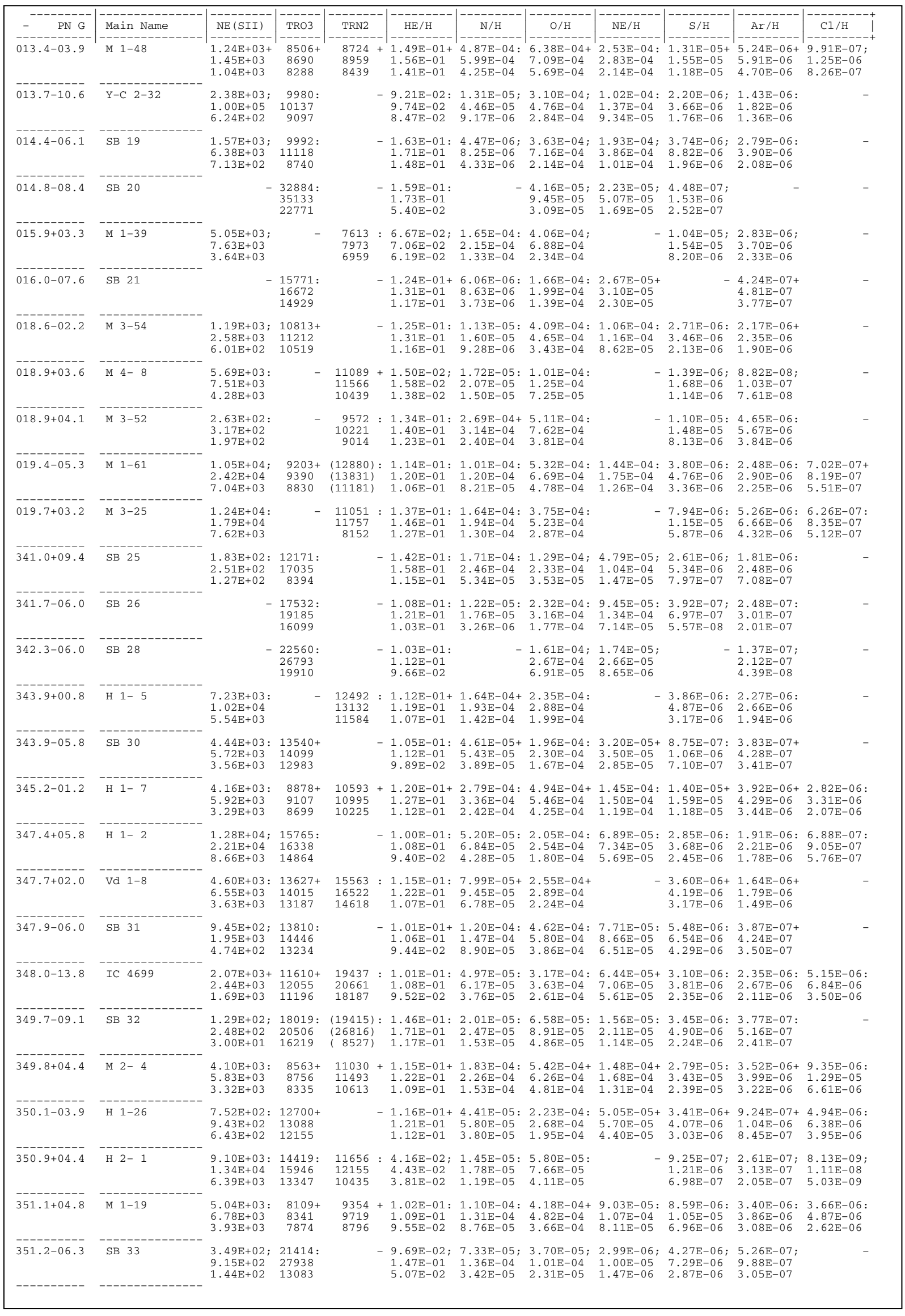


C. Chiappini et al.: Abundance patterns in the Galactic bulge, Online Material p 10

Table B.1. continued.

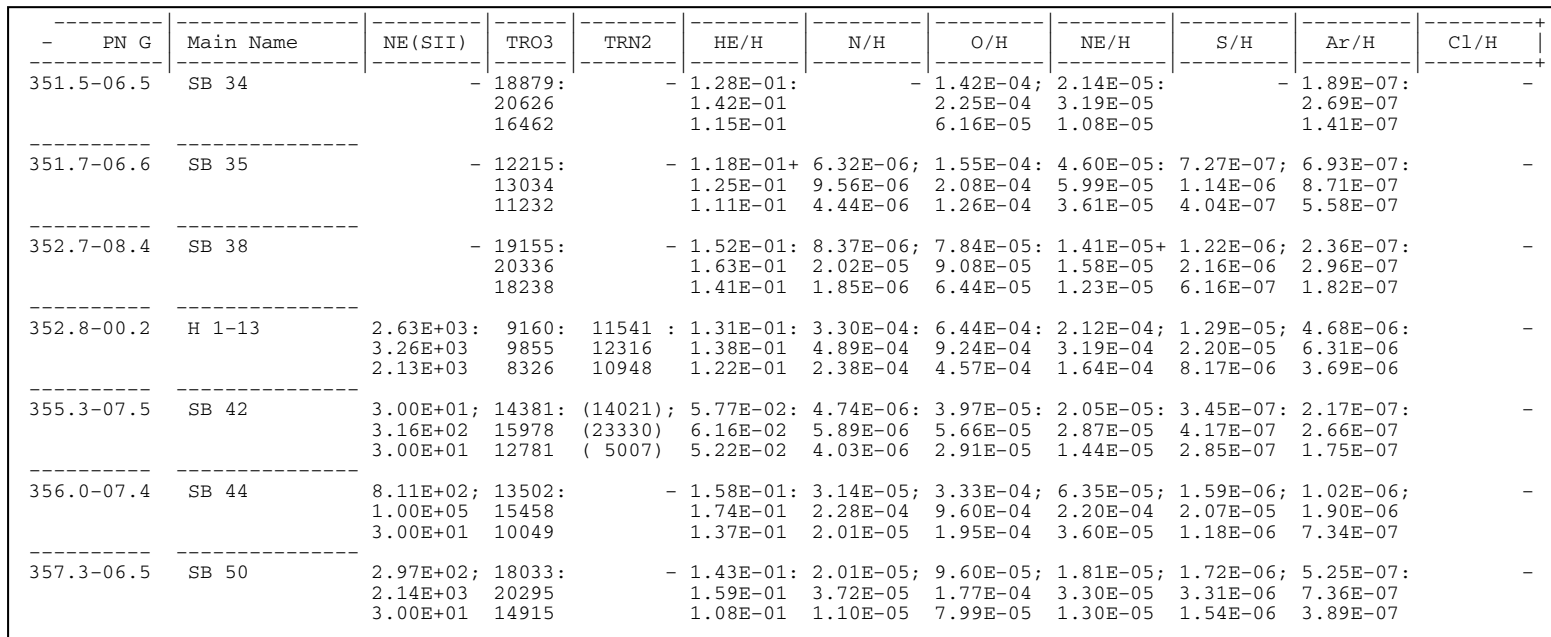


C. Chiappini et al.: Abundance patterns in the Galactic bulge, Online Material p 11

Table C.1. Plasma parameters and chemical abundances (LMC sample).

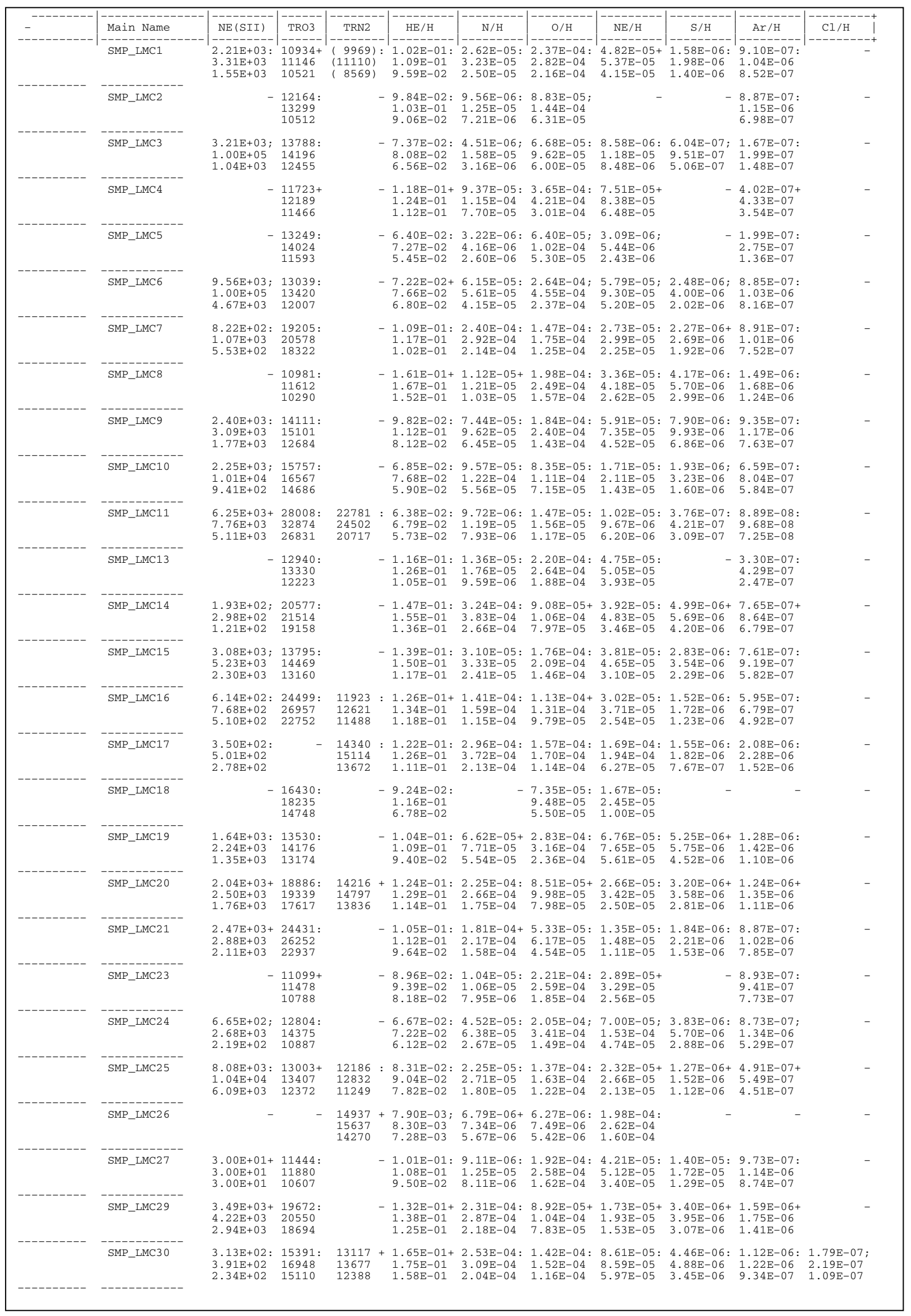


Table C.1. continued.

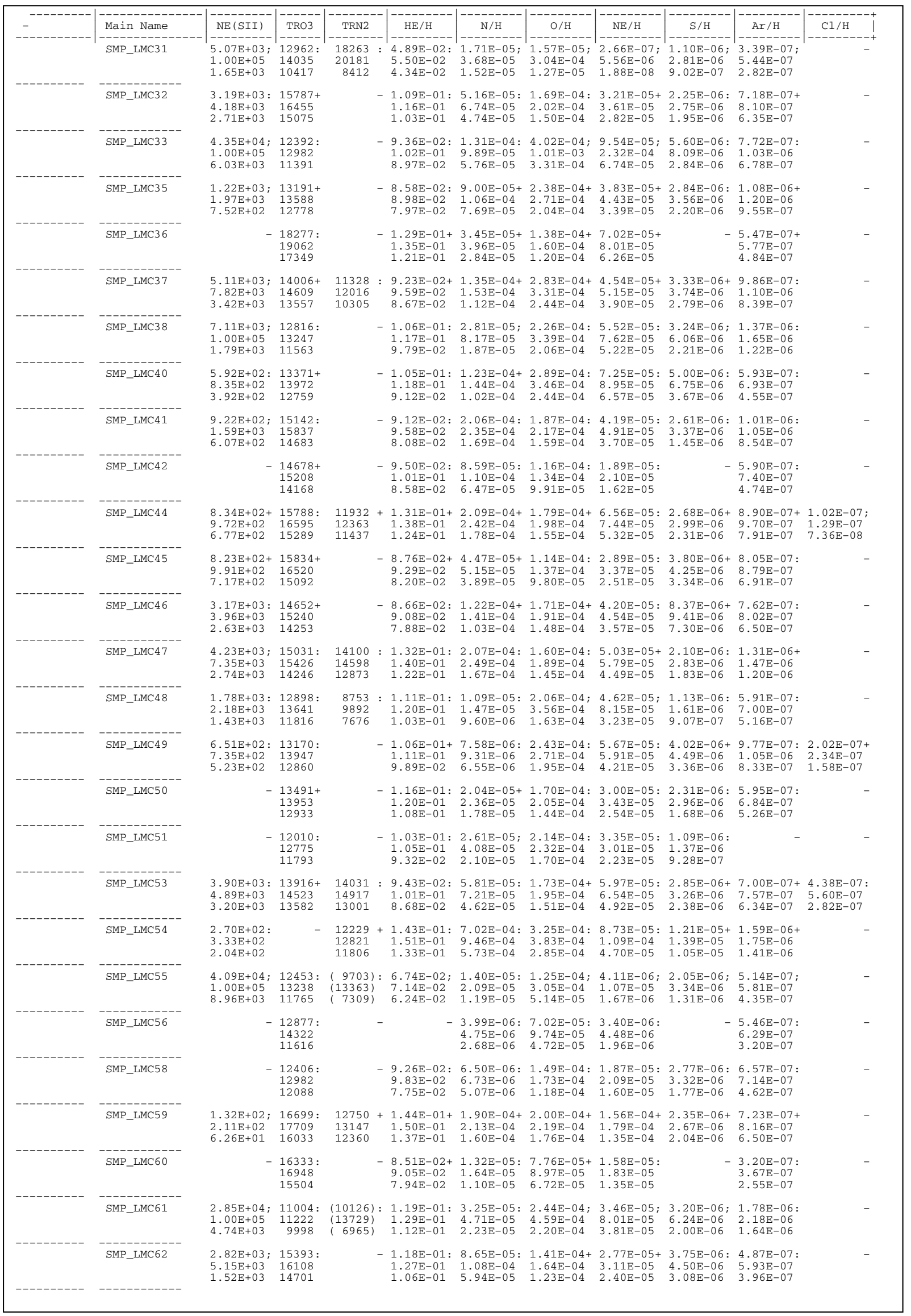


Table C.1. continued.

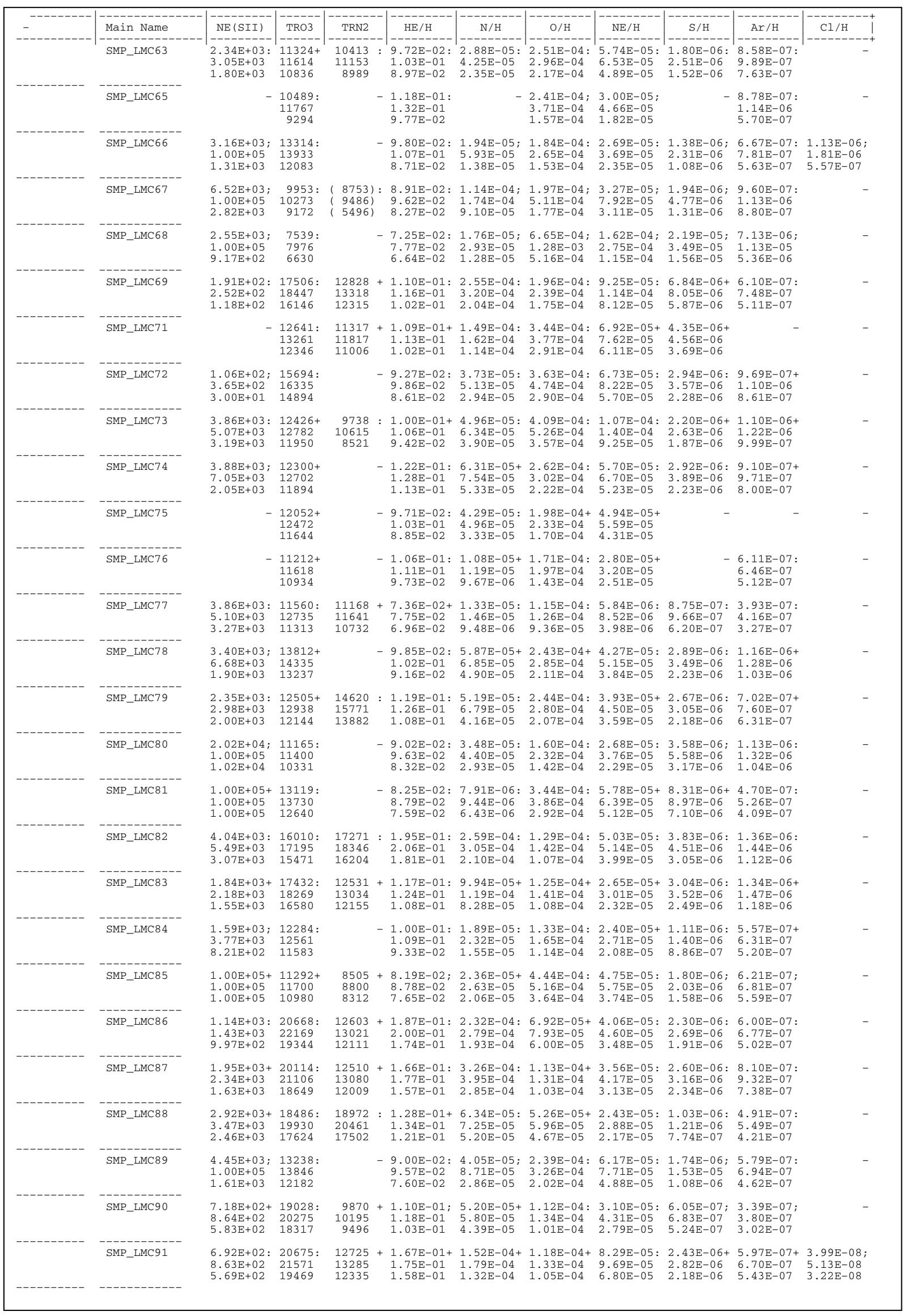


Table C.1. continued.

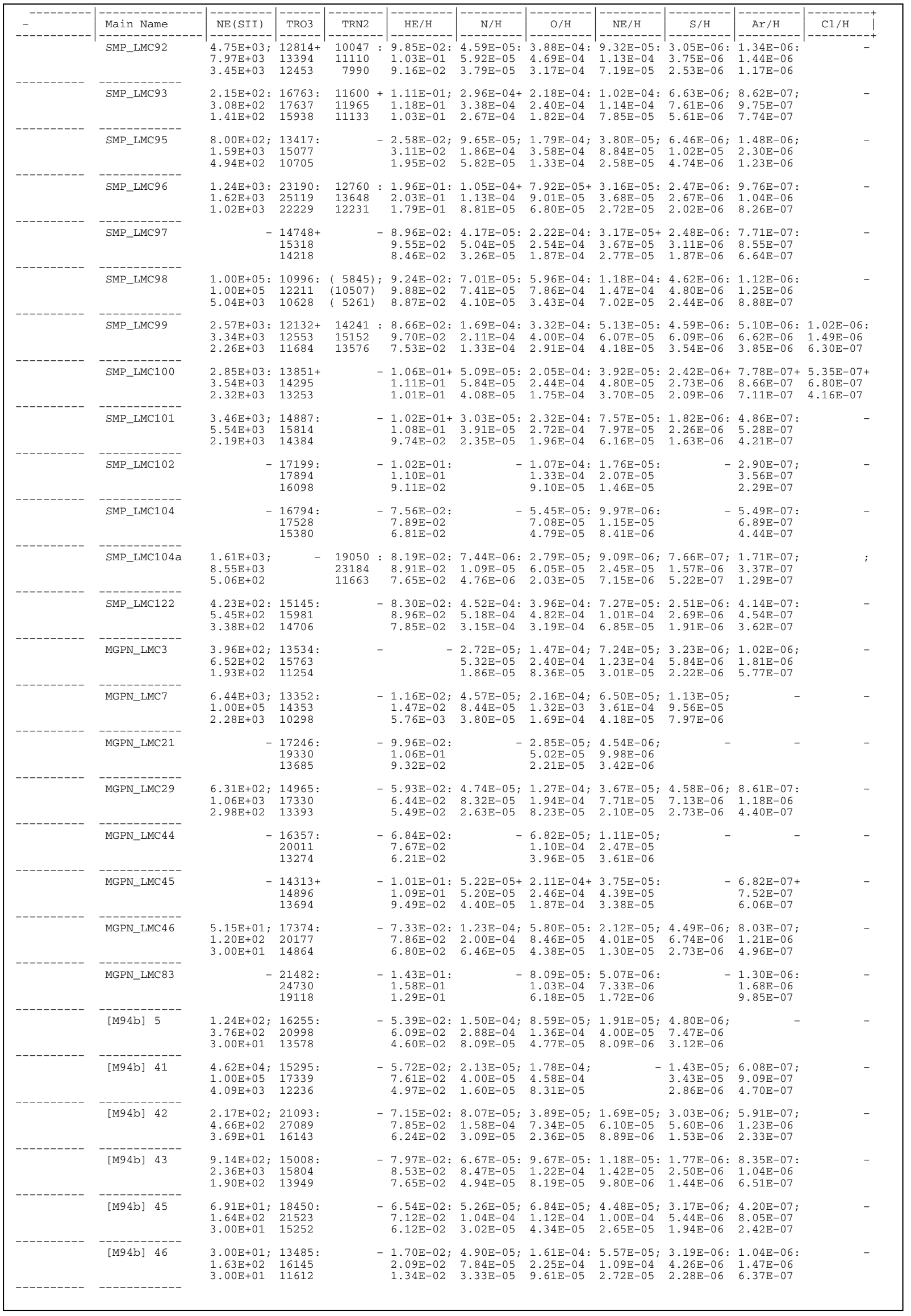


C. Chiappini et al.: Abundance patterns in the Galactic bulge, Online Material p 15

Table C.1. continued.

\begin{tabular}{|c|c|c|c|c|c|c|c|c|c|c|c|}
\hline - & Main Name & $\begin{array}{l}------- \\
\text { NE (SII) }\end{array}$ & $\begin{array}{l}------ \\
\text { TRO3 }\end{array}$ & $\begin{array}{l}------- \\
\text { TRN2 }\end{array}$ & \begin{tabular}{c|c|}
--------- \\
$\mathrm{HE} / \mathrm{H}$
\end{tabular} \mid & $\begin{array}{c}--------- \\
N / H\end{array}$ & $\overline{\mathrm{O} / \mathrm{H}}$ & $\begin{array}{l}-------- \\
\mathrm{NE} / \mathrm{H}\end{array}$ & $\begin{array}{c}--------- \\
\mathrm{S} / \mathrm{H}\end{array}$ & $\begin{array}{c}--------- \\
\mathrm{Ar} / \mathrm{H}\end{array}$ & $\begin{array}{l}-------+ \\
\mathrm{Cl} / \mathrm{H}\end{array}$ \\
\hline & [M94b] 48 & $\begin{array}{l}8.62 \mathrm{E}+03 \\
1.00 \mathrm{E}+05 \\
1.84 \mathrm{E}+03\end{array}$ & $\begin{array}{l}15398: \\
16239 \\
13196\end{array}$ & & $\begin{array}{r}-7.39 \mathrm{E}-02: \\
8.78 \mathrm{E}-02 \\
6.77 \mathrm{E}-02\end{array}$ & $\begin{array}{l}1.15 \mathrm{E}-05 \\
2.53 \mathrm{E}-05 \\
8.37 \mathrm{E}-06\end{array}$ & $\begin{array}{l}3.62 \mathrm{E}-05 ; \\
6.96 \mathrm{E}-05 \\
3.33 \mathrm{E}-05\end{array}$ & & $\begin{array}{l}1.14 \mathrm{E}-06 \\
8.65 \mathrm{E}-06 \\
5.97 \mathrm{E}-07\end{array}$ & $\begin{array}{l}4.02 \mathrm{E}-07: \\
5.32 \mathrm{E}-07 \\
3.38 \mathrm{E}-07\end{array}$ & - \\
\hline & [M94b] 49 & $\begin{array}{l}4.33 E+04 \\
1.00 E+05 \\
1.06 E+04\end{array}$ & $\begin{array}{l}13813: \\
14530 \\
12796\end{array}$ & & $\begin{array}{l}-9.13 \mathrm{E}-02: \\
9.83 \mathrm{E}-02 \\
8.72 \mathrm{E}-02\end{array}$ & $\begin{array}{l}8.47 \mathrm{E}-05: \\
1.19 \mathrm{E}-04 \\
6.42 \mathrm{E}-05\end{array}$ & $\begin{array}{l}2.57 \mathrm{E}-04: \\
3.57 \mathrm{E}-04 \\
2.05 \mathrm{E}-04\end{array}$ & $\begin{array}{l}5.56 \mathrm{E}-05: \\
7.47 \mathrm{E}-05 \\
4.74 \mathrm{E}-05\end{array}$ & $\begin{array}{l}1.76 \mathrm{E}-05 \\
3.81 \mathrm{E}-05 \\
5.80 \mathrm{E}-06\end{array}$ & $\begin{array}{l}9.35 \mathrm{E}-07: \\
1.11 \mathrm{E}-06 \\
8.62 \mathrm{E}-07\end{array}$ & - \\
\hline & LHA_120-N99 & - & - & $\begin{array}{l}12219 \\
12819 \\
11908\end{array}$ & $\begin{aligned}+ & 1.39 \mathrm{E}-02 \\
& 1.46 \mathrm{E}-02 \\
& 1.27 \mathrm{E}-02\end{aligned}$ & $\begin{array}{l}1.60 \mathrm{E}-05+ \\
1.75 \mathrm{E}-05 \\
1.35 \mathrm{E}-05\end{array}$ & $\begin{array}{l}1.70 \mathrm{E}-04: \\
1.86 \mathrm{E}-04 \\
8.41 \mathrm{E}-05\end{array}$ & $\begin{array}{l}9.39 \mathrm{E}-04: \\
1.07 \mathrm{E}-03 \\
2.64 \mathrm{E}-04\end{array}$ & - & - & - \\
\hline
\end{tabular}

